Florida International University FIU Digital Commons

3-24-2010

\title{
Class Placement and Academic and Behavioral Variables as Predictors of Graduation for Students with Disabilities
}

Liana Gonzalez

Florida International University, lianaflower4@aol.com

DOI: $10.25148 /$ etd.FI10041610

Follow this and additional works at: https://digitalcommons.fiu.edu/etd

\section{Recommended Citation}

Gonzalez, Liana, "Class Placement and Academic and Behavioral Variables as Predictors of Graduation for Students with Disabilities" (2010). FIU Electronic Theses and Dissertations. 175.

https://digitalcommons.fiu.edu/etd/175 


\section{FLORIDA INTERNATIONAL UNIVERSITY}

Miami, Florida

\section{CLASS PLACEMENT AND ACADEMIC AND BEHAVIORAL VARIABLES AS PREDICTORS OF GRADUATION FOR STUDENTS WITH DISABILITIES}

A dissertation submitted in partial fulfillment of the requirements for the degree of DOCTOR OF EDUCATION

in

EXCEPTIONAL STUDENT EDUCATION

by

Liana Gonzalez 
To: Interim Dean Marie McDemmond

College of Education

This dissertation, written by Liana Gonzalez, and entitled Class Placement and Academic and Behavioral Variables as Predictors of Graduation for Students with Disabilities, having been approved in respect to style and intellectual content, is referred to you for judgment.

We have read this dissertation and recommend that it be approved.

$\begin{array}{r}\hline \text { Patricia Barbetta } \\ \hline \text { Louis Manfra } \\ \hline \text { Joan Wynne } \\ \hline \text { Elizabeth Cramer, Major Professor }\end{array}$

Date of Defense: March 24, 2010

The dissertation of Liana Gonzalez is approved.

Interim Dean Marie McDemmond College of Education

Interim Dean Kevin O'Shea University Graduate School

Florida International University, 2010 
(C) Copyright 2010 by Liana Gonzalez

All rights reserved. 


\section{DEDICATION}

This dissertation is dedicated to the memory of my father and grandmother, whose values, unconditional love, and stern work ethic shaped who I am today. Also, to my husband and best friend...you are my yang. 


\section{ACKNOWLEDGMENTS}

I wish to thank Dr. Elizabeth Cramer and Dr. Patricia Barbetta for creating the Urban SEALS grant. Without their academic guidance and financial support through the grant, I would have never made it to this point in my career. I particularly wish to express my most heart-felt gratitude to Dr. Elizabeth Cramer, my dissertation chair, for her support, friendship, and dedication.

I would also like to extend my gratitude to my dear friend Bibiana Vega whose clinical experience working with students with disabilities was instrumental in creating the qualitative foundations of this dissertation. My most sincere appreciation also goes to Dr. Isadore Newman and Dr. Ann Nevin, for their academic advice, humor, and overwhelming support. Your lessons were invaluable.

Finally, I wish to thank the members of my committee for their guidance, time, and ongoing support. Dr. Louis Manfra was particularly helpful with the quantitative component and Dr. Joan Wynne's positive attitude brought a sense of reassurance to the entire process. 


\title{
ABSTRACT OF THE DISSERTATION \\ CLASS PLACEMENT AND ACADEMIC AND BEHAVIORAL VARIABLES AS PREDICTORS OF GRADUATION FOR STUDENTS WITH DISABILITIES
}

\author{
by \\ Liana Gonzalez \\ Florida International University, 2010 \\ Miami, Florida \\ Professor Elizabeth Cramer, Major Professor
}

Dropout rates impacting students with high-incidence disabilities in American schools remain staggering (Bost, 2006; Hehir, 2005). Of this group, students with Emotional Behavioral Disorders (EBD) are at greatest risk. Despite the mandated national propagation of inclusion, students with EBD remain the least included and the least successful when included (Bost). Accordingly, this study investigated the potential significance of inclusive settings and other school-related variables within the context of promoting the graduation potential of students with Specific Learning Disabilities (SLD) or EBD.

This mixed-methods study investigated specified school-related variables as likely dropout predictors, as well as the existence of first-order interactions among some of the variables. In addition, it portrayed the perspectives of students with SLD or EBD on the school-related variables that promote graduation. Accordingly, the sample was limited to students with SLD or EBD who had graduated or were close to graduation. For the quantitative component the numerical data were analyzed using linear and logistic regressions. For the qualitative component guided student interviews were conducted. 
Both strands were subsequently analyzed using Ridenour and Newman's (2008) model where the quantitative hypotheses are tested and are later built-upon by the related qualitative meta-themes.

Results indicated that a successful academic history, or obtaining passing grades was the only significant predictor of graduation potential when statistically controlling all the other variables. While at a marginal significance, results also yielded that students with SLD or EBD in inclusive settings experienced better academic results and behavioral outcomes than those in self-contained settings. Specifically, students with SLD or EBD in inclusive settings were found to be more likely to obtain passing grades and less likely to be suspended from school. Generally, the meta-themes yielded during the student interviews corroborated these findings as well as provided extensive insights on how students with disabilities view school within the context of promoting graduation. Based on the results yielded, provided the necessary academic accommodations and adaptations are in place, along with an effective behavioral program, inclusive settings can be utilized as drop-out prevention tools in special education. 


\section{TABLE OF CONTENTS}

CHAPTER

PAGE

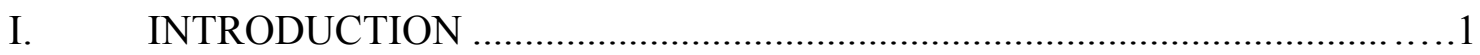

Purpose of the Study .................................................................................. 3

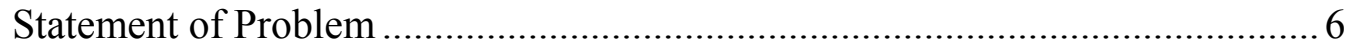

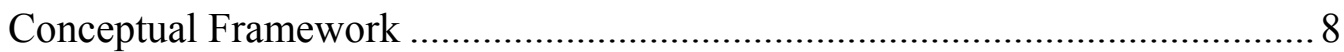

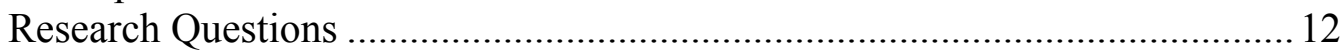

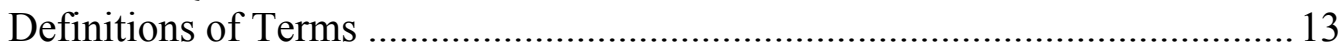

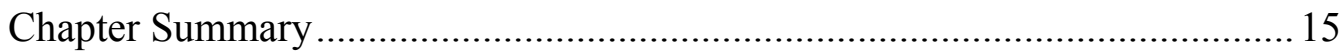

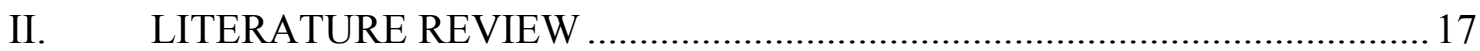

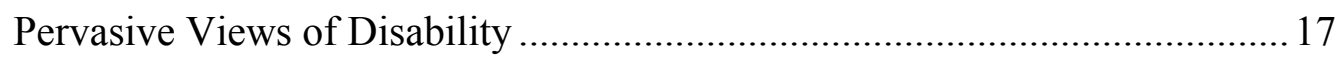

Systemic Causes for Dropout ................................................................... 18

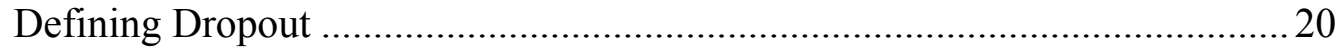

Risk Factors for Dropout in General Education ............................................2

Risk Factors for Dropout in Special Education ...............................................22

Academic Factors ................................................................................. 24

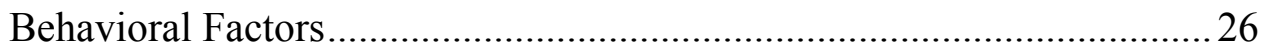

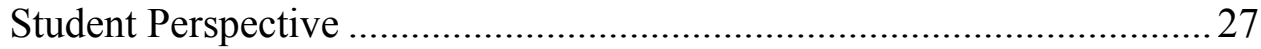

Inclusion as Potential Dropout Prevention Variable ........................................28

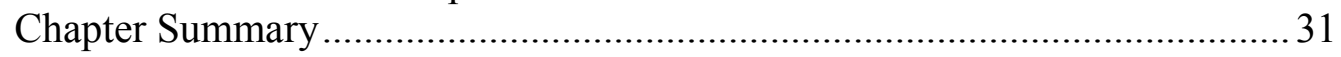

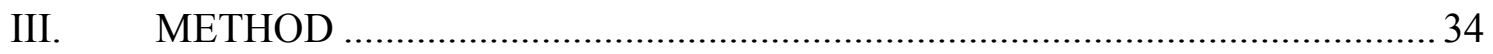

Research Design and Statistical Analysis .......................................................... 34

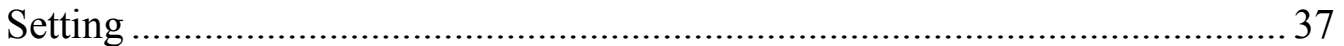

Educational Setting and Continuum of Services ............................................. 40

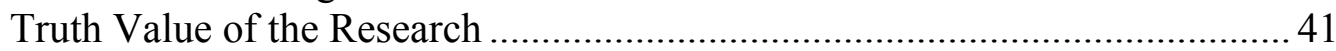

Quantitative Component .................................................................. 42

Qualitative Component ………………............................................. 42

Researcher Background and Beliefs ............................................................. 43

Quantitative Component: Logistic Regression .................................................. 44

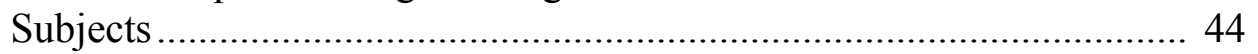

Criteria for Sample Selection............................................................ 44

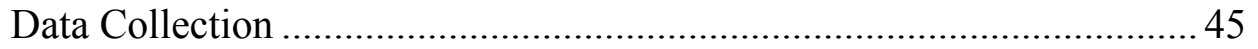

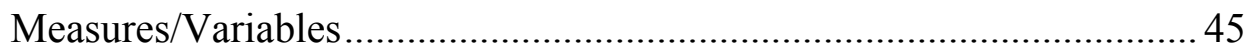

Academic History .............................................................................. 46

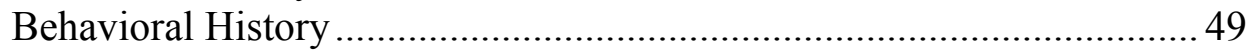

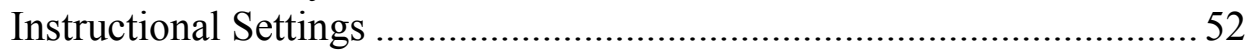

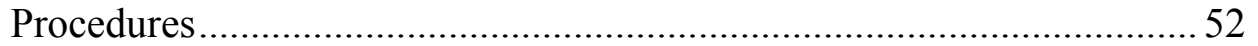

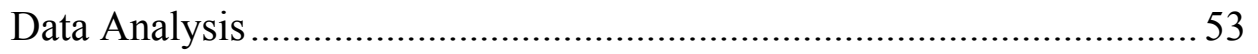

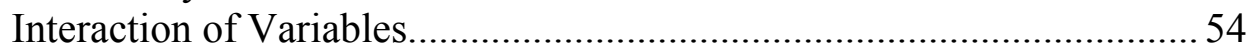

Qualitative Procedures: Student Interviews........................................................ 55 
Criteria for Sample Selection................................................................. 55

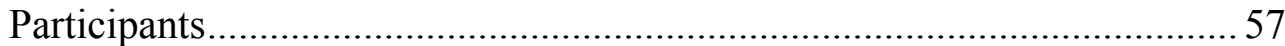

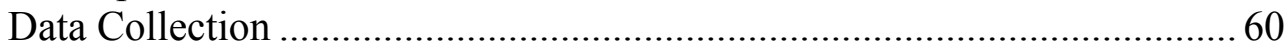

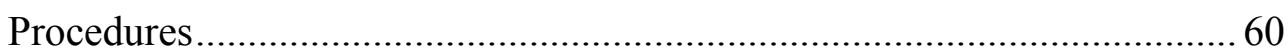

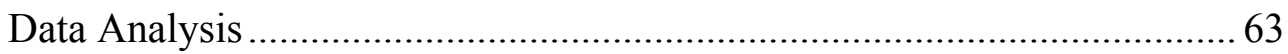

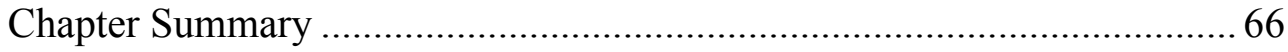

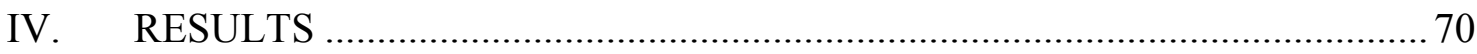

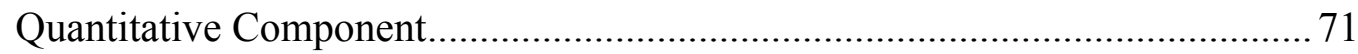

Results for Research Question 1 ....................................................... 72

Summary of Results for Research Question 1...................................... 77

Results for Research Question 2 ......................................................... 77

Summary of Results for Research Question 2...................................... 81

Qualitative Component........................................................................ 81

Meta-theme 1: "I Actually Want to Learn...I Really Do" ......................... 82

Meta-theme 2: "The Teacher Makes it or Breaks it" ................................ 85

Meta-theme 3: "Is Kind of Like a Normal Class...but with Shortcuts" ......89

Meta-theme 4: "There are Normal and Slow Classes".....................93

Meta-theme 5: "I Don't Feel I am Learning”........................................... 95

Meta-theme 6: "I Want to Become the Future of my Family".................... 99

Summary of Results for Research Question 3 ......................................... 101

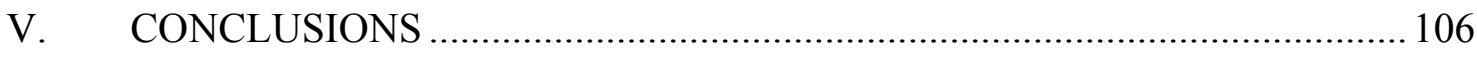

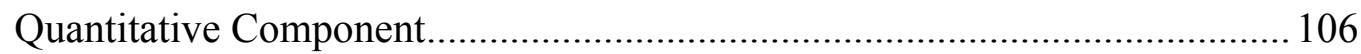

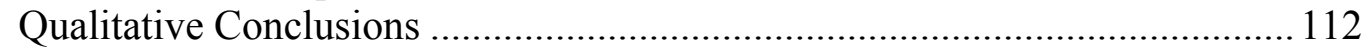

Thematic Analyses of Quantitative and Qualitative Components ................... 126

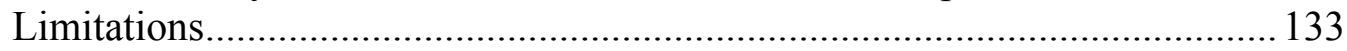

Limitations of Quantitative Component.............................................. 133

Limitations of Qualitative Component ............................................... 133

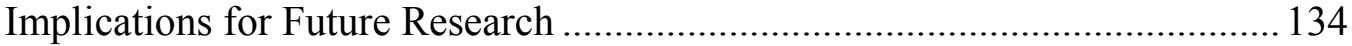

Research Contributions................................................. 136

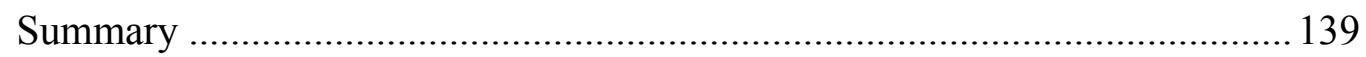

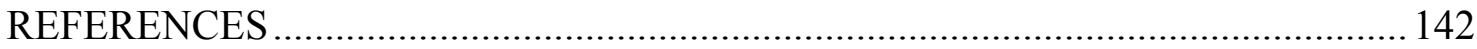

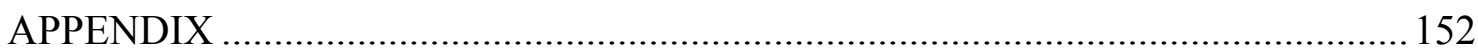

VITA 


\section{LIST OF TABLES}

TABLE

PAGE

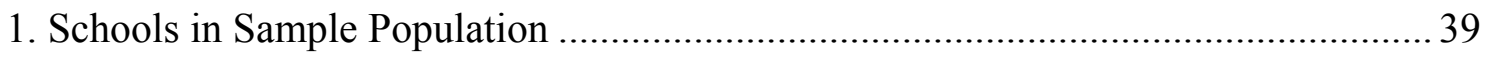

2. Graduation/Dropout Data for Sample ............................................................ 40

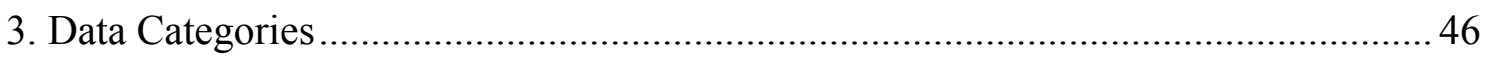

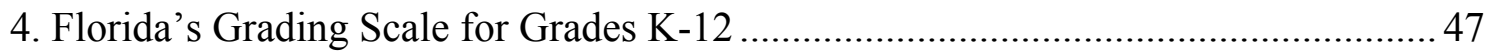

5. FCAT Achievement Level Descriptions ........................................................... 49

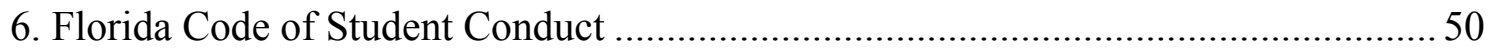

7. Behavioral Data for Schools in Sample ................................................................ 51

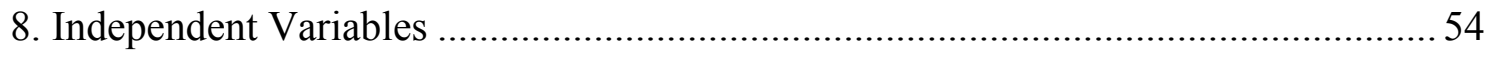

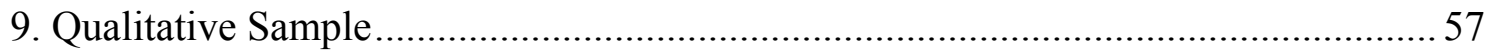

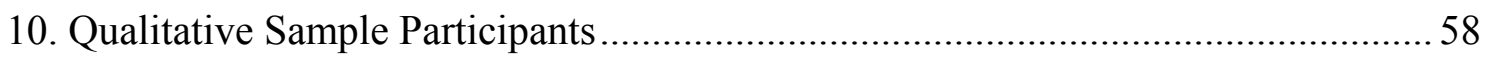

11. Demographics of Qualitative Sample Directly Quoted Participants ...................... 60

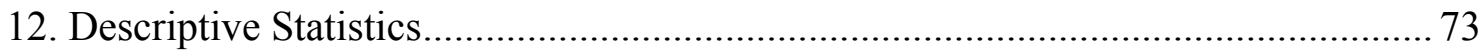

13. Significance of Independent Variables on Graduation Rates .............................. 75

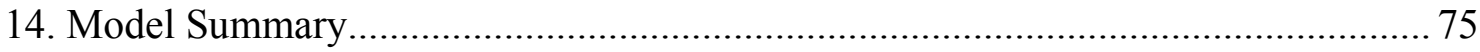

15. Log Regression Model Variables in Equation Predicting

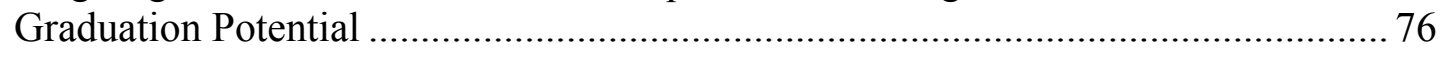

16. Log Regression Variables Not in Equation Predicting

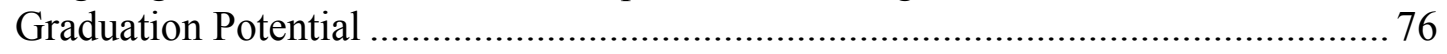

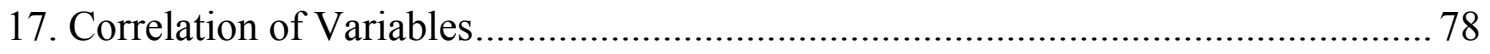

18. Model Summary of Change in Statistics for Correlation

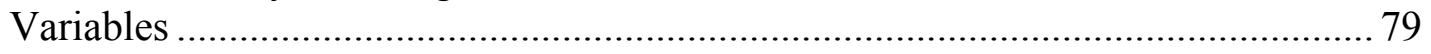

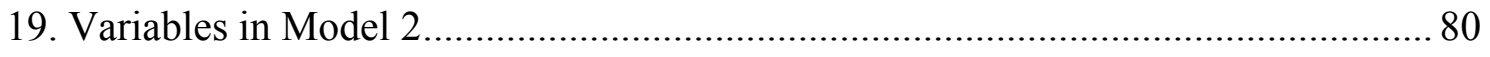




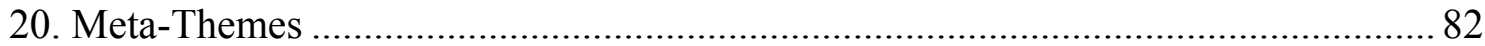

21. Quantitative Results and Related Qualitative Themes....................................... 128 


\section{CHAPTER I}

\section{Introduction}

The national propagation of inclusion has impacted the field of education significantly (Hehir, 2005). Inclusive ideology supports the notion that every student can learn and that those with disabilities benefit greatly from increased interactions with nondisabled peers and direct exposure to the general education curriculum (Fisher \& Frey, 2003; Huefner, 2000; Lee-Tarver, 2006). However, the direct impact of inclusion on school completion remains relatively unknown. This mixed-methods study investigated the school-related variables that predict the graduation potential of students with Specific Learning Disabilities (SLD) or Emotional Behavioral Disorders (EBD), as well as how inclusive practices contribute towards their graduation potential.

As documented by Osgood (2005), focus on the nature and quality of educational practices affecting students with disabilities began in the 1960s during President John F. Kennedy's administration and resulted in increased involvement by the federal government in educational policy. Growing interest in special education and, consequently the ratification of Public Laws $85-905^{1}$ and $85-926^{2}$, prompted public awareness and advocacy. The Education for All Handicapped Children Act of 1975 (renamed the Individuals with Disabilities Act or IDEA in 1990), further promoted assessing the general access of students with disabilities to a free and appropriate education.

\footnotetext{
${ }^{1}$ PL 85-905 authorized loan services for captioned films for the deaf in 1958.

${ }^{2}$ PL 85-926 provided federal support for training teachers for children with mental retardation in 1958
} 
In 1985 through the Regular Education Initiative (REI), the inclusion of students with disabilities was established but did not gain momentum until the early 1990s. In 1992, inclusion became part of the national school reform agenda. Soon after, the REI was renamed inclusive education, and by 1993 inclusive practices were evident in most states. The reauthorization of IDEA in 2004 and the No Child Left Behind Act of 2002 (NCLB), also contributed to supporting the growth of inclusion by mandating that students with disabilities be educated in their neighborhood schools, with their nondisabled peers, and in regular classrooms, to the greatest extent possible. Albeit its positive impact on inclusion-related practices, NCLB's formal assessment requirements have also contributed to the problem of school attrition, which particularly impacts students with disabilities (Cobb, Sample, Alwell, \& Johns, 2006). That is, oftentimes the high-stakes testing mandates of NCLB result in greater disengagement of students with disabilities since they have difficulty meeting these assessment standards (Bost, 2006).

Given the relatively young history of inclusive practices, it is still unclear how it impacts the graduation rates of students with disabilities. Consequently, much discourse exists related to the effectiveness of inclusion. Inclusion advocates assert that students with disabilities have the legal right to be educated alongside their non-disabled peers (Rea, McLaughlin, \& Walther-Thomas, 2002; Walther-Thomas, Korinck, McLaughin, \& Williams, 2000), and point-out that the educational outcomes and graduation rates of students with disabilities educated under the self-contained or pull-out models are generally poor (Rea et al., 2002). Yet, dropout rates for students with disabilities have remained steady even after inclusive practices were put into place (Bost, 2006). 


\section{Purpose of the Study}

School attrition is a national problem with ramifications that impact both society and the individual (Dunn, Chambers, \& Rabren, 2004). Research conducted by the Institute for Educational Leadership (2001) estimated that about \$228 billion is spent on students who drop out via lost revenue, welfare, unemployment, and crime prevention. Individually, students who drop out earn, on average, $\$ 7,174$ less per year than students who graduate (U.S. Bureau of the Census, 2004) and have increasingly limited employability opportunities as well as a propensity towards negative self-esteem (Dunn et al., 2004; Grayson, 1998). States and communities where the dropout phenomenon is particularly problematic have been found to have a higher rate of criminal behavior and greater dependency on the welfare system (Murray \& Naranjo, 2008). Adding urgency to addressing the problem of school attrition and finding solutions, $82 \%$ of prison inmates and $85 \%$ of juvenile justice cases are dropouts (Christle, Jolivette, $\&$ Nelson, 2007). Due to the high dropout rates, it is paramount to identify problematic institutional practices that contribute to students dropping out and to explore initiatives that can contribute to reversing existing dropout trends.

Arguably, research plays a vital role in contributing to reversing dropout rates. Yet, studies addressing the experiences and educational outcomes of minority students have traditionally assumed a deficit-based perspective (Dowdy \& Wynne, 2005). The same trend is observed with students with disabilities (Hehir, 2005). Consequently, researchers must make a conscious and mobilized effort to re-examine the focus of studies that exclusively expose the results of the socio-political hegemony affecting these youth, without offering viable alternatives (Nygreen, 2006). This effort must go beyond 
the legal, educational, and economic implications previously discussed and also include advocacy. Giving the individuals, in this case students being investigated or discussed, a voice is part of this process.

As reported by Miami-Dade County Schools (2008a), the number of students with disabilities who exited school as non-completers increased by $11 \%$ from 2000 to 2005 . During this 5-year time period, $30 \%$ of students with disabilities exiting school in Florida dropped out; of these, 29\% were students with Specific Learning Disabilities (SLD) and $49 \%$ fell into the Emotionally/Behaviorally Handicapped (EBD) category. Given that today $49.9 \%$ of students with disabilities are educated in inclusive settings for most of their school day (Florida Department of Education, 2002), this study investigated how the students viewed, navigated, and assessed its effectiveness within the context of promoting their school completion.

The literature has demonstrated that students with SLD educated in inclusive settings in secondary school had better school attendance, earned better academic grades, and received fewer disciplinary referrals when compared to students with disabilities in self-contained settings (Rea et al., 2002). Those findings are of crucial significance since all of the variables explored (school attendance, academic grades, and behavioral history) have been empirically linked to dropout rates (Croninger \& Lee, 2001; Kemp, 2006; Scanlon \& Mellard, 2002; Sinclair, 1994; Smith, 1986; Wagner, 1991). However, it must be noted that Rea et al. (2002) reported that their findings needed further scrutiny and expansion given the fact their sample was limited to 54 students with SLD from a small suburban district. This study extended their research by identifying the variables that 
contributed toward predicting the graduation potential of students with SLD or EBD and investigated the role of inclusive settings on their graduation potential.

The significant financial and legal ramifications of school attrition also require further scrutiny of the dropout phenomenon in special education. It costs taxpayers 2.3 times as much to support the education of students with disabilities (Kortering \& Braziel, 1999) as compared to their non-disabled peers. Yet, the effectiveness of these specialeducation programs is questionable given current dropout rates in special education. Legally, IDEA mandates “a free and appropriate education” for students with disabilities. However, as trends depict, these students are 50\% less likely to graduate than their non-disabled peers (Barton, 2005; Bost, 2006). Thus, it can be argued that this legal mandate is not being successfully met. The same can be concluded about more recent mandates added to IDEA (20 U.S.C. sec. 1401(a)(20), that specify the need for effective transition services that procure "movement from school to post school activities" (Bakken \& Kortering, 1999, p. 360).

Overall, there is extremely limited empirical evidence on the effectiveness of dropout prevention techniques impacting students with disabilities (Kemp, 2006). Furthermore, despite the fact that students with disabilities are twice as likely to drop out (Bost, 2006; Dunn et al. 2004; Grayson, 1998), the special education school attrition research seldom addresses their perspectives (Dunn et al., 2004; Wagner, 1991). As an entity, special education has typically ignored the feedback or perceptions of students when addressing the dropout problem. Despite the preponderance of studies positively correlating unfavorable student perceptions of schooling and dropout (e.g., Bearden, Spencer, \& Moracco, 1989; Dunn et al., 2004; Gallagher, 2002; Kortering \& Braziel, 
1999), student input continues to be generally ignored. For example, it has been documented that student perceptions of poor relationships with teachers and feeling ostracized from the school's culture, significantly increase dropout potential (Bost, 2006). However, these variables are typically not considered when developing dropout prevention solutions.

It is particularly confounding that student input is generally not reflected when developing dropout prevention programs for students with disabilities; given that the premise of special education is individualization (Kortering \& Braziel, 1999). In response, the qualitative portion of this study identified factors that potentially contributed to increasing graduation rates for students with disabilities by examining the problem grounded in the experiences of students in special education.

The failure of students with SLD or EBD to graduate prevails nationally. As evidence, $51.4 \%$ of students with EBD and $34.1 \%$ of students with SLD drop out (Bost, 2006), indicating the need for further investigation and continuous evaluation of the dropout phenomenon amongst these student populations. Subsequently, this study investigated the variables that contributed towards predicting graduation potential in special education and solicited student perceptions concerning how inclusion impacted their graduation potential.

\section{Statement of Problem}

This study investigated the school-related variables that predict the graduation potential of students with SLD or EBD; as well as the impact of inclusive settings on their graduation potential. Specifically, this study identified the significance of the following school-related variables as potential predictors of graduation in special 
education: (a) academic history, (b) behavioral history, and (c) availability of inclusive support systems. The first two variables (academic and behavioral history) have been empirically established as significant contributors to dropout in non-disabled student populations (Croninger \& Lee, 2001; Kemp, 2006; Scanlon \& Mellard, 2002; Sinclair, 1994; Smith, 1986; Wagner, 1991). This study was innovative in that it determined whether these variables also impact students with SLD or EBD. The third variable (availability of inclusive support systems) examined the perspectives of students in special education on the impact inclusive settings have on their graduation potential. Research in the area of school- to-work transition indicates that students with disabilities who spend more time in general education experience better results after high school (U.S. Department of Education, 2002).

In addition, this study sought to add clarity to the research on school attrition since, to date, the extent to which school-related variables contribute to dropout rates has not been clearly established. For instance, poor academic achievement has consistently been identified as a significant tenet of dropout in studies conducted by Dunn et al. (2004), Scanlon and Mellard (2002), and Suh and Suh (2007). While other studies (i.e., Bear, Kortering \& Braziel, 2006; Croninger \& Lee, 2001; Kemp, 2006) have found no significant academic achievement differences amongst youth with disabilities who drop out versus those who do not. In addition, despite the fact Rea et al.'s (2002) preliminary findings indicated that many of the variables associated with dropout were improved by exposing students with disabilities to inclusive settings, no studies to date had directly examined the effect of inclusion on the graduation potential of students with SLD or EBD. 
This study built on Rea et al.'s 2002 research by addressing many of the limitations cited by the authors. These included: (a) limited sample size, (b) lack of generalization to urban populations, and (c) archived data dating back 4 years. Limited sample size was among the limitations cited by the authors based on the principle of generalization potential. This study expanded the sample size from their 58 to 515 and included students with EBD. It took place in an urban setting which is part of the fourth largest school district in the nation. Additionally, it analyzed data from the current (20082009) and previous school years (2007-2008). It also differed in that it directly addressed the impact of inclusion on graduation potential by targeting high school students. Furthermore, this study included a qualitative component consisting of students' perceptions regarding how their educational setting impacts their graduation potential. By identifying the variables that contribute towards graduation in SLD and EBD populations, and obtaining the students' points of view regarding how inclusion impacts their graduation potential, this research study potentially conveys findings that no other studies to date have established.

\section{Conceptual Framework}

Due to the social, economic and educational ramifications of dropout previously addressed, investigating its causes must also include a thorough discussion on dominant theories that affect how students in special education who drop out are generally perceived. Several theories or conceptual frameworks were examined in order to address or explain the fact that dropout rates are higher in special education than in general education (Bost, 2006). Subsequently two dominant ideologies emerged. 
An extensive body of research indicates that non-school related factors such as family socioeconomic standing and parental education are the most serious negative influences behind school attrition, impacting graduation potential regardless of disability status (Farmer \& Payne, 1992; Gruskin, Campbell, \& Paulo, 1987; Orr, 1987; Payne, 1989; Reyes, 1989; Roderick, 1993; Tindall, 1988; Valdivieso, 1986; Vallerand, Fortier, \& Guay, 1997; Wehelage, 1989). In Figure 1, parental education, socioeconomic status, and dropout are depicted as being interconnected.

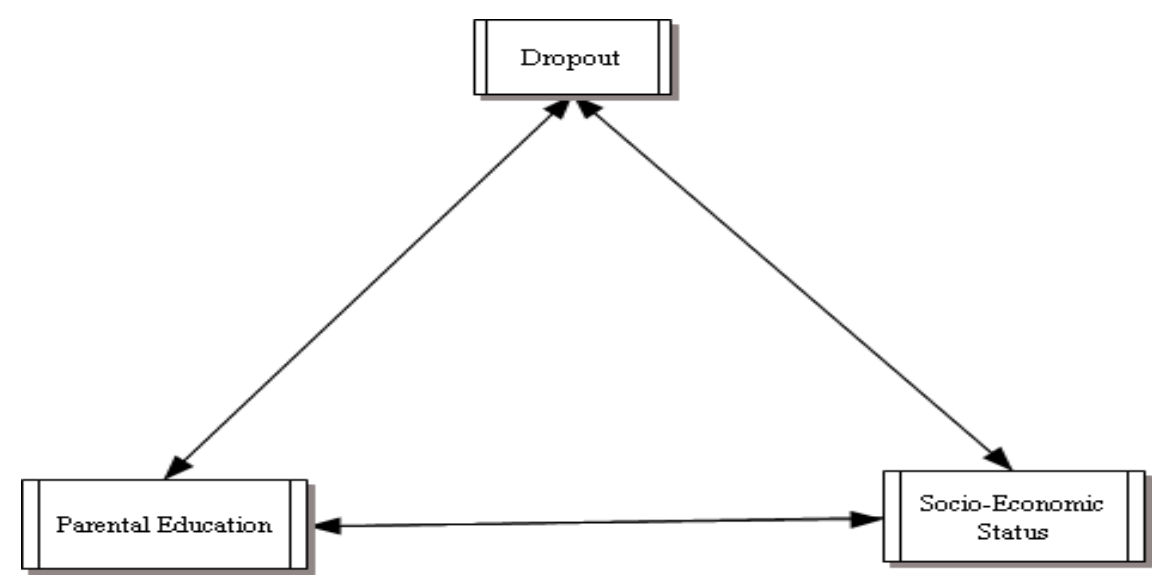

Figure 1. Socioeconomic dropout factors.

More recent studies on the topic of school attrition suggest that school-related factors primarily and significantly contribute towards school completion or attrition, and that schools and teachers should be held accountable (Bakken \& Kortering, 1999; Bost \& Riccomini 2006; Dunn et al., 2004; Lee \& Burkman, 2003; Rea et al., 2002). Specifically, based on the conceptual framework suggested by Bost (2006), the school as an institution is responsible for creating a climate that provides pro-social behaviors, academic success, highly qualified teachers, and effective transition services to 
potentially increase successful outcomes. In order to foster this school climate, teachers need to increase the likelihood that students have instructional and behavioral support, as well as access to relevant content and quality instruction. In Figure 2, academic and behavioral components are depicted as being interconnected.

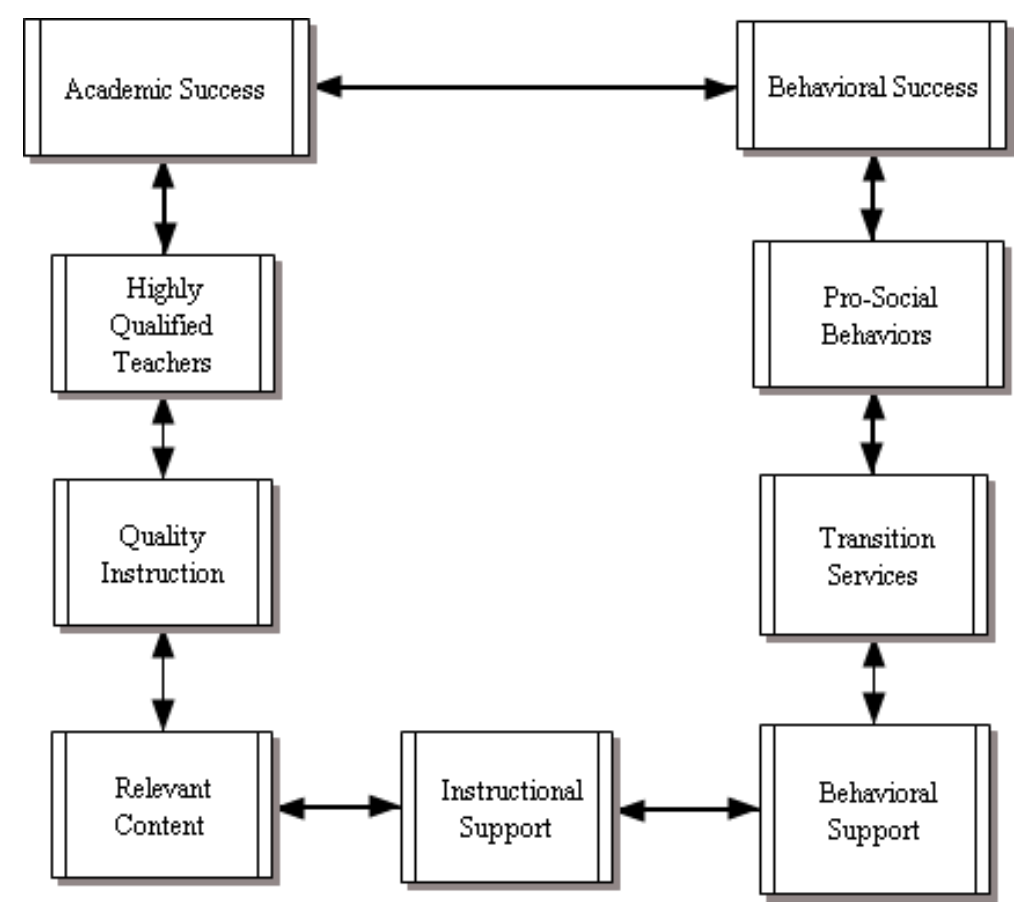

Figure 2. School-related dropout prevention variables.

Due to the complexity of the dropout phenomenon, particularly as it affects individuals with a disability status, it was also necessary to explore socio-political theories in order to provide a more complete perspective and encourage deeper understandings. Closely mirroring the previously discussed findings indicating that family income and education are negatively correlated to potential dropout, Bordieu (1977) contended that an individual's life experiences are generally predetermined by the family's socioeconomic and intellectual background. Given research findings suggesting 
that students who do not graduate generally come from low socioeconomic backgrounds and from parents who also did not graduate, these larger theoretical implications should be taken into account when investigating dropout rates. In doing so, researchers must be cautious not to equate poverty with academic ineptness and must consciously explore if and how the educational system functions from a deficit-based perspective, where students in special education are somehow expected to do poorly and thus potentially drop out. Subsequently, this study investigated the dropout issue from the perspective of students with disabilities who had successfully graduated or were close to doing so.

Yosso (2002) proposed an alternative to theories that view socioeconomic background as the main contributor to school failure. Specifically, despite perceptions that generally attribute failure in school to low family socioeconomic background, other more powerful forms of cultural capital can counteract this effect. Yosso (2002) asserted that people's social standing (regardless of belonging to a lower socioeconomic stratum) and related experiences can actually help them achieve as opposed to hindering them. Specifically, Yosso's theory points toward the idea that each individual possesses

- Aspirational capital-maintaining dreams and aspirations

- Linguistic capital-the intellectual skills that result from bilingualism or multilingualism

- Familial capital-knowledge communicated via family history or personal stories

- Social capital-networking and community resources

- Navigational capital-ability to understand how societal institutions function

- Resistance capital-challenging and mobilizing against injustice 
Understanding the possible interaction of the theories discussed and how they affect schooling in America can potentially lead towards making more informed decisions on the type of systems that must be in place to effectively reduce school attrition in special education.

\section{Research Questions}

This study identified the school-related factors that increase the graduation rates of students with SLD or EBD, as well as potential first order interactions among these factors. It also investigated the impact of inclusive settings on the graduation potential of students with SLD or EBD. The following research questions were addressed:

1. Do specified school-related variables predict the graduation potential of students with SLD or EBD?

2. Do specified school-related variables show first-order interactions?

3. What are the self-reported perceptions of students with disabilities in selfcontained settings versus those in inclusive settings with regards to support systems that promote graduation?

The research design consisted of a two-component, mixed-methods approach. The quantitative component identified the school-related variables that predict the graduation potential of students with SLD or EBD as well as potential first-order interactions amongst these variables. The qualitative component consisted of guided interviews addressing the students' perceptions on the nature and availability of support systems that promote graduation.

A significant number of studies on the topic of school attrition have identified school-related variables such as: (a) academic history, (b) behavioral history, and (c) 
availability of inclusive support systems as potential risk-factors for dropout. Academic histories that depict consistent failure are among the main reasons as to why students, regardless of any existing disability, drop out and fail to graduate (Croninger \& Lee, 2001; Kaplan, Peck, \& Kaplan, 1997; Kemp, 2006; Scanlon \& Mellard, 2002; Sinclair, 1994; Smith, 1986; Wagner, 1991).

In special education, students with EBD have the highest rate of dropping out, indicating a possible link between behavioral history and school attrition (Bost, 2006; Kemp, 2006; Suh \&Suh, 2007; U.S. Department of Education, 2007; Wagner, 1991). Given that school attrition rates generally decrease when appropriate support systems are in place (Bost, 2006; Dunn et al., 2004; Suh \& Suh, 2007), and the current trend towards implementing the inclusion model, the effects of the latter on student graduation rates were examined.

\section{Definitions of Terms}

The following section provides definitions of terms often referred to throughout this study in alphabetical order. These include educational terms used by Miami-Dade County Public Schools as well acronyms used in the field of education.

\section{Emotional/Behavioral Disturbance (EBD)}

Emotional/behavioral disturbance (EBD) is defined as a condition where students are diagnosed based on exhibiting one or more of the following symptoms:

- Inability to learn that cannot be explained by intellectual, sensory, or other health factors.

- Difficulty building or maintaining satisfactory interpersonal relationships with peers and teachers. 
- Exhibiting inappropriate types of behavior or feelings under normal circumstances.

- Demonstrating a general pervasive mood of unhappiness or depression.

- Developing physical symptoms or fears associated with personal or school problems.

- Diagnosis of schizophrenia.

\section{Florida Comprehensive Assessment Test (FCAT)}

State mandated standardized exam for all public schools in Florida. Both student and school performance are measured based on related results.

\section{Inclusive Settings}

Settings where students with disabilities learn alongside their non-disabled peers, and are generally taught by a team of teachers consisting of a general education teacher and a special education teacher

\section{Specific Learning Disability (SLD)}

Specific Learning Disability (SLD) is defined as a disorder in one or more of the basic psychological processes involved in understanding or in using language, spoken or written, that may impact the ability to listen, think, speak, read, write, spell, or do mathematical calculations. The term also encompasses perceptual disabilities, brain injury, minimal brain dysfunction, dyslexia, and developmental aphasia.

\section{Logistic Regression}

A model used for prediction of the probability of occurrence of an event by fitting data to a logistic curve. It makes use of several predictor variables that may be either numerical or categorical. 


\section{Magnet Schools}

Public schools where students from all areas of the county are selected to participate via a lottery system, except for the visual and performing arts academies where students are chosen based on auditions.

\section{Pull-Out Programs}

Setting where students with disabilities are pulled from their general education class and are given instruction by a special education teacher on the subject most impacted by manifestations of their disabilities. This setting is most pervasive in the primary grades.

\section{Standard Diploma}

Diploma option that requires the fulfillment of state mandates, including a passing score on district and state assessments as well as earning sufficient graduation credits.

\section{Zero Tolerance Policies}

Educational disciplinary policies where possession of any item defined as a weapon by the school system, ranging from metal nail files, to pocket knives and toy or real guns, result in immediate expulsion from school regardless of the context or situation.

\section{Chapter Summary}

Despite the fact dropout rates have decreased across the nation, there has not been a decrease in the school attrition rate for students with disabilities. Furthermore, students with disabilities make up a large percentage of those who fail to graduate (Bost, 2006). Among all disability categories, students with EBD or SLD contribute the greatest number of students who drop out (U.S. Department of Education, 2007). Even with the 
high percentage of students with disabilities who drop out, the extensive research pool on school attrition has mostly concentrated on general education dropout issues. This has created a gap in information related to factors that influence the dropout rates of students with disabilities. This study investigated the impact of inclusion on the graduation potential of students in special education, which was one of the issues that remained relatively unexplored.

While previous studies have consistently identified academic factors (e.g., academic aptitude) and behavioral history (e.g., number of suspensions) as definite variables in the dropout equation, related findings contradict the extent to which these actually impact graduation potential. In essence, this study revisited the problem of school attrition in special education from a renewed perspective that took into account empirically established variables related to academics and behavior, within the context of the present educational inclusive models. Along with this, in order to potentially gain greater understanding of the factors leading students to dropout, this study also included the perspectives and experiences of those most severely affected by school attrition, the students.

The effects of dropout transcend the educational milieu and permeate society by increasing the number of individuals in both the welfare and penal systems. This study identified the school-related variables that contribute towards predicting the graduation potential of students with SLD or EBD from an innovative perspective that assessed the impact of inclusive settings on graduation potential. 


\section{CHAPTER II}

\section{LITERATURE REVIEW}

Despite recent improvements in dropout rates of students in general education, the dropout phenomenon has remained fairly robust and stable over the last few decades in special education (Bost, 2006). Multiple factors increase the potential for dropout, some

of which include: (a) misperceptions about disability and related systemic factors, (b) the failure to provide a cohesive definition for dropout, (c) at-risk factors for dropout in general and special education, and (d) the failure to generally consider student perspective on the issue of dropout. This study examined the significance of these factors and investigated the potential of inclusive practices as dropout prevention tools. Subsequently, this chapter will provide a review of the literature associated to this research.

\section{Pervasive Views of Disability}

Perceptions play an important role on the expectations placed on students (Hehir, 2004). In discussing the school attrition rates of students with disabilities from the lens of inclusive practice, it is important to recognize how disability is generally perceived in education and in the broader context of society. Related to these perceptions is the concept of ableism defined as "the pervasive system of discrimination and exclusion that oppresses people who have mental, emotional, and physical disabilities" (Hehir, 2005, p. 15). Narrow views on the aspirations, capabilities, and contributions of students with disabilities can potentially lower expectations and result in a curriculum that enables as opposed to one that empowers. Oftentimes the disability is maximized and becomes the reference point for developing expectations, consequently isolating the students from the 
general school culture; the latter being one of the predictors of potential dropout (Bost, 2006; Lehr, Sinclair, \& Christensen, 2004).

\section{Systemic Causes for Dropout}

"Some students see schools as locations where they can develop their human capital...for others schools are places where they are reminded on a daily basis of their lack of success in the academic world" (Lee \& Burkman, 2003, p. 356). Accepting this

notion includes the realization that studies on the topic of school attrition seldom focus on how the existing educational milieu contributes to student dropout. Generally, related explanations function from the perspective that race and/or ethnicity, socioeconomic status, and academic/behavioral history are the sole culprits (Lee \& Burkman, 2003). Given that dropout rates in urban areas are significantly higher (Council of Great City Schools, 1994; Lee \& Burkman, 2003), special attention must be given to the systems in place at these schools. Following this line of thought, Lee and Burkman (2003) concluded that the organizational structures in high schools are inherently designed to service students exhibiting characteristics that coincide with the school's general culture and perceptions of success, but also serve as gate-keepers for those who do not.

From a more theoretical perspective, it can be argued that capitalism's glorification of the individual oftentimes regards personal responsibility above all else, and as a result, capitalism can become blind about the impact of social constructs. Epitomizing these views, seminal works in the area of academic outcomes and school attrition, such as Equality of Educational Opportunity (Coleman et al., 1966) and Inequality (Jencks et al., 1972) placed all the blame on the students and none on the 
institutions. Interestingly, a significant quantity of the more current research on dropout still follows the same ideology (Lee \& Burkman, 2003).

Lee and Burkman (2003) reported that when a school's environmental factors are uncertain due to violence and ineffective instruction, students are more likely to drop out. In a similar study, Rumberger and Thomas (2000) argued that dropout rates were: (a) significantly more prevalent in public schools than in private or religious schools, (b) higher in urban than in suburban and rural schools, (c) lower in schools where students had favorable views of their teachers, and (d) generally low in schools with lower teacher-student ratios. Adding to these findings, Lee and Burkman (2003) illustrated that the most important variable affecting dropout was the quality of interactions among students and teachers. Specifically, students who attended schools where collaboration and interaction between students and teachers were promoted and valued were $86 \%$ less likely to drop out. Lee and Burkman (2003) also noted that establishing significant relationships with students was generally easier in smaller schools due to the fact teachers had more time to spend addressing the needs of individual students. Subsequently, there is an eminent need to recognize the importance of building effective interactions via equitable relationships in education. These types of interactions are characterized by open and honest dialogue, respect and acknowledgement of the students' social and cultural capital (Solorzano \& Yosso, 2001), as well as high expectations for academic success.

Despite the obvious need to effectively and proactively address the educational outcomes and graduation rates of students with disabilities, as discussed in a study conducted by Riccomini, Zhang, and Katsiyannis (2005), disciplinary policy that encourages zero tolerance generally responds to behavior problems with suspension from 
school as opposed to more proactive measures. Consequently, the lack of proactive measures in dealing with behavior problems potentially increases the dropout potential of students with EBD.

\section{Defining Dropout}

Typically, the first step in designing effective interventions or solutions is providing generally consistent criteria and definitions to identify the problem. Kemp (2006) conducted a study contending that while it is widely accepted that students with disabilities drop out at higher rates, the exact magnitude of this problem still remains unknown. This is due to discrepancies amongst states and school districts on the type of variables used to identify dropout and related calculation strategies. Subsequently, the exact number of students who drop out is generally underestimated (Bartnick \& Parkay, 1991; Kemp, 2006; Sinclair, 1994). Contributing to this problem is the fact school districts have complete autonomy in defining dropout and conducting associated calculations, which often results in distortion of the data to depict more favorable outcomes (Kemp, 2006; Sinclair, 1994).

The three generally implemented computation methods for calculating dropout rates consist of the event, cohort, and status rate measure methods (Kemp, 2006; Rumberger, 1997; Sinclair, 1994). The event method records the number of dropouts that occur in a particular year, and provides related percentages. Due to its lack of restrictions, this method generally fails to provide accurate results and tends to provide lower dropout figures. Perhaps not surprisingly it is the most commonly used method among school districts (Kemp, 2006). 
Increasingly more involved from a statistical perspective, the cohort method has longitudinal characteristics and concentrates on documenting the educational outcomes of a group of students projected to graduate at the same time. This most conservative and accurate method depicts the number of students in specific grades and districts that were projected to graduate and instead drop out. Yet despite its precision, the cohort method is the least implemented calculation technique (Kemp, 2006; Morrow, 1986; Wolman, Bruininks \& Thurlow, 1989). The status rate measure is seldom used and basically estimates the percentage of students that have yet to graduate from high school and are not registered on a given day.

As suggested by Kemp (2006) and Sinclair (1994), there needs to be consensus on which type of method is to be utilized, preferably the cohort due to its attributes. In the absence of this general consensus, related data must include specific mention and descriptions of the methods implemented. Only then can objective assessments be made regarding the magnitude of school attrition and concerning the effectiveness of dropout prevention programs.

\section{Risk Factors for Dropout in General Education}

Suh and Suh (2007) conducted an extensive study with a population of 9,000 students ranging from 12 to 16 years of age. In this study, a multiple logistic regression was conducted where 180 variables were considered as potential dropout factors. The related results revealed that academic failure, low socioeconomic status, and behavioral history were the main three antecedent contributors to increasing school attrition; these factors were further sub-categorized into related quantitative and qualitative factors. The quantitative variables included (a) level of absenteeism or truancy, (b) number of 
aggression-related incidents in school, (c) number of people in household, (d) percentage of friends considering college degrees, (e) opportunities for academic enrichment index, and (f) environment risk-factors index.

The qualitative or nominal variables explored that were found to have significant impact on dropout rates consisted of (a) low socioeconomic status, (b) behavioral problems, and (c) academic failure. Both sets of variables coincide with previously discussed findings, arguably making a case for the strength of the variables identified. However, in this particular 2007 study, Suh and Suh also concluded that students who usually drop out are impacted by various risk variables or factors simultaneously. Specifically, a low GPA, socioeconomic factors, and behavior problems combined were found to be significant indicators of potential dropout, suggesting that related interventions must target all identified risk-factors in conjunction.

It is also crucial to point out that while generally socioeconomic factors are identified as contributing to school attrition and Suh and Suh's (2007) study was no exception, education as a system must be cautious not to equate poverty with academic inaptitude. Despite the fact that Bordieu (1977) made a case for accepting the idea that ethnic and socioeconomic backgrounds typically dictate the future quality of experiences, including those in education, Yosso (2002) contended this argument has long been used to explain why minorities are not successful in education. Having a disability constitutes minority status in schools.

\section{Risk Factors for Dropout in Special Education}

While dropout rates for students with disabilities have decreased by $15 \%$ since the 1990s (National Longitudinal Transition Study 2 [NLTS 2], 2006), this progress does not 
apply to certain disability categories, in particular SLD, mental retardation (MR), and EBD (Bost, 2006; NLTS 2, 2003). In a study regarding the factors related to dropout rates of students with SLD and MR (Dunn et al., 2004), the case was made that graduating high school has shifted from an asset to a necessity.

Dunn et al. (2004) concluded that disability status, identification of a helpful class and teacher, and the belief that school successfully prepares students for the job force were the most significant variables contributing towards graduation potential in special education. However, the fact that these findings were generalized among SLD and MR populations raise some potential concerns. Students with SLD are typically first diagnosed within the context of education, and as such appropriate identification becomes more susceptible to bias (U.S. Department of Education, 2002b). Additionally, the intelligence quotient (IQ) associated with these students typically ranges in the gifted to average spectrums (Siegel, 1999). In contrast, students with MR are first diagnosed by a physician based on organic causes, have generally lower IQs ranging from 50-75 in the mild category, $35-55$ in the moderate category, $20-40$ in the severe category, and $20-25$ or below in the profound category (Greenspan, 2006); and in some cases, these students have limited academic potential due to other physical conditions associated with their disabilities. Due to these vast differences, the educational goals, experiences, and transition plans related to school completion vary significantly amongst students with MR and SLD making it rather difficult to accept that both populations have similar reasons for dropping out, and even more difficult to develop appropriate related interventions across both disability categories. Typically students with SLD or EBD are first identified in the context of education, are overly represented in special education, 
and drop out in disproportionately high numbers (Bost, 2006; U.S. Department of Education, 2002a). Both populations (SLD \& EBD) generally perform below their academic non-disabled counterparts and consequently often lack the skills necessary to successfully transition into the workplace (Scanlon \& Mellard, 2002). Additionally, associated profiles indicate that both disabilities can severely impact post-academic experiences and quality of life (Bost, 2006; Reiff, Ginsberg, \& Gerber, 1990). Despite the fact that, in some cases, the manifestations of related behaviors decrease during late adolescence and early adulthood (Reis, Neu, \& McGuire, 1997), documented trends for these populations generally reflect socialization problems, difficulties developing quality relationships, generally poor academic experiences and results, as well as economic dependence (Scanlon \& Mellard, 2002).

Based on the nature of the risk factors considered which include aggressive incidents in school, behavior problems, and academic failure; students with EBD are particularly at risk of dropping out (Bost, 2006). This population is also typically the least included, which points towards a possible relationship between inclusion and dropout prevention (NTLS 2, 2006).

\section{Academic Factors}

A significant amount of the existing literature on school attrition identifies low academic achievement amongst the potential indicators of dropout (Blackorby \& Wagner, 1996; Dunn et al., 2004; Scanlon \& Mellard, 2002; Suh \& Suh, 2007). More recently, it has also been established that related patterns do not emerge in high school but actually begin during the primary school years (Bear et al., 2006; Bost, 2006) Further exploring the impact of low academic achievement on the school attrition of students 
with students with SLD, Bear et al. (2006) conducted a study comparing students who had graduated versus those who had not. Standardized tests were implemented to measure academic achievement and intellectual capability, as well as first person accounts on self-perceptions with regards to reading achievement, interactions with teachers, and overall self-esteem. Related findings suggested that intellectual capability and self-esteem were not significantly related to school attrition. In contrast, low academic achievement and poor interactions with teachers were found to increase dropout potential.

Related to the purpose of this study, Kortering, Haring, and Klockars (1992), implemented a discriminate analysis with the function of distinguishing the factors that contributed to dropout or graduation of students with SLD. The study found that the school-related variables contributing to dropout consisted of school initiated interruptions (indoor and outdoor suspensions) and school transfers. The one social variable identified as also affecting graduation potential was family intactness. Students from divorced parents were found to be more likely to drop out. Giving closer scrutiny to findings citing family intactness as a potential dropout variable, national divorce data depict that since 1970 divorce rates have increased 40\%. Specifically by 1992 (the year the study in question was conducted), $8 \%$ of the population was divorced (Hardi, 2003). Based on this information it can be argued that the probability of showing larger numbers of students who have dropped out come from single-parent homes is not as significant a variable in the dropout equation. Rather it is a reflection of the fact that drawing a sample population from a general population composed of a high number of divorced families increases the probability of this variable emerging. On the other hand, the remaining variables, school 
initiated interruptions and school transfers potentially lead towards withdrawal from the school's culture, which as found by Bost (2006) contributes to school attrition.

\section{Behavioral Factors}

Aggressive and/or anti-social behavior in middle and high school is an indicator of potential dropout (Cobb et al., 2006; French \& Conrad, 2001; Boulerice, \& Tremblay, 2000). Accordingly, the highest dropout rate occurs amongst students with EBD (Blackorby \& Wagner, 1996; Cobb et al., 2006).

Cobb et al. (2006) sought to review the findings of 16 research studies addressing behavioral problems in EBD and SLD student populations, with the purpose of identifying the most effective approaches or methods of increasing pro-social behaviors. Resulting from this analysis, Cobb et al. concluded that cognitive-behavioral interventions or strategies that emphasize contingencies and environmental factors, as opposed to internal motivators, are most effective in reducing dropout.

The one common factor found across the 16 studies analyzed by Cobb et al. (2006) was that students with EBD or SLD tended to feel out of place in school due to lack of social skills and the ability to socially navigate the educational system, especially during demanding or taxing situations. The highly structured features of self-contained settings often do not reflect the realities of social life in schools and arguably shelter the students from the social demands of general education and society at large (Hehir, 2005). Thus, potentially posing the need to provide students with EBD or SLD with access to inclusive settings in which these appropriate social behaviors can be learned, practiced, and generalized in real scenarios. 


\section{Student Perspective}

Student perspective did not become a focus point in school attrition research until the mid 1990s. Resulting from these efforts, Kortering and Braziel (1999) conducted a study depicting the perceptions of students who had dropped-out. The self-reported variables identified as contributing to their decision to drop out included: (a) school attendance, (b) personal effort and attitude, (c) school's disciplinary methods, (d) teacher behavior, and (e) circle of friends. Interestingly, some of these coincide with previously discussed findings that identified student attendance history and the school's disciplinary methods as school attrition predictors. More importantly, these variables indicate the importance the role of the educational environment plays on graduation rates, and points towards the need to develop equitable and inclusive educational opportunities.

Supporting the importance of providing students with equitable educational environments, Bear et al. (2006), found that students with disabilities who had droppedout felt pushed-out. In line with findings reported by Bearden et al. (1989) and Gallagher (2002), Bear et al. (2006) also found that students who drop out typically disclose poor interactions with teachers and view the latter as not caring, taking advantage of their position of power, and being manipulative. When prompted to explain what schools could do to prevent dropout, all students unilaterally agreed that student-teacher interactions must be improved upon. However, it must be emphasized that Kortering and Braziel's (1999) study involved a sample population composed of exclusively ninth graders. Due to the fact that the students still have a long way until graduation, the study generally failed to provide a solid argument as to whether or not the student-reported variables will significantly impact their future decision to graduate or drop out. Kortering 
and Braziel (1999) explained that students reported social interactions with peers in school as extremely important. On the other hand, they identified "having to go to some classes" as the least favorable aspect of school (p. 109). Given the exclusionary nature of traditional special education practices many problematic issues arise. Specifically, following the self-contained model students with disabilities typically remain in the same class for most or all of their school day, which can become daunting if they do not like the class. What then would be the motivation for attending school? Remaining with the same peers and teacher the entire day can limit the students' accessibility to general education services and peers and potentially keep them from making adequate social gains. Supporting this notion, research suggests that students make reliable gains in social development and competence when enrolled in inclusive settings and achieve significant growth in IEP related domains (Fisher \& Mayer, 2002; Rea et al., 2002).

Including students with disabilities in general education classes has also been found to increase their academic outcomes (Fisher \& Mayer, 2002; Rea et al., 2002). Students with disabilities at the elementary school level taught in general education classrooms, implementing early reading intervention strategies made significant learning gains (Briggs \& Edmonds, as cited by Fisher \& Frey, 2003, p. 64). Similarly, students with disabilities in secondary school educated in inclusion classes effectively mastered and generalized vocabulary words (McDonnell et al., 2007).

\section{Inclusion as Potential Dropout Prevention Variable}

In assessing the outcomes of the studies discussed from the perspective of inclusive education, it is important to restate that inclusion offers students with disabilities the opportunity to learn alongside their non-disabled peers. As stated earlier, 
Rea et al. (2002) conducted a study where the educational outcomes of students with SLD in secondary school, educated in inclusive settings, were compared to those of students in self-contained or pull-out settings. The variables compared amongst the three samples consisted of academic grades, school attendance, disciplinary referrals, performance in formal assessments, and mastery of IEP goals. Results yielded that students in inclusion settings performed significantly better than their counterparts in self-contained or pull-out settings across all measures. Rea et al.'s study specifically found that students with SLD exposed to the general education curriculum earned better grades in math, language arts, social studies and science than others educated in selfcontained settings or pull-out programs. Subsequently, the students in inclusion classes achieved better scores in language arts and math formal assessments. With regards to behavior, those in inclusion settings were not more likely to have behavior problems despite the significant increase in the student-to-teacher ratio and less structure. Lastly, school attendance was significantly higher in the inclusion sample than evidenced in the self-contained or pull-out samples. Based on this, the argument can be made that absenteeism, one of the variables associated with potential dropout, often occurs due to disengagement from the general culture of the school (Rea et al., 2002). Arguably absenteeism has the potential to decrease if students have more access to the social relationships and academic experiences general education provides.

Along this vein, inclusive theory is largely based on the premise that all students must be welcomed contributors to the classroom, school, and community culture (Fisher \& Frey, 2003). As previously discussed, Dunn et al. (2004) conducted a study consisting of 228 students with SLD or MR and found that both disability categories exhibited 
similar dropout factors, all closely linked to the direct impact of disability on their educational experiences. While, as argued earlier, significant limitations may arise as a result of generalizing findings across two markedly different disability categories (SLD and MR). The variables identified as impacting graduation potential (i.e., disability status, identification of a helpful class and teacher, and the general perception that school was preparing them for the real world) point towards an eminent need to provide students with disabilities with inclusive educational experiences. Educational label or disability must not exclude them from access to environments that resemble the diverse make-up of society, curriculum that places high expectations and offers necessary supports, and a school culture that values them as contributing members.

A general conceptual summary of school attrition variables identified in the literature revealed that students who drop out have consistently experienced failure in education. The current wait-to-fail model associated with special education, where students first have to underperform in order to receive the necessary educational interventions (U.S. Department of Education, 2002) suggests students with disabilities are put at risk from early on in their educational lives. Gradual disengagement from the school's culture due to lack of involvement in school activities can begin as early as first grade for students experiencing academic and behavioral difficulties (Croninger \& Lee, 2001; Kemp, 2006). As a possible alternative, inclusion has the potential to change these outcomes.

These findings strengthen the case for implementing inclusive models to prevent dropout, and support the relevance and need for this study's exploration of the impact inclusive practices have on graduation potential. Given the preponderance of evidence 
discussed on the magnitude and significance of school attrition on students with disabilities, the urgency of finding solutions to decrease its detrimental effects, and the propagation of inclusive practices across the nation, this study explored how inclusion impacts school completion.

\section{Chapter Summary}

The gradual disengagement of students with disabilities from school occurs due to a myriad of social, academic, and behavioral factors that are exacerbated by limiting perceptions of what a disability status constitutes. These often result in the students' removal from the general culture of the school and the failure to view and treat them as contributing members of the school's milieu (Hehir, 2005). Compounding these systemic causes that contribute to school attrition, even operationally defining dropout has become difficult due to lack of consistency in the methods used to determine dropout rates (Kemp, 2006). This lack of objectivity in measuring the magnitude of the problem potentially adds to its propagation.

School attrition in special education is most prevalent in populations of students with SLD and/or EBD (Bost, 2006; NLTS 2, 2003). As empirically supported by the existing literature, academic and behavioral variables have been consistently found to contribute to school attrition (Bear et al., 2006; Blackorby \& Wagner, 1996; Bost, 2006; Cobb et al., 2006; Dunn et al., 2005; French \& Conrad, 2001; Scanlon \& Mellard, 2002; Suh \& Suh, 2007). Given the academic and behavioral problems students with SLD and EBD often experience and manifest, both populations are considered at a greater risk for dropping out. 
In finding solutions to this problem, researchers have arguably identified the factors that lead to dropout, but have failed to apply these to existing inclusive models, and have generally ignored the student perspective, particularly students with disabilities. The latter is particularly troublesome given that special education is based on the notion of individualization and empowering the student to self-advocate. The few studies that have included student voice reported that students with disabilities do not feel they belong or are valued in school, have generally negative opinions of their relationships with teachers, and even alluded to the idea that the existing educational constructs are designed to flush them out (Bear et al., 2006 ; Kortering \& Braziel ,1999).

A significant number of studies related to dropout also revealed that regardless of any existing disability, students who drop out disengage from the school's culture (Baken \& Kortering, 1999; Bost \& Riccomini 2006; Dunn et al., 2004; Lee \& Burkman, 2003; Rea et al., 2002). This process typically involves extreme absenteeism or truancy and, consequently, poor academic success. In examining this notion from a special education angle, the ramifications are extremely detrimental. Students in special education must often deal with the implications of having a disability within the constructs of a system that has historically separated them from the general population in order to provide services. Furthermore, and increasingly more troubling, to qualify to receive these services the students must have a pervasive history of academic failure. These systemic practices can potentially lead to students feeling left out and inadequate, which arguably promotes disengagement from school and eventual dropout.

School attrition in special education is a complex issue requiring further research, an increase in advocacy efforts, and a myriad of prevention-based solutions. Inclusive 
settings have the potential to become part of these solutions since they can provide students with disabilities special education services within the context of general education. By being educated alongside their non-disabled peers, students with disabilities might potentially feel more accepted by the general culture of the school. Moreover, related research has shown that students with disabilities in inclusion classes increase academic performance as well as pro-social behaviors (Rea et al., 2002). Based on these preliminary findings, this study investigated the impact of inclusion on the graduation potential of students with disabilities.

When compared to dropout rates in general education, the steadily increasing school attrition rates in special education have become a chronic reality across the nation, particularly in the categories of SLD and EBD. Given the educational system's legal, educational, and social responsibilities to these students and society at large, every potential avenue to provide relief must be explored. The findings of this study provide some viable solutions to this very complex situation. 


\section{CHAPTER III}

\section{METHOD}

The purpose of this study was to investigate the school-related variables that predict the graduation potential of students with SLD or EBD; as well as to determine if and how the inclusion model contributes towards potential graduation. The following research questions were formulated in order to potentially achieve this purpose:

1. Do specified school-related variables predict the graduation potential of students with SLD or EBD?

2. Do specified school-related variables show first order interactions?

3. What are the self-reported perceptions of students with disabilities in selfcontained settings versus those in inclusive settings with regards to support systems that promote graduation?

\section{Research Design and Statistical Analysis}

This study aimed to yield information based on a holistic perspective on the specific risks for potential dropout that students with SLD and EBD face, and also sought to give a voice to the affected students. To achieve these objectives a mixed methodology following an interactive continuum was applied (Newman \& Benz, 1998; Ridenour \& Newman, 2008; Teddlie \& Tashakkori, 2006). This research design was selected because it follows an iterative continuum where the main focus is on the research purpose and the research question and does not assume the data must be primarily quantitative or qualitative (Ridenour \& Newman, 2008). Consequently, the researcher had considerable freedom in selecting procedures based on the nature and purpose of the research questions. 
Based on the research questions outlined in this study, following the interactive continuum methodology allowed the researcher to identify and analyze quantitative variables while also portraying and integrating the experiences, perspectives, and needs of the population being investigated (Tashakkori \& Creswell, 2007). Specifically, the quantitative component was designed to yield which variables contribute towards increasing the graduation potential of students with SLD or EBD, as well as to identify first-order interactions among these variables. The qualitative component gave these students an active voice, as well as identifying how the perceptions of the population being investigated related or compared to the results of the quantitative strand.

The first strand consisted of a logistic regression identifying the factors which significantly predict graduation potential in populations of students with SLD or EBD and finding if these variables showed first-order interactions. A logistic regression was utilized because the dependent variable was a dichotomy and the independent variables were continuous, categorical, or both (Menard, 1995; Nagelkerke, 1991; Rice, 1994). In making this decision, it was considered that in this study the independent variable was not normally distributed, and the dependent variable was not homoscedastic for each level of the independent. Specifically, a logistic regression was utilized because its implementation does not assume a linear relationship between the dependent and independent variables and thus handles non-linear effects.

It must also be noted that similar studies on the topic of school attrition have implemented a discriminant analysis to answer similar questions (e.g., Johnson, 1997; Kortering et al., 1992); due to the fact logistic regressions and discriminate analyses have very similar attributes and can generally yield the same conclusions. However, logistic 
regressions are considered a more appropriate method in cases when the assumptions of multivariate normality are not met (Meyers, Gamst, \& Guarino, 2005; Press \& Wilson, 1978). For the purposes of this study a logistic regression was chosen due to the disproportional attributes in the sample, which would violate the following two important assumptions of discriminant analyses:

1. The sizes of the dependent variables must not be grossly different

2. Homoscedasticity: within each group of the dependent, the variance of each interval dependent should be similar between groups

The variables investigated in relation to potential graduation consisted of academic history, behavioral history, and instructional setting (self-contained or inclusion). These factors have been supported empirically by the existing literature on school attrition as significantly impacting graduation potential (Bear et al., 2006; Blackorby \& Wagner, 1996; Bost, 2006; Cobb et al., 2006; Dunn et al., 2004; French \& Conrad, 2001; Scanlon \& Mellard, 2002; Suh \& Suh, 2007).

In the second strand the researcher implemented qualitative techniques and conducted guided interviews. As stated earlier, the qualitative portion of this study was designed to give a voice to the sample being investigated, which is generally not done in studies related to school attrition (Bost, 2006). Both strands will be discussed in greater detail throughout the following sections.

Ridenour and Newman (2008) pointed out that "for the qualitative researcher the purpose is often theory building, while for the quantitative researcher is hypothesis testing" (p. 29). Accordingly, this study conducted a thematic comparative analysis to identify similarities and discrepancies between the variables yielded by the logistic 
regression and those that emerged as foci points during the student interviews. By combining both qualitative and quantitative procedures, the results of this study successfully pointed out where disconnects exist between how students with SLD or EBD believe their educational placement (i.e., inclusion or self-contained) affects their graduation potential, and the actual contributing variables yielded by the quantitative component.

\section{Setting}

Miami-Dade County, Florida, houses the fourth largest school district and the second largest population of racial and ethnic minority students in the nation. MiamiDade County Public Schools (M-DCPS) is a vast urban district that provides services for a total of 339,087 students (M-DCPS Demographics Report, 2008a) and is divided into four geographic regions. In comparison to other states in the nation, Miami-Dade County has the greatest percentage of immigrants as residents and one of the highest poverty rates amongst big cities; the cost of living in Miami-Dade County is $29.32 \%$ higher than the national average (Watnick \& Sacks, 2006).

As of 2008 M-DCPS housed 45 high schools, 12 of which are magnet schools, and are divided into four geographic regions. For the purposes of this study, one school per demographic region was chosen, totaling four. For the purposes of this study the following conditions were established in selecting participating schools: (a) school grade of C or lower, (b) students with SLD or EBD represent $20 \%$ or more of the dropout population, and (c) students with SLD or EBD make-up more than 50\% of the students with disabilities population. 
Schools with a grade of $\mathrm{C}$ or lower were chosen since these generally report the highest numbers of dropouts, regardless of disability category (U.S. Department of Education, 2002) thus providing a clearer picture of the dropout phenomenon. Schools where students with SLD or EBD made up more than $50 \%$ of the student population were chosen in order to provide a larger sample and, thus, a clearer picture of the two disability categories investigated by this study.

Magnet schools were purposely excluded due to the fact that students are chosen to participate and are required to keep a satisfactory academic and behavioral history in order to remain enrolled. Subsequently, the dropout phenomenon in magnet schools is almost non-existent. Similarly, Opportunity Schools, Juvenile Justice Centers, and other Specialized Centers were purposely omitted based on the fact that the inherently selfcontained nature of these institutions counteracted the purpose of this study. In order to provide a clearer picture of the schools selected to take part in this study, the following tables provide information about their corresponding graduation trends.

Table 1 provides information about student enrollment, ethnic/racial make-up, and school performance (i.e., school grade). The decision to include the racial/ethnic make-up of the student body in these schools was made based on the fact that race/ethnicity is one of the independent variables of this study. Conversely, given that research focused only on students with SLD or EBD graduating with a standard diploma, the percentages of students graduating with a special diploma were not included in Table 1. School performance was included since school grade was one of the variables considered when selecting participating schools. 
Table 1

Schools in Sample Population

\begin{tabular}{|c|c|c|c|c|c|c|c|}
\hline \multirow[b]{3}{*}{ Schools } & \multicolumn{5}{|c|}{ Percent of Graduates } & \multirow{3}{*}{ Interracial } & \multirow{3}{*}{$\begin{array}{l}\text { School } \\
\text { Grade }\end{array}$} \\
\hline & Student & Standard & \multicolumn{3}{|c|}{ Percentages } & & \\
\hline & Enrollment & Diploma & Hispanic & Black I & White & & \\
\hline 1 & 3684 & $60.0 \%$ & $92.3 \%$ & $2.1 \%$ & $4.6 \%$ & $1.0 \%$ & $\mathrm{C}$ \\
\hline 2 & 3618 & $72.0 \%$ & $40.0 \%$ & $29.0 \%$ & $29.0 \%$ & $2.0 \%$ & $\mathrm{C}$ \\
\hline 3 & 3493 & $63.0 \%$ & $93.0 \%$ & $2.0 \%$ & $4.0 \%$ & $1.0 \%$ & $\mathrm{C}$ \\
\hline 4 & 2189 & $64.0 \%$ & $52.0 \%$ & $41.0 \%$ & $6.0 \%$ & $2.0 \%$ & $\mathrm{~F}$ \\
\hline
\end{tabular}

Table 2 provides the specific number of students who graduated or dropped out during the 2008-2009 school year. As shown, School 4 has the greatest number of dropouts, having almost half of the students who were supposed to graduate dropout. School 1 was second as it relates to number of students dropping out, followed by schools 3 and 2 consecutively.

Specific dropout data (i.e., the number of students who graduated or dropped-out) were included based on the fact that school culture is one of the variables that has been consistently identified as affecting dropout trends (Bost, 2006) in both general and special education (Baken \& Kortering, 1999; Bost \& Riccomini 2006; Dunn et al., 2004; Lee \& Burkman, 2003; Rea et al., 2002). 
Table 2

Graduation/Dropout Data for Sample

School Number of Students Graduating Number of Dropouts

1

2

3

4
861

795

796

421
190

50

96

191

\section{Educational Setting and Continuum of Services}

With regards to educational setting, it is important to discuss the continuum of educational services that the students in the sample have experienced. Generally, the students in the sample were referred to special education during their first 2 to 3 years of school. Prior to, and during this referral process, they attended general education classes. Depending on the severity of their disability they were subsequently placed in selfcontained or inclusive settings. Students who require significant and intensive specialized help in order to be academically successful, and/or a highly structured behavioral program are generally placed in self-contained settings. The fact that students with EBD often require these highly structured behavioral programs perhaps explains research findings (e.g., Bost, 2005) that indicate they are generally the least included. As evidence, most of the students from the self-contained sample had the EBD label. 
It is also pertinent to note that the guided student interviews revealed that with the exception of one, all of the students in the qualitative sample had been in special education since elementary school; yet they could not remember if they were originally placed in self-contained or inclusive settings. Based on their average age (i.e.,16), and the fact the referral process into special education is generally started from second to third grade, they were likely first diagnosed 9-10 years ago, dating back to 2001-2002. Given that inclusion in MDCPS was in its early stages of wide-spread implementation during said time, these students were likely placed in self-contained settings. Corroborating this assumption, additional analyses of the interviews revealed that all of the students (even those currently in inclusive settings) referred back to past experiences in self-contained settings. Specifically, all of the students in the sample likely experienced self-contained settings. Moreover, students can be placed in inclusive settings for some classes and in self-contained for others; as was the case for one of the students in the qualitative sample. For the purposes of this study, the setting where the students spent most of their time in school (i.e., self-contained or inclusion) was the primary educational setting.

\section{Truth Value of the Research}

In order to explain the links between the research questions and truth value, features of the model established by Ridenour and Newman (2008) and Guba and Lincoln (1981) were applied. The specific measures implemented to explain the truth value methods employed for the quantitative and qualitative components of this study will be discussed throughout this section. 


\section{Quantitative Component}

The design features of the quantitative component included random assignment and random selection. Specifically, the sample investigated included all of the students with SLD or EBD from the four participating schools. To support the reliability of the instrument employed, in this case logistic regression, the test-retest format was followed. Specifically, three trials of all the regressions and interactions were conducted in order to assess if the results were consistent. To facilitate internal consistency linear regressions were implemented to answer all of the quantitative research questions.

\section{Qualitative Component}

To establish the links between the research questions and truth value (a) triangulation, (b) peer debriefing, (c) member checking, (c) thick description, and (d) audit trail were employed. The researcher purposely included the variables addressed in the quantitative component in the guided, student interviews to facilitate triangulation.

Member checking was provided as a reliability measure and to best honor the authenticity of the participants' perceptions. Specifically, member checking was implemented for all interviews conducted, and a copy of the study in its entirety was personally delivered by the researcher to each participant. The participants' responses to the transcribed interviews will be discussed later in this chapter.

Thick descriptions of the participants' non-verbal cues and perceived mood were included in the naturalized versions of the interviews. Based on this, the researcher was able to determine why some of the terminology used by the participants was deemed derogatory. Specifically, with the exception of one of the students in self-contained settings, all of the participants looked down, and/or frowned when using the term slow to 
describe the curriculum and sometimes the students in self-contained settings. An audit trail was established by explaining exactly how the meta-themes were developed. This will be discussed within the context of data analysis.

\section{Researcher Background and Beliefs}

Even when intending to remain unbiased and adopt a neutral tone, strong convictions and deeply rooted personal beliefs can permeate through. With this in mind, the researcher in this study deemed essential to disclose her current role in the educational system, as well as her beliefs regarding education and inclusive practices. The researcher is a veteran special education teacher and a strong advocate of inclusion, who believes that the goal of education should be intellectual emancipation.

Intellectually emancipated individuals question the world around them while having the academic tools necessary to successfully navigate it, and if needed produce significant changes to benefit society. The researcher regards inclusion as a step towards the intellectual emancipation of all individuals regardless of disability. From the perspective of the researcher, self-contained settings inherently seclude individuals and thus fail to provide them with contextual experiences from which to navigate and negotiate the world around them. In essence, self-contained settings can deny individuals with disabilities the right to be intellectually emancipated.

Acknowledging these biases encouraged the researcher to take the necessary precautions to keep these out of the data. As evidence, the quantitative sample was random and included all of the students with SLD or EBD from the participating schools. In addition, an expanded format was implemented in the quantitative component of this study, to show that all the variables were regressed and none were purposely omitted to 
skew the data. Member checking also assisted the researcher in curtailing the potential to introduce personal opinions in the students' narrative.

\section{Quantitative Component: Logistic Regression}

\section{Subjects}

The subjects in this study consisted of a heterogeneous (i.e., boys and girls) group of 573 students from African American or Hispanic backgrounds with SLD or EBD, ranging from 15 to 18 years of age. This sample included students with SLD or EBD expected to graduate with a standard diploma in the 11th or 12th grade, previously enrolled (2007-2008) or attending at the time of the study (2008-2009) four local public high schools during the 2007-2008 and 2008-2009 school years, and receiving instruction in inclusive or self-contained settings. It must be noted that this study was not designed to focus only on minority students with EBD or SLD, but resulted in a population of mostly Black and Hispanic students due to the demographic make-up of the schools as a whole and the over-representation of individuals in these ethnic and gender categories (Donovan \& Cross, 2002; Harry \& Klinger, 2006; Harry, Klinger, \& Cramer 2007; Hart, 2003; U.S. Department of Education, 2002; U.S. Department of Education, 2002b). Similarly, while the population was heterogeneous by design, due to the over-representation of boys in the EBD category (Sugai \& Horner, 1999; U.S. Department of Education, 2002a; U.S. Department of Education, 2007) most of the subjects were male.

\section{Criteria for Sample Selection}

This particular sample was selected based on literature sited in the previous discussion that explained students with disabilities, particularly those with EBD or SLD, have been consistently identified as having the highest dropout rates (Blackorby \& 
Wagner, 1996; Bost \& Riccomini 2006; Dunn et al. 2004; Grayson, 1998; Repetto, Pankaskie, De Palma-Hankins, Schwartz, \& Perry, 1997). Complicating matters, the actual dropout problem amongst students with disabilities may actually be more extensive than generally expected due to discrepancies in objectively measuring dropout rates (Barton, 2005; Kemp 2006; Murray \& Naranjo, 2008; Orfield, Losen, Wald, \& Swanson, 2004). Despite these well-documented problems, the existing literature is limited when addressing the graduation or dropout patterns of students with SLD or EBD. Furthermore, no studies to date were found that have demonstrated how the fairly recent national implementation of inclusion affects previously observed patterns of graduation rates amongst students with disabilities. This study potentially provides seminal information on this topic.

\section{Data Collection}

M-DCPS produces yearly reports depicting graduation and dropout rates for all its public schools. Students from the participating schools, with SLD or EBD, who graduated in the 2008-2009 school year, were compared to those who dropped out with the purpose of identifying differentiating factors, based on academic and behavioral histories.

\section{Measures/Variables}

A logistic regression was conducted using: (a) primary exceptionality, (b) gender, (c) ethnicity/race, (d) grade, (e) current enrollment, (f) academic history, (g) behavioral history, (h) FCAT performance, (i) educational setting, and (j) behavioral history as likely predictor variables of graduation potential. The following table illustrates the 
categories associated with each, as well as the numerical values assigned to each data group (see numbers in parentheses) to facilitate data analysis.

Table 3

Data Categories

\begin{tabular}{|c|c|c|c|c|c|c|c|}
\hline \multirow{3}{*}{$\begin{array}{l}\text { Primary } \\
\text { Exceptionality }\end{array}$} & \multicolumn{2}{|l|}{ Gender } & \multirow{3}{*}{$\begin{array}{c}\text { Current } \\
\text { Enrollment }\end{array}$} & \multirow{2}{*}{\multicolumn{2}{|c|}{$\begin{array}{c}\text { FCAT } \\
\text { Academic Performance }\end{array}$}} & \multirow{3}{*}{$\begin{array}{l}\text { Educational } \\
\text { Setting } \\
\text { Variables }\end{array}$} & \multirow{3}{*}{$\begin{array}{c}\text { Behavioral } \\
\text { History } \\
\text { Variables }\end{array}$} \\
\hline & \multicolumn{2}{|l|}{ Ethnicity/ } & & & & & \\
\hline & Race & Grade & & History & Variables & & \\
\hline LD (1) & Male $(1,0)$ & 11 th $(0)$ & Enrolled $(0,1)$ & Pass (1) & Pass (1) & Inclusion (1) & Suspension \\
\hline \multirow[t]{5}{*}{$\operatorname{EBD}(0)$} & Hispanic $(1,0)$ & 12th (1) & & Fail (0) & Fail (0) & Self-Cont. (0) & None (0) \\
\hline & Black $(0,1)$ & & & & & & \\
\hline & & & & & & & Indoor (1) \\
\hline & & & & & & & Outdoor (2) \\
\hline & & & & & & & Expulsion (3) \\
\hline
\end{tabular}

Note. All variables are based on the 2008-2009 academic year.

${ }^{a}$ Academic history and FCAT performance will be reported for the student's current grade (11th or 12th).

\section{Academic History}

States have significant discretion in establishing high school graduation requirements. The areas where most of the discrepancies amongst states are observed are in the number of credits required to graduate and the exit exam standards (Mitani, 2007). In Florida, all students working towards a standard diploma must earn 24 credits to graduate and passing grades based on the criteria set by the state's grading scale. As of 2001, the student grading scale in Florida was revised to set a common standard between Florida and most other states (U.S Department of Education, 2007). The following table depicts the grading scale currently implemented in Florida. Numerical values were not 
assigned to each specific letter grade because only pass or fail status will be utilized in the analyses of the data.

Table 4

Florida's Grading Scale for Grades K-12

Grade Point Criteria Performance Criteria

\begin{tabular}{|c|c|c|}
\hline A & $90-100$ & $\begin{array}{l}\text { Excellent/above average, student } \\
\text { shows mastery of subject }\end{array}$ \\
\hline B & $80-89$ & $\begin{array}{l}\text { Above average, student shows } \\
\text { mastery of subject with few } \\
\text { exceptions }\end{array}$ \\
\hline $\mathrm{C}$ & $70-79$ & $\begin{array}{l}\text { Average, student shows partial } \\
\text { mastery of subject }\end{array}$ \\
\hline $\mathrm{D}$ & $60-69$ & $\begin{array}{l}\text { Below average, student shows } \\
\text { minimal mastery of subject }\end{array}$ \\
\hline $\mathrm{F}$ & 59-below & $\begin{array}{l}\text { Failing, student fails to show any } \\
\text { mastery of subject }\end{array}$ \\
\hline
\end{tabular}

Note. Student pass or fail status is based on the criteria outlined.

As also established by the state of Florida, students must meet the criteria set forth by the Florida Comprehensive Assessment Test (FCAT) in order to graduate with a standard diploma. However, this does not always apply to students in special education because they can obtain an FCAT waiver and complete a portfolio assessment. Despite this option students can special education are still required to make several attempts at meeting the exam's standards.

Extensive consideration was given to using the FCAT as a variable that can potentially predict the graduation potential of students with disabilities since as per current state mandate this population can obtain an FCAT waiver. It was, however, determined using such a measure was appropriate based on the fact FCAT outcomes 
significantly impact the experiences of students with disabilities throughout their schooling due to the following:

- Regardless of the FCAT waiver option for students in special education, they must make several attempts at passing the test if working on a standard diploma option.

- Most students are typically placed in classes based on their FCAT results.

- Students with disabilities who do not pass standardized exams, in this case the FCAT, typically have a difficult time accessing general education (Bost, 2006). Table 5 describes the FCAT criteria or standards. These are based on achievement levels which describe the success a student has achieved on the FCAT Reading, Mathematics, Science, and Writing assessments. The achievements levels consist of scale scores and developmental scale scores that range from Level 1 (lowest) to Level 5 (highest) and apply to all FCAT subjects. In order to pass the FCAT, students must obtain an achievement level of 3 or above. Numerical values were not assigned to FCAT levels because only the pass or fail statuses were analyzed and not specific FCAT scores.

As shown in Table 5, level 5 constitutes the highest possible score. Accordingly, students who achieve this level are able to answer most of the questions on the FCAT regardless of difficulty level. As defined in Table 5, Level 4 indicates that the student was able to answer most of the questions in the FCAT but was not able to answer most of the more challenging questions. Similarly, Level 3 indicates that the student generally answered the test questions correctly, with the exception of the more challenging questions. Levels 1 and 2 indicate that the student was not able to correctly answer most of the questions (regardless of difficulty level) and thus did not pass the FCAT. 
Table 5

FCAT Achievement Level Descriptions

Levels Descriptions

Level 5

A student scoring in Level 5 answers most of the test questions correctly, including the most challenging questions

Level 4

A student scoring in Level 4 answers most of the test questions correctly, but may have only some success with questions that reflect the most challenging content

Level 3 A student scoring in Level 3 answers many of the test questions correctly but is generally less successful with questions that are the most challenging

Level 2 A student scoring in Level 2 has limited success with the challenging content of the Sunshine State Standards

Level 1 A student scoring in Level 1 has little success with the challenging content of the Sunshine State Standards

Note. The Florida Sunshine Standards outline specific competencies to be met by the student for each subject (including electives). The FCAT currently assesses competency in Reading, Writing, Math, and Science.

\section{Behavioral History}

For the purposes of this study behavioral history is operationally defined as the number of suspensions or expulsions the student received. In Florida, each student's behavioral history is documented through a disciplinary referral process that classifies behavioral infractions based on a multi-level system. Table 6 describes each level and provides examples of behavior associated with each. It is important to note that in Florida the Zero Tolerance initiative is followed and consequences are generally imparted accordingly. 
Table 6

Florida Code of Student Conduct

\begin{tabular}{|c|c|c|c|c|c|}
\hline & I & II & III & IV & $\mathrm{V}$ \\
\hline $\begin{array}{l}\text { Types of } \\
\text { Offenses }\end{array}$ & Disruptive & $\begin{array}{l}\text { Seriously } \\
\text { Disruptive }\end{array}$ & $\begin{array}{c}\text { Offensive/ } \\
\text { Harmful }\end{array}$ & $\begin{array}{l}\text { Dangerous or } \\
\text { Violent }\end{array}$ & $\begin{array}{c}\text { Most Serious } \\
\text { Dangerous or } \\
\text { Violent }\end{array}$ \\
\hline $\begin{array}{l}\text { Common } \\
\text { Offences }\end{array}$ & $\begin{array}{l}\text { Unauthorized } \\
\text { location } \\
\text { Cutting class }\end{array}$ & $\begin{array}{l}\text { Defiance } \\
\text { Cheating/ } \\
\text { Misrepresentation }\end{array}$ & & & \\
\hline Confrontation & $\begin{array}{l}\text { Confrontation } \\
\text { with another } \\
\text { student }\end{array}$ & $\begin{array}{l}\text { Confrontation } \\
\text { with staff } \\
\text { member }\end{array}$ & $\begin{array}{l}\text { Assault/threat } \\
\text { non-staff } \\
\text { member }\end{array}$ & $\begin{array}{l}\text { Battery } \\
\text { non-staff } \\
\text { member }\end{array}$ & $\begin{array}{l}\text { Aggravated } \\
\text { assault }\end{array}$ \\
\hline \multicolumn{6}{|l|}{ Property } \\
\hline Crimes & & & $\begin{array}{l}\text { Breaking/ } \\
\text { entering } \\
\text { Burglary }\end{array}$ & $\begin{array}{l}\text { Grand theft } \\
\text { over } \\
\$ 300,000\end{array}$ & Armed robbery \\
\hline \multicolumn{6}{|l|}{ Violent Crimes } \\
\hline
\end{tabular}

The nature of the behavioral infraction committed by the student typically decides the type of consequence that will apply, and school administrators have a myriad of choices that range from issuing a warning to requesting the student's expulsion.

Figure 3 contains Florida's definitions for suspensions and expulsions. The numerical values assigned (see numbers in parentheses) to suspensions and expulsions were created based on the fact that each succeeds the other in severity. Despite the fact that Florida follows the Zero Tolerance initiative, prior to recommending any type of disciplinary action for a student with special needs, administrators must first establish that the student's behavior was not a manifestation of his/her disability. A variable 
labeled conduct was created where numerical values (see numbers in parentheses) were assigned based on where the student fell on the chart.

In-School Suspension (1) Out-Of-School Suspension (2) Expulsion (3)

The temporary

removal of a student from
The temporary

removal of a student from

a school (not exceeding 10 days)
The permanent removal of a student from school.

Figure 3. State Definitions of Suspensions and Expulsions.

Table 7 was designed to provide greater understanding of the behavioral patterns observed in the sample selected. As shown, schools 1 and 4 have a greater number of outdoor suspensions and expulsions. Schools 3 and 4 have more indoor suspensions. It is important to note that these data portray the behavioral patterns of the entire student population of these schools and not just the sample analyzed.

Table 7

Behavioral Data for Schools in Sample

\begin{tabular}{cccc} 
Schools & Indoor Suspensions & Outdoor Suspension & Expelled \\
\hline 1 & 428 & 273 & 13 \\
2 & 346 & 192 & 6 \\
3 & 871 & 197 & 5 \\
4 & 915 & 711 & 9 \\
\hline
\end{tabular}




\section{Instructional Settings}

This study focused on two types of instructional settings: self-contained and inclusion. Self-contained settings are operationally defined as following an instructional model where a special education teacher facilitates all the academic subjects. Students being educated following this model remain with the same teacher all day and generally have very limited contact with their general education peers. Typically, students with EBD are placed in these types of settings (Bost, 2006) due to negative perceptions of the challenges their behavior poses.

Operationally, the current models associated with inclusion programs range from consultation to co-teaching. The external support or consultative model provides accommodations for the student with special needs, but does not provide direct services. In contrast, the internal support model is based on co-teaching and is perhaps the most widely implemented (Watnick \& Sacks, 2006). Following this inclusive model, a special education teacher and a general education teacher impart instruction to a class composed of special needs and general education students.

\section{Procedures}

After meeting all the ethical and legal standards set forth by M-DCPS and Florida International University with regards to conducting research, archived data were obtained for each of the four schools in the sample based on information provided in yearly reports by M-DCPS. Specific student information was withheld and only general information such as gender, ethnicity, disability category, and pass or fail status regarding grades and 
standardized exams were utilized. These data were entered into a data file constructed in SPSS version 17.0, where data analysis occurred.

\section{Data Analysis}

The data categories were extracted using archived information from yearly reports provided by M-DCPS. These data were entered into a SPSS file in order to be analyzed. The independent variables were regressed onto the dependent variables using the $\mathrm{Y}=\mathrm{b}+$ $b^{1} \mathrm{x}$ equation. The standardized regression weight implemented to interpret results in linear regression or Beta weight was interpreted as a log odd estimate and compared to the odds ratio estimate, which is generally thought to be a more efficient way to show the relationship between the independent and dependent variables (Meyers et al., 2005). Specifically, the odds ratio yields the increase or decrease in probability that a unit of change in the independent variable has in the probability that the event of interest will occur (Meyers et al., 2005; Nagelkerke, 1991).

To interpret the overall validity of the model proposed, the Cox and Snell's $R$ and the Nagelkerke $R^{2}$ were considered. Due to the fact in logistic regression there is no true $R^{2}$, the Cox and Snell $R$ and the Nagelkerke $R^{2}$ attempt to imitate the interpretation of $R^{2}$. Both tests are used to find the percentage of variance in the dependent variable justified by the independent variable (Meyers et al., 2005). Despite the fact both the Cox and Snell $R$ and the Nagelkerke ${ }^{2}$ can be generally used interchangeably, the Cox and Snell $R$ can have a maximum less than 1.0 which can make it rather complicated to interpret the data. The Nagelkerke's $R^{2}$ essentially modifies the Cox and Snell $R$ coefficient to guarantee that it can vary from 0 to 1 . For the purposes of this study the Nagelkerke $R^{2}$ 
was used due to the fact it can achieve a maximum value of 1 which is generally preferred (Meyers et al., 2005).

The dependent variable consisted of enrollment (in-school or dropped out), and was coded as (Enrolled 0,1). Table 8 outlines the independent variables; numerical values (see numbers in parentheses) were assigned to each data category.

Table 8

Independent Variables

\begin{tabular}{|c|c|c|c|c|c|c|c|}
\hline Primary & & Ethnicity/ & & Educational & Academic & FCAT & Behavioral \\
\hline Exceptionality & Gender & Race & Grade & Setting & History & Performance & History \\
\hline $\mathrm{LD}(0)$ & Male (1) & Hispanic (0) & 11 th $(0)$ & Inclusion (1) & $\begin{array}{l}\text { Grades: } \\
\text { Pass (1) }\end{array}$ & Pass (1) & $\begin{array}{l}\text { Suspension } \\
\text { Levels }\end{array}$ \\
\hline \multirow[t]{4}{*}{ EBD (1) } & Female (0) & Black (1) & 12 th $(1)$ & $\begin{array}{l}\text { Self- }(0) \\
\text { Contained }\end{array}$ & Fail (0) & Fail (0) & None $(0)$ \\
\hline & & & & & & & Indoor (1) \\
\hline & & & & & & & Outdoor (2) \\
\hline & & & & & & & Expulsion (3) \\
\hline
\end{tabular}

Note. The numbers in the column labeled Behavioral History belong to a continuum that ranges from no suspensions (0) to expulsion from school (3). Each successive variable indicates a more severe offense and related consequence.

\section{Interaction of Variables}

Interaction is the test of the multiplicative of and above the additive effects. It suggests that the effect of one variable depends on the value of one or more other variables. This study investigated the potential existence of first- order interactions between (a) educational setting and academic history, (b) educational setting and behavioral history, (c) primary exceptionality and academic history, and (d) primary exceptionality and behavioral history. These variables were tested for possible first-order 
interactions in the regression. Both variables were multiplied together to create the interaction variable and were coded as follows:

1. Educational Setting * Academic History

2. Educational Setting * Behavioral History

3. Primary exceptionality * Academic History

4. Primary exceptionality * Behavioral History

To provide a clearer picture of the relationship between these variables correlations were also conducted.

\section{Qualitative Procedures: Student Interviews}

Student interviews were conducted in order to give the population being investigated a voice. As stated earlier, student voice is generally absent in the research pool on school attrition (Bost, 2006). Similarly, student voice is seldom referenced in the special education literature. The student interviews contributed richer descriptions of the phenomenon being investigated, which provided significant points of reference when analyzed and included with the quantitative findings. Specifically, the researcher conducted a thematic analysis describing if or how the quantitative findings related to the qualitative meta-themes. This type of analysis revealed where misconceptions exist between student perceptions and actual dropout trends.

\section{Criteria for Sample Selection}

In order to achieve equal representation from the schools involved in this study, administrators and counselors from all the participating schools were contacted. While the unequal representation across the schools was considered, given that some schools reported more students willing to participate than others, it was still deemed an 
appropriate sample based on the idea that meta-themes typically become evident across fairly homogenous populations (Guest, Bunce, \& Johnson, 2006). Another aspect in considering the unequal representation is that all of the students share the commonalities of being in special education, having either an SLD or EBD label, having ethnic and/or racial minority status, and having met or being close to meeting all the graduation requirements.

To facilitate transparency or to provide a vivid picture of the researcher's methods (Bogdan \& Biklen, 2007), it must be noted that initially, some schools reported up to 30 students being interested in participating in the initial introductory meeting; however, these numbers drastically decreased after the students were informed their answers would be audio-taped. Furthermore, despite the fact the students were scheduled to meet with the researcher individually in the counselor's office, thus potentially decreasing the chance of compromising anonymity and decreasing peer-pressure; some schools had significantly higher numbers of students willing to participate than others. Specifically, out of a possible 500 students across all four schools, only 45 agreed to attend the initial introductory visit, and 20 of these were from the same school. Moreover, out of the overall sample consisting of 45 students, 30 were students with SLD and 15 were students with EBD. After the initial introductory visits, 26 students agreed to participate; however, only 15 actually submitted the required consent forms required for participation.

Table 9 describes trends in the sample that constituted the qualitative strand of this study. As shown, School 2 had the greatest number of participants followed by School 1. Schools 3 and 4 had the same number of participants. To protect confidentiality 
all the participating schools were given numbers as a means of identification (see Table $1)$.

Table 9

Qualitative Sample

\begin{tabular}{cc}
\hline $\begin{array}{c}\text { Participating } \\
\text { Schools }\end{array}$ & $\begin{array}{c}\text { Number of } \\
\text { Participating Students }\end{array}$ \\
\hline 1 & 4 \\
2 & 5 \\
3 & 3 \\
4 & 3 \\
\hline
\end{tabular}

Given that there are no specific rules when selecting sample sizes that are not based on probability or other quantitative measures (Guest et al., 2006), it was deemed appropriate to have a sample of 15 , and thus conduct 15 interviews, based on the principle of saturation. Generally, saturation is reached when themes in the data begin to repeat or overlap and no new information is generated (Bogdan \& Biklen, 2007; Guest et al., 2006; Rubin \& Rubin, 2005). Guest et al. (2006) conducted an in-depth, thematic analysis of personal interviews and found that saturation occurred within the initial 12 interviews in their fairly homogenous sample. The related meta-themes were found to overlap after the sixth interview. However, it must be noted that Guest et al. conducted 60 interviews prior to determining that 12 was the saturation point, and explained that in some cases this may not always apply. In this study saturation occurred after the fourth interview, accordingly no new themes emerged beyond this point. 


\section{Participants}

The participants in this component of the study consisted of 15 students with SLD or EBD who had already met or were close to meeting graduation criteria. Said criteria consisted of accumulating at least 24 academic credits or a passing FCAT score (see Table 5). Either measure (sufficient credits or passing the FCAT) constituted an appropriate predictor of graduation; because, as per state guidelines students with disabilities can graduate if they earned sufficient credits, made several attempts to pass the FCAT, and completed a portfolio assessment. The following table describes the participants based on grade level, ethnicity, gender, disability category, and educational setting.

Table 10

Qualitative Sample Participants

\begin{tabular}{lllll}
\hline Grade & $\begin{array}{c}\text { Race/ } \\
\text { Ethnicity }\end{array}$ & Gender & $\begin{array}{c}\text { Primary } \\
\text { Exceptionality }\end{array}$ & $\begin{array}{c}\text { Educational } \\
\text { Setting }\end{array}$ \\
\hline 11 th-6 & Hispanic-12 & Female-4 & SLD-7 & Inclusion-7 \\
12 th-9 & Black-3 & Male-11 & EBD-8 & Self-Contained-8 \\
\hline
\end{tabular}

Corroborating evidence suggesting that there is significant over-representation of minority students in the high-incidence special education categories (Donovan \& Cross, 2002; Harry \& Klinger, 2006; Harry et al., 2007; Hart, 2003; U.S. Department of Education, 2002a), all of the students in the sample were of racial or ethnic minorities. Similarly, in line with findings that suggest there is an over-representation of males in the high-incidence special education categories (Sugai \& Horner, 1999; U.S Department of 
Education, 2002b), only four girls were part of the sample. Along this vein, supporting longitudinal data indicating that students with EBD are the least included (NTLS 2] 2006), with the exception of one female participant, all students in self-contained classes were labeled EBD. Twelve of the 15 students in the sample interviewed had been receiving special education services since elementary school.

To facilitate transparency, it must be noted that while 15 students agreed to participate in this study, 3 asked not to be directly referenced at all, not even through the use of a pseudonym. Consequently, while their responses were taken into account in developing the meta-themes, to honor their wishes they were not directly referenced or given a pseudonym. When questioned as to why they felt so strongly against being referenced anonymously, they disclosed that they wanted to help others kids, and discuss their experiences in school, but felt they would be made-out by their teachers and administrators if their ideas and words were quoted. Table 11 describes the 12 participants who agreed to be directly quoted based on gender, ethnicity, grade, primary exceptionality, and educational setting. It was deemed important to provide the participants' demographic information because it can provide a more vivid picture of who the participants are. In addition, gender, ethnicity, grade, primary exceptionality, and educational setting constitute some of the variables addressed by the quantitative component of this study and are also sited in the literature addressing school attrition (e.g., Bost, 2006; Suh \&Suh, 2007; Wagner, 1991) as potentially impacting dropout. As shown in Table 11 with the exception of one student, all of the participants in self-contained settings had the EBD label. This corroborates Bost's (2006) claim that students with EBD are the least included. It is important to note that while the qualitative 
sample shown is heterogeneous (i.e., males and females are equally represented), the overall random sample of 573 students it was chosen from consisted of mostly males, which also corroborates the literature on overrepresentation (Bost, 2006; Wagner, 1991). Table 11

Demographics of Qualitative Sample Directly Quoted Participants

\begin{tabular}{lccccc}
\hline Participants & Gender & $\begin{array}{c}\text { Race/ } \\
\text { Ethnicity }\end{array}$ & Grade & $\begin{array}{c}\text { Primary } \\
\text { Exceptionality }\end{array}$ & $\begin{array}{c}\text { Educational } \\
\text { Setting }\end{array}$ \\
\hline Barbara & $\mathrm{F}$ & $\mathrm{H}$ & 12 & $\mathrm{EBD}$ & S.C. \\
Lorenzo & $\mathrm{M}$ & $\mathrm{M}$ & 12 & $\mathrm{EBD}$ & S.C. \\
Zack & $\mathrm{M}$ & $\mathrm{B}$ & 12 & $\mathrm{EBD}$ & S.C. \\
Gregory & $\mathrm{M}$ & $\mathrm{B}$ & 11 & EBD & S.C. \\
Magdalena & $\mathrm{F}$ & $\mathrm{H}$ & 12 & EBD & S.C. \\
Josh & $\mathrm{M}$ & $\mathrm{B}$ & 11 & SLD & I. \\
Tomas & $\mathrm{M}$ & $\mathrm{H}$ & 12 & SLD & I. \\
Monica & $\mathrm{F}$ & $\mathrm{H}$ & 12 & EBD & I. \\
Ernesto & $\mathrm{M}$ & $\mathrm{H}$ & 11 & SLD & I. \\
Lola & $\mathrm{F}$ & $\mathrm{H}$ & 11 & SLD & I. \\
Ignacio & $\mathrm{M}$ & $\mathrm{H}$ & 12 & SLD & I. \\
\hline
\end{tabular}

Note. $\mathrm{H}=$ Hispanic, $\mathrm{B}=$ Black, $\mathrm{S} . \mathrm{C}=$ Self-Contained, and $\mathrm{I}=$ Inclusion.

${ }^{a}$ All participants' names are pseudonyms.

\section{Data Collection}

The data collection method consisted of guided interviews (see Appendix). One hour, in-person, guided interview sessions were conducted with a purposeful sample consisting of 15 students intending to graduate during the 2008-2009 school year.

\section{Procedures}

The school psychologists or counselors from the eight participating schools were contacted by the researcher, with the purpose of talking to their 11th- and 12th-grade 
students with SLD or EBD, who had already met or were close to meeting all the graduation requirements, about the possibility of participating in this study. After receiving feedback from the students, initial introductory visits to the schools were scheduled.

During the initial introductory interviews the researcher explained to the students the purpose of the study, the nature and importance of their potential participation, the fact that anything they say would be confidential, and the required parental consent. As mentioned earlier, most students expressed concern about being audio-taped and in many cases declined participation altogether.

After the introductory visits were completed, 1-hour, guided interview sessions were conducted for each of the 15 participants (see Appendix). While the possibility of needing more than one interview session was considered, based on the rapport developed in the initial visit and the quantity and depth of the data collected during the first 1-hour interviews, no additional sessions were required. The guided interviews took place in the counselor's office and were recorded after obtaining student or parental consent, if the student was under 18 years of age.

The interview questions (see Appendix) were formulated to obtain information on the major topics addressed in this study. Accordingly, most of the questions addressed the variables tested in the quantitative component of this study (see Table 9). These included obtaining the participants' perceptions on (a) positive and negative aspects of school, (b) how being in special education and having a disability label impacts graduation potential, (c) current educational setting (self-contained or inclusion), (d) how current educational setting impacts graduation potential, (e) important variables or influences impacting 
graduation potential, (e) academic history, (f) favorite and least favorite classes, (g) behavioral history, (h) the impact of the FCAT on graduation potential, and (i) the most difficult areas to overcome within the context of promoting graduation potential.

The questions addressing the participants' perceptions on school were developed to obtain a clearer picture of their daily experiences and general attitude towards school. Questioning the participants' on how special education and disability labels impacted their graduation potential was deemed necessary in order to give the participants' and active voice on topics seldom addressed by the literature from the students' perspective, as well as to obtain greater insights on the student's overall educational history. The questions that focused on educational setting were designed to address one of the main goals of this study, which was to investigate how inclusive settings impact graduation potential. Similarly, the questions that focused on important variables or influences impacting graduation potential were developed to further elaborate on another key feature of this study, which is to investigate variables that impact graduation potential. The questions dealing with academic and behavioral history as well as the impact of the FCAT on graduation potential were developed in order to obtain qualitative data on the quantitative variables investigated, and thus obtaining a broader perspective on the variables that impact the graduation potential of students with SLD or EBD.

Regarding ethical matters, the rationale and purpose of the study was explained to all students prior to the interviews. In addition, all students were provided with a written consent form outlining confidentiality procedures. These were explained and students were guaranteed their names and school would remain confidential; consequently all participants were given pseudonyms. To provide a reliability measure and to best honor 
the authenticity of the participants' perceptions, member checking was implemented for all interviews conducted, and a copy of the study in its entirety was provided to each participant. Specifically, the researcher once again visited some of the participating schools and hand-delivered a copy of the completed transcripts to each participant. One of the participants, Barbara, contacted the researcher via e-mail and expressed her approval, specifically she wrote: "You go girl!" Another participant from the group of three that asked not to be quoted contacted the researcher by phone and expressed his gratitude about the fact his wishes about not being quoted were respected. He also inquired about the possibility that this would change upon publication, and was once again reassured this would not occur. Moreover, the researcher promised him a copy of the completed, published dissertation.

One of the counselors that originally assisted the researcher with identifying some possible candidates for the study contacted the researcher via e-mail and reported two of the participants from inclusive settings (Josh and Tomas) were interested in the possibility of being interviewed for other studies. The researcher contacted them via email and asked them about their interest in research. Only one of the participants, Josh, responded and explained that "being interviewed gave him the chance to talk to a teacher like if she were a person and not just someone that tells them what to do".

\section{Data Analysis}

The constant comparison method was used to analyze the data obtained from the guided interviews. Following this process the researcher looked for key issues, recurrent events, or activities in the data that became foci points (Bogdan \& Biklen, 2007) in the personal interviews. Specifically, the researcher used highlighters of different colors 
(i.e., green, orange, and pink) to identify similar themes evidenced among students in self-contained settings, as well as inclusive settings. The color green was used to recognize similar responses among students in self-contained settings. Similarly, the color orange was used to identify similar responses among students in inclusive settings. The pink highlighter was used to identify themes that became apparent across both educational settings (i.e., inclusion and self-contained). These themes were sorted out and compared following the constant comparison method. Upon completion of this process, it became apparent that most of the prevalent themes were evident across both educational settings.

To promote successful interview sessions, probing questions were developed beforehand to assist in managing the conversation while interviewing. These probes were used to assist the participants on expanding their answers, or when necessary to steer conversation back to the topic being discussed (Rubin \& Rubin, 2005). Probing questions were also developed to further elaborate on answers to questions that solicited yes or no responses with the purpose of gaining a better understanding of the participants' answer and related topic. Additionally, probing questions were implemented to expand upon answers that consisted of one or two sentences in an effort to obtain a more detailed and realistic perspective of the topics discussed. Some of the probing questions developed beforehand included:

- Would you mind providing some specific examples that led you to make that yes or no statement?

- Can you please discuss a specific situation that led you to have such a strong opinion? 
- Let's go back to the question and create a mental list of all the memories that come to your mind in response to that question.

- How would you solve the problem you are describing?

- Do you think your opinion is different from other students your age and in similar situations? Why do you think that is?

Subsequently, as also suggested by Rubin and Rubin (2005), interview answers were sorted and compared in order to develop themes. To provide greater insights as to the role of inclusion in promoting graduation, the answers of the students in inclusion classes were compared to those in self-contained settings, with an emphasis on portraying potential differences in the students' experiences.

It is important to clarify that while the quotes of the students that asked not to be quoted were omitted, these generally corroborated the perceptions of the participants that were quoted. Accordingly, the perspectives of the students that were not quoted were considered and included when developing the qualitative meta-themes.

As suggested by Oliver et al. (2005), a combination of naturalized and denaturalized approaches to transcribing the student interviews was implemented. Consequently the transcription process involved two versions, a naturalized and a denaturalized version. In the naturalized version speech idiosyncrasies, pauses or hesitations, and powerful non-verbal cues were recorded or noted. However, in order to facilitate accuracy during member checking and promote overall understanding, a denaturalized version was subsequently created. In the denaturalized version of the interviews, footnotes were implemented to convey the intended meaning of some slang 
words, and brackets were utilized to highlight some clarifications made by the researcher. The bracketed information was juxtaposed with the purpose of explaining some acronyms used by the students which were endemic to M-DCPS or their specific school. Footnotes and brackets were also implemented throughout the results section to explain or clarify intended meanings.

\section{Chapter Summary}

This study implemented mixed methodology in order to investigate the schoolrelated variables that predict the graduation potential of students with SLD or EBD. Specifically, it followed Ridenour and Newman's (2008) mixed methodology model where the quantitative component tests hypotheses and the qualitative component builds hypotheses. The quantitative component of this study analyzed specified school-related variables as likely predictors of graduation potential, and the qualitative component sought to gain the insight of students with SLD or EBD on how these variables, within the context of their daily experiences, impact their graduation potential.

For the purposes of this study, the following conditions were established in selecting participating schools: (a) school grade of C or lower, (b) students with SLD or EBD represent $20 \%$ or more of the dropout population, and (c) students with SLD or EBD make-up more than $50 \%$ of the students with disabilities population. Accordingly, one school per demographic region was selected totaling four.

To explain the links between the research questions and truth value, components of Ridenour and Newman's (2008) and Guba and Lincoln's (1981) model were applied. For the quantitative component these included: (a) random assignment and selection, (b) test- retest format, and (c) internal consistency. For the qualitative component, the links 
between the research questions and truth value were established by: (a) triangulation, (b) peer debriefing, (c) member checking, (c) thick description, and (d) audit trail. These measures were deemed specially important in order to decrease the likelihood that bias on the part of the researcher, who is an advocate of inclusion, would skew the data.

The quantitative sample consisted of a heterogeneous group of 573 students with SLD or EBD. This study was not designed to include only racial or ethnic minority students in the sample. However, due to the demographics of the participating schools and the phenomenon of overrepresentation in the high incidence categories of SLD and EBD (Donovan \& Cross, 2002; Harry \& Klinger, 2006; Harry et al., 2007; Hart, 2003; U.S. Department of Education 2002, 2007), the entire sample consisted of minority students.

In order to answer the first research question which sought to identify the schoolrelated variables that predict the graduation potential of students with SLD or EBD a logistic regression of the numerical data derived from school records was conducted. Specifically, the dependent variable was enrollment (i.e., in school or dropped out) and the independent variables included (a) primary exceptionality, (b) gender, (c) ethnicity/race, (d) grade, (e) academic history, (f) behavioral history, (g) FCAT performance, (h) educational setting, and (i) behavioral history as likely predictor variables of graduation potential. These variables were selected based upon a review of the current literature (e.g., Bear et al., 2006; Bost, 2006; Cobb et al., 2006; Dunn et al., 2004; French \& Conrad, 2001; Scanlon \& Mellard, 2002; Suh \& Suh, 2007) where they were generally identified as contributing to dropout. 
To answer the second research question, specified variables were tested for the existence of first order interactions. Specifically, this study investigated the potential existence of first-order interactions between (a) educational setting and academic history, (b) educational setting and behavioral history, (c) primary exceptionality and academic history, and (d) primary exceptionality and behavioral history.

The qualitative component of this study consisted of one hour, in person, guided student interviews. The interview questions were developed beforehand and sought to obtain a broader perspective on how students with SLD or EBD view and navigate school within the context of promoting graduation potential (see Appendix). Accordingly, questions directly addressing some of the quantitative variables (i.e., educational setting, academic and behavioral history, and FCAT performance) were also included. Probing questions were developed beforehand to stir the conversation back to the topic being discussed when necessary, to expand upon questions that solicited a yes or no answer, and to elaborate and/or expand on short responses consisting of less than three sentences.

The purposeful sample consisted of 15 willing participants from the quantitative sample of 573. The decision to have a sample consisting of 15 students was based on the idea that over-lapping themes can occur as early as the sixth interview in fairly homogenous populations (Guest et al., 2006) and on the principle of saturation. The latter occurs when themes in the data begin to overlap and no new themes occur (Bogdan \& Biklen, 2007; Guest et al.2006; Rubin \& Rubin, 2005). However, it must be noted that the researcher planned to interview more students if necessary.

The data were analyzed implementing the constant comparison method. Specifically, interview answers were sorted between groups (i.e. students in self- 
contained settings, and students in inclusive settings) and across groups. The latter was implemented in order to emphasize the potential differences in perspectives and experiences between students in inclusive or self-contained settings, which were one of the main goals of this study. Upon completion of this process, it became apparent that most of the prevalent themes were evident across both educational settings.

Two versions of the transcripts, naturalized and denaturalized, were developed. In the naturalized version thick description was implemented, which included noting the participants' overall mood and obvious or exaggerated non-verbal expressions, as well as use of slang or any other authentic student lingo. This decision was made based on the idea that faithfulness to the students' authentic voice could facilitate a greater understanding of the participants' anecdotes (Oliver et al., 2005). The denaturalized version was implemented to facilitate accuracy during member checking as well as data analysis. Member checking was implemented for all the interviews conducted, and a copy of the transcripts was personally delivered to each participant. 


\section{CHAPTER IV}

\section{RESULTS}

The subsequent session will discuss the results of both quantitative and qualitative components within the context of answering each respective research question. Accordingly, the results of the first research question were organized as follows: (a) descriptive sample statistics, (b) table summary of results and related analyses, and (c) summary of results. The descriptive analysis of the sample was designed to provide the reader with the precise numerical breakdown of each variable. The table summary of results and related analyses was designed to increase replicability and reliability. Showing the actual results in tables followed by the related analyses arguably provides more insight into the researcher's methods and facilitates the scrutinizing of the related findings since the numerical data are provided in detail. To further increase both replicability and reliability an expanded format was implemented in showing the related results; specifically, tables and related analyses for the variables that were not statistically significant were also included.

The results of the second research question were structured following the same patterns and logic and consequently were organized as follows: (a) correlation tables of independent variables, (b) table summary of results and related analyses, and (c) summary of results.

The results for the third research question which encompassed the qualitative component were organized based on the general meta-themes that emerged from the student interviews, and were worded using quotes from the participants. The students' 
responses were subsequently grouped into self-contained and inclusion settings in order to emphasize potential differences in student perspectives.

\section{Quantitative Component}

The results of the logistic regression conducted will be discussed in relation to answering the two quantitative research questions posed which sought to investigate:

1. Do specified school related variables predict the graduation potential of students with SLD or EBD?

2. Do specified school-related variables show first order interactions?

In order to answer the first question, a linear regression was conducted that tested each individual variable for significance. The dependent variable consisted of enrollment, and the independent variables consisted of (a) exceptionality, (b) ethnicity, (c) gender, (d) grade, (e) academic history, (f) FCAT performance, (g) educational setting, and (h) suspension. Subsequently, a logistic regression was conducted which tested all of the variables together for significance. As noted earlier, the variables tested have been overwhelmingly identified in the dropout prevention literature as contributing to dropout (e.g., Bear et al., 2006; Blackorby \& Wagner, 1996; Bost, 2006; Dunn et al., 2004; Scanlon \& Mellard, 2002; Suh \& Suh, 2007); but had never been tested together for significance or generalized to students with SLD or EBD.

Linear regressions were conducted to answer the second research question. These investigated the potential existence of first- order interactions between (a) educational setting and academic history, (b) educational setting and behavioral history, (c) primary exceptionality and academic history, and (d) primary exceptionality and behavioral history, within the context of predicting graduation potential. Given the existing 
educational climate which mandates inclusion, one of the main objectives of this study was also to determine the effect of inclusive settings on graduation potential. With this in mind, it was deemed important to investigate if educational setting significantly interacted with a student's academic and behavioral history and thus their graduation potential. As students with EBD are generally the least included (Bost, 2006; NLTS-2, 2001); it was also deemed important to test for interaction between exceptionality (i.e., SLD or EBD) and academic as well as behavioral history within the context of predicting graduation potential.

\section{Results for Research Question 1}

Descriptive sample statistics. The sample consisted of 573 minority students with SLD or EBD. This study sought to investigate a random sample of students with SLD or EBD from four local high schools. However, the entire random sample consisted of Hispanic and Black students, possibly occurring due to the demographic make-up of the schools as a whole and the over-representation of minority students in the high incidence categories of SLD and EBD (Donovan \& Cross, 2002; Harry \& Klinger, 2006; Harry et al., 2007; Hart, 2003; U.S. Department of Education, 2002, 2007).

The following tables and subsequent analyses will illustrate and describe the related findings. Table 12 provides a statistical description of the variables analyzed and breaks down each variable into related percentages. Of the total 573 student sample, $59 \%$ had the educational label of SLD and the remaining $49 \%$ had the educational label of EBD. With regards to ethnicity, $18 \%$ of the students were Black and $82 \%$ were Hispanic. Additionally, $65 \%$ were males and $35 \%$ were females. Of these, $42 \%$ consisted of 11 th graders and $58 \%$ consisted of 12 th graders. The dependent variable, enrollment, yielded 
$88 \%$ of the students who graduated and $12 \%$ who dropped out. This directly mirrored the academic history variable with $88 \%$ of the students obtaining passing grades (see Table 4 for detailed description of Florida's grading scale and what constitutes a passing grade) and $12 \%$ failing their academic classes. On the reading component of the FCAT, $41 \%$ of the students in the sample passed this portion of the test (see Table 5 for detailed description of what constitutes a passing FCAT score) and 59\% failed to meet the criteria required to obtain a passing score. In the math portion, $64 \%$ of the students passed and $36 \%$ failed. The educational setting variable consisted of $79 \%$ of the students in the sample in inclusion classes for $80 \%$ or more of the school day and $21 \%$ of the students in self-contained settings. Lastly, the suspension variable (on a continuum that ranges from zero suspensions to expulsion from school) was purposely omitted from Table 12 because it was not a dichotomous variable, and thus would not show correct percentages.

Table 12

Descriptive Statistics

\begin{tabular}{llllll}
\hline Variables & Codes & $\mathrm{N}$ & Minimum & Maximum & Percents \\
& & & & & \\
\hline & & & & & \\
Exceptionality & LD (0) EBD (1) 573 & .00 & 1.00 & .5951 \\
Ethnicity & $\mathrm{H}(0) \mathrm{B}(1)$ & 573 & .00 & 1.00 & .1885 \\
Gender & $\mathrm{M} \mathrm{(1)} \mathrm{F} \mathrm{(0)}$ & 573 & .00 & 1.00 & .6527 \\
Grade & $11^{\text {th }}(0) 12^{\text {th }}(1) 573$ & .00 & 1.00 & .4241 \\
Enrollment & $\mathrm{G}(1) \mathrm{D}(0)$ & 573 & .00 & 1.00 & .8866 \\
Academic History & $\mathrm{P}(1) \mathrm{F}(0)$ & 573 & .00 & 1.00 & .8866 \\
FCAT Reading & $\mathrm{P}(1) \mathrm{F}(0)$ & 573 & .00 & 1.00 & .4171 \\
FCAT Math & $\mathrm{P}(1) \mathrm{F}(0)$ & 573 & .00 & 1.00 & .6440 \\
Educational Setting & $\mathrm{I}(1) \mathrm{S}$ S.C (0) & 873 & .00 & 1.00 & .7941 \\
& & & & & \\
\hline
\end{tabular}

Note. $\mathrm{G}=$ Graduated; $\mathrm{D}=$ Dropped-Out, $\mathrm{P}=$ Pass; $\mathrm{F}=$ Fail

${ }^{\text {a }}$ Enrollment is the dependent variable. 
Table summaries and related analyses of findings. The following tables were designed to depict the results related to the first research question which sought to identify the school-related variables that are likely predictors of graduation potential. Specifically, Table 13 depicts the significance of individual school-related variables, and Table 14 summarizes the overall significance when holding all the variables constant. Tables 15 depicts the results of the logistic regression model for the variables in the equation, or those that were found to be significant. Table 26 illustrates the results of the logistic regression model for the variables not in the equation, or those that were not found to be significant.

Table 13 contains the independent variables and shows the statistical significance of each. As shown, only academic history accounted for a significant amount of unique variance in predicting graduation when controlling for (a) exceptionality, (b) ethnicity, (c) gender, (d) grade, (e) FCAT reading, (f) FCAT math, (g) educational setting, and (h) suspension. Specifically, the student's academic history (i.e., passing or failing grades) was found to be the strongest predictor of graduation when including all the other variables. Only the variable ethnicity approached significance and indicated that Blacks were more likely to graduate than Hispanics when holding all the other variables constant.

Due to the fact one of the main goals of study was to explore the significance of inclusive settings on graduation potential, it is important to note that educational setting (self-contained or inclusion) did not account for significant variance when holding all other variables constant or statistically controlling them. 
Table 13

Significance of Independent Variables on Graduation Rates

\begin{tabular}{lcccc}
\hline Variables & Standard Error & Standardized Beta & $t$ & Significance \\
\hline Exceptionality & .013 & -.024 & -1.183 & .237 \\
*Ethnicity & .015 & .036 & 1.925 & .055 \\
Gender & .012 & .003 & .185 & .853 \\
Grade & .013 & -.014 & -.734 & .463 \\
*Academic History & .019 & .912 & 48.786 & $<.009$ \\
FCAT Reading & .012 & -.003 & -.177 & .859 \\
FCAT Math & .013 & .003 & .138 & .891 \\
Educational Setting & .015 & .003 & .169 & .866 \\
Suspension & .008 & -.021 & -1.097 & .237 \\
\hline
\end{tabular}

Table 14 includes a statistical summary of the variables analyzed. As illustrated, the regression model indicated that all the statistically controlled variables account for a significant amount of variance in predicting graduation. The $R^{2}$ was .836 , and the adjusted $R$ was .833 . In addition, $p$ was less than or equal to $.0009(p \leq .0009)$.

Table 14

Model Summary

\begin{tabular}{ccccc}
\hline$R$ & $R$ Square & Adjusted $R$ Square & $F$ & Significance \\
\hline .914 & .836 & .833 & 318.498 & .000 \\
\hline
\end{tabular}

Note. The model summary shows the significance of all the statistically controlled variables.

Table 15 depicts the logistic regression model implemented. As shown, the only significant predictor of graduation when statistically controlling all the other variables 
was having a satisfactory academic history. Moreover, as depicted its predictability potential was extremely high.

Table 15

Log Regression Model Variables in Equation Predicting Graduation Potential

\begin{tabular}{llllll}
\hline Variable(s) & $B$ & S.E & Wald & $d f$ & Significance
\end{tabular}

Academic

$\begin{array}{lllllll}\text { History } & 7.096 & .647 & 120.276 & 1 & .000 & 1207.200\end{array}$

Table 16 portrays the variables left out of the equation or those that were not significant. As shown, when statistically controlled none of the other factors (i.e., exceptionality, ethnicity, gender, grade, FCAT reading, FCAT math, educational setting, suspensions) were significant predictors of graduation.

Table 16

Log Regression Model Variables Not in Equation Predicting Graduation Potential

\begin{tabular}{lrrr} 
Variables & Score & $d f$ & Significance \\
\hline Exceptionality & .972 & 1 & .324 \\
Ethnicity & 2.683 & 1 & .101 \\
Gender & .177 & 1 & .674 \\
Grade & .063 & 1 & .802 \\
FCAT Reading & .193 & 1 & .660 \\
FCAT Math & .005 & 1 & .942 \\
Educational Setting & .048 & 1 & .826 \\
Suspensions & .285 & 1 & .593 \\
\hline
\end{tabular}




\section{Summary of Results for Research Question 1}

The first research question sought to identify the school-related variables that predict the graduation potential of students with SLD or EBD. Results indicated that academic history is the only significant predictor of graduation among students with SLD or EBD when all the other school-related variables are controlled statistically (i.e., exceptionality, ethnicity, gender, grade, educational setting, and suspensions).

\section{Results for Research Question 2}

Table summaries and related analyses of findings. Following the same organizational pattern implemented to answer the first research question, the following tables and subsequent analyses will show and discuss: (a) results of correlations conducted among all the independent variables tested for the existence of first order interactions, (b) significance of correlation variables, and (c) summary of results.

As depicted in Table 17, there is a significant association between: (a) educational setting and academic history, (b) educational setting and behavioral history, (c) primary exceptionality and academic history, and (d) primary exceptionality and behavioral history. As also portrayed, all of the independent variables except primary exceptionality are associated with the dependent variable (i.e., enrollment).

The results yielded a significant association between being in inclusion classes and having a successful academic history, $r=.267, p<.001$. Specifically, $93 \%$ of the students in the sample educated in inclusive settings obtained passing grades, while in comparison $72 \%$ of students in the sample from self-contained settings obtained passing grades. The results also yielded a significant association between being in inclusion classes and having a successful behavioral history, $r=-.289, \mathrm{p}<001$. Specifically, $79 \%$ 
of the students from self-contained settings were suspended, in comparison to $22 \%$ of the students from inclusive settings.

Table 17

Correlation of Variables

Variables

\begin{tabular}{|c|c|c|c|c|c|c|}
\hline & & $\begin{array}{l}\text { Primary } \\
\text { Exceptionality }\end{array}$ & Suspension & $\begin{array}{l}\text { Academic } \\
\text { History }\end{array}$ & $\begin{array}{l}\text { Educational } \\
\text { Setting }\end{array}$ & Enrollment \\
\hline Exceptionality & $\begin{array}{l}\text { Correlation } \\
\text { Coefficient } \\
\text { Sig. (2-tailed) } \\
\text { N }\end{array}$ & $\begin{array}{l}1.000 \\
573\end{array}$ & $\begin{array}{l}.025 \\
\\
.554 \\
573\end{array}$ & $\begin{array}{l}.064 \\
\\
.128 \\
573\end{array}$ & $\begin{array}{l}.248^{* *} \\
.000 \\
573\end{array}$ & $\begin{array}{l}.041 \\
\\
.324 \\
573\end{array}$ \\
\hline Suspension & $\begin{array}{l}\text { Correlation } \\
\text { Coefficient } \\
\text { Sig. (2-tailed) } \\
\text { N }\end{array}$ & $\begin{array}{l}.025 \\
.554 \\
573\end{array}$ & $\begin{array}{l}1.000 \\
573\end{array}$ & $\begin{array}{l}-.307^{* *} \\
.000 \\
573\end{array}$ & $\begin{array}{l}-.289^{* *} \\
.000 \\
573\end{array}$ & $\begin{array}{l}-.288^{* *} \\
.000 \\
573\end{array}$ \\
\hline $\begin{array}{l}\text { Academic } \\
\text { History }\end{array}$ & $\begin{array}{l}\text { Correlation } \\
\text { Coefficient } \\
\text { Sig. (2-tailed) } \\
\text { N }\end{array}$ & $\begin{array}{l}.064 \\
.128 \\
573\end{array}$ & $\begin{array}{l}-.307^{* *} \\
.000 \\
573\end{array}$ & $\begin{array}{l}1.000 \\
573\end{array}$ & $\begin{array}{l}-.267^{* *} \\
.000 \\
573\end{array}$ & $\begin{array}{l}.913^{* *} \\
.000 \\
573\end{array}$ \\
\hline $\begin{array}{l}\text { Educational } \\
\text { Setting }\end{array}$ & $\begin{array}{l}\text { Correlation } \\
\text { Coefficient } \\
\text { Sig. (2-tailed) } \\
\text { N }\end{array}$ & $\begin{array}{l}.248 * * \\
.000 \\
573\end{array}$ & $\begin{array}{l}-.289^{* *} \\
.000 \\
573\end{array}$ & $\begin{array}{l}.267^{* *} \\
.000 \\
573\end{array}$ & $\begin{array}{l}1.000 \\
573\end{array}$ & $\begin{array}{l}.240^{* *} \\
.000 \\
573\end{array}$ \\
\hline Enrollment & $\begin{array}{l}\text { Correlation } \\
\text { Coefficient } \\
\text { Sig. (2-tailed) } \\
\text { N }\end{array}$ & $\begin{array}{l}.041 \\
.324 \\
573\end{array}$ & $\begin{array}{l}-.288^{* *} \\
.000 \\
573\end{array}$ & $\begin{array}{l}.913^{* *} \\
.000 \\
573\end{array}$ & $\begin{array}{l}.240 * * \\
.000 \\
573\end{array}$ & .1000 \\
\hline
\end{tabular}

Note. Correlation is significant at the 0.01 level

${ }^{a}$ Enrollment is the dependent variable. 
A logistic regression was conducted to determine the effect of the dependent variable (i.e., enrollment) on the independent variables: (a) academic history, (b) behavioral history (i.e., suspensions), and (c) educational setting. This was done in two steps (i.e., model 1 and model 2). As shown in Table 18, the overall model without the interactions (i.e., model 1) was significant. While model 2 was also significant, there was not a significant change between model 1 and model $2, \chi^{2}(3)=3.66, n$.s. The Nagelkerke $R^{2}$ was used to interpret the overall variance of the model; accordingly, the $R^{2}$ was .84 . This indicates that $84 \%$ of the variance of the dependent variable is explained by the independent variables.

Table 18

Model Summary of Change in Statistics for Correlation Variables

\begin{tabular}{lllll}
\hline Models & $X^{2}$ & $d f$ & Significance & Nagelkerke $R^{2}$ \\
\hline Model 1 & 314.28 & 3 & $<.009$ & .83 \\
Model 2 & 317.94 & 6 & $<.009$ & .84 \\
\hline
\end{tabular}

Table 19 shows the variables for model 2 . The only significant variable is academic history. Despite the fact that there were associations between the independent variables illustrated (i.e., academic history, behavioral history, and educational setting) and the dependent variable (i.e., enrollment), when the other variables were controlled the only significant variable was academic history. This indicates that the variance between academic history and enrollment overlaps with the variance between behavioral history and enrollment (i.e., it explains overlapping variance). Similarly, the relationship between 
educational setting and academic history overlaps with the relationship between educational setting and enrollment. Given that one of the goals of this study was to investigate the effect of educational setting (i.e., self-contained and inclusion) on academic history, it is important to note that it was not significant. However, the interaction between educational setting and academic history did approach significance. Therefore, the effect of academic history on enrollment might depend on the educational setting. Specifically, students in inclusive settings are more likely to have a successful academic history when compared to students in self-contained settings, which was the only significant predictor of graduation potential when statistically controlling the other specified variables.

Table 19

Variables in Model 2

\begin{tabular}{|c|c|c|c|c|c|c|}
\hline Variables & $B$ & S.E & Wald & $d f$ & Significance & $\operatorname{Exp}(B)$ \\
\hline Academic History & 5.694 & 1.040 & 29.959 & 1 & .000 & 297.097 \\
\hline Suspensions & -.197 & .407 & .234 & 1 & .629 & .821 \\
\hline Educational Setting & -1.624 & 1.231 & 1.739 & 1 & .187 & .197 \\
\hline $\begin{array}{l}\text { Educational Setting X } \\
\text { Academic History }\end{array}$ & 2.670 & 1.524 & 3.070 & 1 & .080 & 14.446 \\
\hline $\begin{array}{l}\text { Academic History X } \\
\text { Suspensions }\end{array}$ & -.146 & .648 & .051 & 1 & .822 & .864 \\
\hline $\begin{array}{l}\text { Educational Setting X } \\
\text { Suspensions }\end{array}$ & .123 & .769 & .025 & 1 & .873 & 1.131 \\
\hline Constant & -1.774 & .654 & 7.361 & 1 & .007 & .170 \\
\hline
\end{tabular}

Note. The (X) indicates the variables were multiplied 


\section{Summary of Results for Research Question 2}

The second research question sought to identify the existence of first order interactions between (a) educational setting and academic history, (b) educational setting and behavioral history, (c) primary exceptionality and academic history, and (d) primary exceptionality and behavioral history, within the context of predicting graduation potential. Bivariate correlation showed that the variables (a) suspensions, (b) academic history, and (c) behavioral history significantly predict school enrollment (i.e., graduation or dropout). While at a marginal significance, results also yielded that students with SLD or EBD in inclusive settings experienced better academic results and behavioral outcomes than those in self-contained settings. Specifically, students with SLD or EBD in inclusive settings were found to be more likely to obtain passing grades and less likely to be suspended from school.

\section{Qualitative Component}

The following narrative details the responses obtained from the guided, student interviews. As suggested by Guest et al. (2006), meta-themes became evident early on, accordingly after the eighth interview six meta-themes emerged. Saturation occurred after the fourth interview since no new themes emerged thereafter.

The students' responses were subsequently grouped into self-contained and inclusion settings in order to depict potential differences in perspectives and categorized into six meta-themes. In order to give the participants an active voice, the meta-themes were titled using some of their quotes. In addition, to convey their ideas as authentically as possible, their grammar was not edited and slang words were not omitted. The choice not to edit slang words was made based on the idea that intended meanings, as well as 
cultural speech patterns which potentially provide snapshots of the participants' daily experiences, may have been lost (Oliver, Serovich, \& Mason, 2005). Table 20 depicts the meta-themes that became evident across both inclusive and self-contained settings.

Table 20

Meta-Themes

Student Quotes Reflecting Meta-Themes

"I actually want to learn...I really do"

"The teacher makes it or breaks it"

"Is kind of like a normal class...but with shortcuts"

"There are normal and slow classes"

“I don't feel I am learning"

"I want to become the future of my family"

\section{Meta-theme 1: "I Actually Want to Learn...I Really Do"}

Self-contained student responses. All students educated in self-contained settings (see Table 12 for participants' profiles) expressed an interest in learning. This theme became evident in most of the topics addressed by the guided interviews. Some of these topics included what were the best and worst aspects of school, based on personal experiences what classes were most conducive to passing or failing and why; and although it was not originally included in the guided interviews (see Appendix), the topic of learning extended to the rating of teacher performance. 
Regarding what is enjoyable or likeable about school; Barbara put it all in perspective by explaining:

What I like about school is the learning. I actually like to learn, I really do." When probed about what she liked to learn, Barbara was more specific, "I don't come here to chill $^{3}$, if I'm already here I want to make it worth it and go home knowing something.

Ignacio echoed the same theme by explaining that school can be enjoyable, he remarked, "The fact is that I like to learn and express myself. I like the fact that you can be creative in school and learn things." On the other hand, Lorenzo cited learning as a potential problem in his school, he explained, "I would have wanted to learn more stuff. I like the challenge and I like to learn." After the researcher requested that he provide some specific examples of exactly what he would have liked to learn, Lorenzo answered, "I don't' know...I just haven't gotten too much, I could have learned more." Yet, other participants cited learning as the reason they enjoyed and were successful in certain classes. As evidence, Zack stated, "I like my history and reading classes because I like to learn new things." Similarly Gregory emphasized, "I like ESE [Exceptional Student Education] because it helps me understand classes better and learn." In reply to a probe asking him to explain how ESE classes helped him to learn more, Gregory responded, “They have less people, so you can get more help." Interestingly, Magdalena brought up the issue that students generally like teachers who help them learn, she later personalized the issue by stating, "I like teachers that help me learn." After some inquiry into what teacher behaviors helped her to learn, Magdalena elaborated, "Good teachers always explain more than one time, and take time with you, without making you feel stupid."

\footnotetext{
${ }^{3}$ Chill: Slang referring to being in a state of relaxation.
} 
Inclusion student responses. Mirroring the various aspects of learning within the context of school reported by the students in self-contained settings, the participants in inclusive settings (see Table 12 for participants' profiles) also cited learning as the catalyst for liking school, and even rating teacher performance. However unlike the students from self-contained settings, some of the participants in inclusion classes directly related learning to a future career endeavor.

Both Josh and Tomas agreed that learning was the deciding factor in determining if they liked the school or not. Specifically Josh commented, "What I like about school the most is learning something new everyday. If I were principal for a day I would start by having more school hours and more school days so that people can learn more." When asked to describe exactly how more days and hours in school would help him to learn more Josh explained, "I would have more days to practice new things, sometimes we move fast through stuff and then I forget." Echoing Josh's thought, Tomas said, "I like school when the learning environment is good." In response to a probe addressing what constitutes a good learning environment he exclaimed, "A good learning environment helps you really understand things...not too much talking or messing around." Monica however, explained that she did not feel she generally had teachers that helped her to learn, she strongly stated, “The teachers here don't teach. I really have not learned anything at all." After some probing with regards to making such a blanket statement about all teachers in the school she replied, "Look, I did pass the FCAT but I failed it 3 times before I was able to pass it; what does that tell you?"

As mentioned earlier, two of the participants from inclusion classes made direct remarks linking learning to their future career plans. Specifically, Ernesto pointed out, 
"What I like the most about school is learning about things that could help you succeed in life. Since I want to be an engineer I need math and science.” Similarly, Lola agreed that, “Since I'm going to college and I know that I need to be prepared, I like classes that help me learn." When invited to describe how her classes helped her to learn, Lola said, "If I know I can really use the stuff they are teaching me to better myself, I think that is learning."

\section{Meta-theme 2: "The Teacher Makes it or Breaks it"}

Self-contained student responses. The guided interviews did not directly address teacher- student interactions, but rather focused mostly on obtaining information about which classes students were most successful or unsuccessful in and why. Yet, the topic of teacher-student interactions became evident in the first interview and dominated throughout.

The idea that the teacher holds great responsibility for the learning and ultimate success of students, was continuously implied by all of the participants in self-contained settings. Based on their perspectives, the teacher is the one variable that determines if they learn, like the school, and have successful outcomes in their classes; or as Zack explained:

I rather be in one class all the time with a teacher I like, because it doesn't give you the chance not to go to class or mess up, 'cause you don't get along with the teacher...the teacher makes it or breaks it.

In this vein, Lorenzo added, "I like being in ESE classes 'cause I like my teacher. Ninth grade was my best year because I got along really well with my new teachers. Now I like math because I work really good with that teacher." After Lorenzo was posed the idea of defining what working well with a teacher looked like, he immediately answered, "They 
don't judge you, they help you learn stuff, and they teach you in a way that you learn...maybe teach you different ways of doing something."

Two of the participants expressed that being in special education classes helped them to graduate because of the teachers. Specifically, Ignacio remarked, "I think ESE has helped me graduate because the teachers are more understanding and you are able to express yourself." When probed about how exactly special education teachers were more understanding, he added, "They have more patience...they are willing to explain things over, and give you more time to finish the work". Offering a similar perspective Magdalena added, "What I like about school the most is the teachers...how they help us...I think ESE has helped me graduate because the teachers give me extra time."

Showing the negative effects of poor teacher-student relationships, two of the participants expressed great concern over some teacher behaviors. Barbara firmly stated:

I like some teachers, I don't like them all, depends on the teachers. Some are nice and others are rude. I learn really 'good' with the nice ones, and I really do good with my counselor; she makes sure I don’t skip.

When further probed on the topic, with the purpose of clarifying what were the main differences between nice and rude teachers, she quickly added:

A nice teacher seems happy that you are there, she cares, and teaches you in a way that you get it...she doesn't diss ${ }^{4}$ you. A mean one is just there for the pay check and doesn't care if you understood or not, she basically wants you out of her face...is like whatever."

Gregory also expressed similar concerns. He shared:

If the teachers go over something and you still don't understand it, they tell you that they just went over it and you should understand it. That's why I have problems passing English 4 and Health. I can't learn with teachers like that... and

\footnotetext{
${ }^{4}$ Diss: Slang used as a synonym for disrespect.
} 
look is not me 'cause' my Math ESE teacher really helped me to study, study, study and she got me to pass the FCAT.

Inclusion student responses. The students in inclusive settings also made direct references regarding teacher behavior throughout most of the topics discussed. It quickly became apparent that all participants, regardless of educational label or educational setting, viewed teacher-student relationships as crucial to their success. This phenomenon was perhaps most succinctly explained by Monica when she affirmed, 'If the teacher sucks ${ }^{5}$, you're stuck!”

Most of the participants from inclusive settings made some remarks about student-teacher dynamics with more than one teacher in the classroom, which was perhaps indicative of the fact many inclusion classes in M-DCPS implement the coteaching model. As Josh explained:

"I really like having the ESE teacher in the classroom because she helps me out a lot. In Government they wanted me to do a research, but I do not have a computer and I can't get a library card, because my old one expired; and I can't get a new one until I pay my old fines and I don't have money. I told the ESE teacher and she is going to give me extra time to turn it in, so that helps. Help is really important in any class."

When asked to use a number from one to five to rate if receiving extra help from teachers helped him to graduate, he quickly responded, "Five times a thousand...definitely".

Following this line of thought, Tomas disclosed:

"I like having a class with two teachers because then one can help you out without putting you on the spot. Being in inclusion helped me a lot in the sense that if I needed help or had questions, I had somebody to go to for help and the teacher usually helped me. I don't think I would have been able to graduate without the

\footnotetext{
${ }^{5}$ Sucks: Slang used as a synonym for incompetency.
} 
help of Mr. Vadis ${ }^{6}$ in inclusion. If I couldn't keep up one of the teachers was always there to help me and explain things."

Lola echoed this sentiment by adding, "In one of my inclusion classes, if one teacher is busy the other one can help you, if they are both busy you never have to wait too long to get help, but the ESE teacher helps me more."

These same participants also had plenty to say when it came to describing why they disliked some teachers and some classes. Joshua commented,

What I can't stand about school is some of the teachers... sometimes their attitude. For example, sometimes you do work and they choose not to grade it, and then sometimes when you don't do it, they decide to grade it, and then give you zero.

Also making reference to grading policies and teacher behavior, Lola explained,

I had another teacher in $10^{\text {th grade }}$ that said nobody in Intensive Math ${ }^{7}$ deserved an A, even if that was the 'kinda' work they turned-in. What he did was to give you a good effort grade and then a bad academic grade... I never got it.

Subsequently, both students were asked whether or not they had complained to administrators about teacher grading policies, and both were resolute on the fact that nothing would have been done to honor their concerns. Specifically, Joshua replied:

Having to do anything in the office is impossible. Like I went several times to show doctor notices to get my absences excused and it never got done. Everything having to do with the office is a mission, they don't do anything.

Lola added, "You know how you asked me before if I was principal for a day what I would change? Well, I would change stuff like that [the grading policies], and I would actually listen to what the students say."

On the topic of teacher disposition towards explaining topics thoroughly, Tomas conveyed:

\footnotetext{
${ }^{6} \mathrm{Mr}$. Vadis is a pseudonym

${ }^{7}$ Intensive Math: In M-DCPS, when students do not pass the FCAT they are placed in 'intensive' classes.
} 
If the teachers don't put you on the spot when they help you, they are good teachers. How are you supposed to put yourself out there and say you didn't get it, if you know the teacher is gonna throw you under the bus ${ }^{8}$ ?

Lola included:

Some of the teachers are 'kinda' mean; they get on your case...like that is hard to learn. Like in $9^{\text {th }}$ grade the teacher wasn't that nice to explain it again. I also don't understand why teachers don't explain to you when you are not understanding before you leave the class and get even more lost. They tell you to get tutoring but I can't because I have to go home to take care of my grandmother, and do stuff around the house. My dad doesn't get home until like 10.

Ernesto brought a slightly different perspective to the topic of teacher behavior;

he was mostly concerned with their ability to deal with student misbehavior and promote student organizational skills. On these topics Ernesto disclosed, "When the teachers don't have control over their class, the gangsters, the thugs, the people that don't care about school; you can't learn." Based on his answer, he was subsequently asked if he generally felt safe in school and in all of his classes. To this Ernesto replied, "The gangsters, the thugs, the people that don't care about school aren't really in my inclusion classes, but there are more in the ESE classes". He further volunteered, "The way my English teacher teaches is not good, she is disorganized and since I have problems with organization....I don't know... I get disorganized too.” To sum it all up, in her usual straight forward manner Monica stated, "If I were principal for a day I would change who they hire to more competent people."

\section{Meta-theme 3: "Is Kind of Like a Normal Class...but with Shortcuts"}

Self-contained student responses. In response to one of the interview questions which directly asked the participants whether or not being in self-contained classes had

\footnotetext{
${ }^{8}$ Throw you under the bus: slang used to convey that another will embarrass and/ or expose you to others.
} 
helped them to graduate, most students agreed that self-contained classes had many benefits. In fact, most of the participants expressed that special education classes gave them learning strategies that significantly increased their learning outcomes. Zack was the exception, and had mixed feelings on the topic, he explained, "ESE's straight", like I said it has helped me, but it's like cheating....it is just easier to pass." After being asked to be more specific, he responded, "Well, everyone knows ESE classes don't give as much or hard work like regular classes, that's why it's ESE."

In contrast, Lorenzo felt that, "In ESE you learn shortcuts to help you learn better". Magdalena and Barbara also shared similar perceptions. Magdalena found that, "ESE classes show you special ways of doing things." Barbara further elaborated, "In ESE they give you more ways to do something...like shorter ways that help you understand."

Both Ignacio and Magdalena agreed that there were not too many differences between self-contained and inclusion classes, with the exception of class size. With regards to this topic Ignacio stated, "In ESE I still feel challenged, but with less students." Along this vein, Magdalena explained, "ESE is just smaller and you get more attention." To further explore their answers, Ignacio and Magdalena were asked to share specific examples of how being in self-contained classes had helped them to graduate. Ignacio explained, "I need extra time to do the work and it is hard for me to pay attention for a long time, in ESE they understand that and work with me." Magdalena simply said, "All I can say is that in regular classes I was making D's, and F's and in ESE I make A's, B's, and some C's."

\footnotetext{
${ }^{9}$ Straight: Slang word sometimes used as a synonym for something being good.
} 
Despite the fact most students in self-contained reported overall positive experiences regarding how being educated in this particular setting had impacted their graduation potential, two of the participants used vocabulary that indicated they did not feel self-contained classes represented the norm. Specifically, Ignacio said, "I guess selfcontained is 'kinda' like a normal class and Barbara later stated, "I guess they [ESE classes] are pretty normal sometimes." When questioned regarding their choice of vocabulary, in particular the use of the word 'normal' to describe general education classes, both of their replies indicated that at some point they were teased about being in Special Education classes. Ignacio explained, "Well, everyone says ESE classes are easier and some people think you are dumb if you're ESE...that doesn't really bother me anymore, but it used to." In turn, Barbara replied, "I have two inclusion classes and they are different than self-contained, not that self-contained is bad, but it is like slower sometimes, but not in a stupid way like everyone thinks."

Inclusion student responses. When inclusion students were asked to explain if and how being in inclusion classes had helped them to graduate, their answers closely resembled those of the self-contained students. Generally, they shared that inclusion classes had certain advantages that other classes did not, and reiterated the benefits of having two teachers in the same classroom. Interestingly, some of the students emphasized that inclusion classes were not special education classes, but rather just like general education classes. It is also important to note, that despite the fact the sample of students selected to participate in the interviews represented various schools, and thus quite different special education programs, all the participants used the words normal or regular to describe general education classes. 
Joshua and Ernesto highlighted some of the benefits they associated with inclusive settings. On this topic Joshua asserted, "The inclusion classes are normal classes, but with more 'hook-ups' ${ }^{10}$. For me, they made some of the most difficult subjects easier to understand, but they are not ESE classes." Upon being prompted to explain exactly how inclusion classes helped him understand difficult subjects, Joshua explained:

Because you have two teachers, they give you more than one way to do things, so if you don't get it from one, the other one can explain it. If you like one better than the other or one is nicer; you can always go to that one for help.

Based on his previous statement asserting that inclusion classes were not special education classes, Joshua was also prompted to describe the differences between special education and inclusion classes. He quickly added, "It [inclusion] is not like ESE because you learn the same stuff all the other kids learn.” Almost identically Ernesto exclaimed, "Inclusion is like a normal class, but in a way better, because you always have somebody for help...one of the teachers can help you." Monica was even more precise with her answer:

Inclusion is a normal class, but they do teach you shortcuts. Because there were two teachers in the class, when we didn't understand, they would sit with us, and that helped us out even more. If the regular teacher would get frustrated with us because we didn't get it, the inclusion teacher would make us understand it.

In response to being asked to describe how the inclusion teacher would "make her understand" she replied, "She just explained it better, took her time. I really needed the inclusion teacher in math." Lola shared the same views and explained, "I think inclusion

\footnotetext{
${ }^{10}$ Hook-ups: Slang word often used as a synonym for perks.
} 
classes are just like normal ones, they just teach more ways to learn...they help me understand more...they help me a lot."

Lola summarized the topic by explaining, “Look, I know what I'm talking about because I have done 'good' in both [inclusion and regular classes]. Inclusion is kind of like a normal class...but with shortcuts...they teach you the same stuff but you have two teachers, so you hear the same thing but in different ways"

\section{Meta-theme 4: "There are Normal and Slow Classes"}

Self-contained student responses. Early on during the interviews it became apparent that the participants used words with quite negative connotations when they referred to special education classes and students receiving special education services. Substantiating this point, in response to a prompt asking him to describe the type of help he received in special education classes, Zack remarked, "ESE classes did help me a lot...but they are just slower. Everyone, even the teachers, think ESE kids are slower...that's just how it is." When asked to provide specific examples that backed-up his claim, he responded:

Look, some things don't have to be said and you still know... it's not the type of thing you go around bragging about, and don't even try like you don't know what I'm talking about...you said you were a teacher...you know what's up.

Even when expressing that self-contained classes had helped them to graduate, the participants still used potentially derogatory words when describing special education classes and the students in these classes. On this topic Lorenzo remarked, "Teachers in normal classes don't teach shortcuts, that would be a big help to slow kids"; and Barbara felt that, "EBD kids are not normal and you need a lot of patience to be their teacher, patience is the key to being a good teacher, and ESE teachers have more patience." In 
response to being asked why she felt EBD kids were not normal, she responded, "I don't know, but I'm not the only one that thinks that...not all of them though, some are not really EBD but something happened with a teacher or a principal and they put them in ESE." When asked to further elaborate on this comment, she replied:

If a teacher, or even worse a principal or assistant, or whatever, disrespects you; and you go crazy on them, even if you're right to go crazy, they turn around and say you're out of control, and before you know it, you're ESE.

Magdalena and Gregory actually indicated they preferred self-contained classes, but still used words such as 'normal' and 'slow' to compare general and special education. According to Magdalena, “ESE classes are so much better, I'm glad I'm not in normal classes. That sounds weird, but I like to move slower.” Gregory further stated, "Self-contained are slower classes but that helps me understand better." Similarly Ignacio added, "ESE is like a normal class, maybe slower."

Inclusion student responses. When asked to describe how inclusion classes had helped them to graduate, many of the participants made distinctions between selfcontained and inclusion classes. In addition, their choice of words when comparing both settings was almost identical to that of the students in self-contained classes. They too used words such as 'normal' and 'slow' to compare inclusion and self-contained classes. For example Joshua explained, “ Now I'm in inclusion, but when I was in ESE classes they did go slower than normal classes...I think...but it is not bad...I think it helps." On the other hand Monica shared that:

My old classes, the ESE classes, were boring and slower. But I have to say sometimes the regular teachers just don't understand that with some kids you gotta move slower. I am not saying that all ESE kids are stupid but some are just slower, and some regular teachers just don't' understand that sometimes there are normal and sometimes there are slow classes. 
Tomas and Ernesto were even more specific when comparing inclusion and selfcontained classes, however their focus was mostly on student behavior. Tomas explained, "The normal classes have more kids interested, they are not slow; I can get into them. When asked to describe how inclusion classes had more kids interested he elaborated, "More people do what they are supposed to, less problems with behavior." In line with Tomas' observations Ernesto noted:

The inclusion classes are better than the slow classes; it [being in inclusion classes] has made me realize that school is important. By being around other kids that want to do something with their lives I have learned. I come across kids like that more in inclusion classes than in the special classes. I take all those classes seriously, 'cause' there's other kids in there that get good grades too, and I try to compete with them.

In response to being asked why he felt less competitive when in was in self-contained classes he added, "I told you, a lot of the kids didn't care about school, so if you did, they picked on you or wanted to copy off of you."

\section{Meta-theme 5: "I Don't Feel I am Learning"}

Self-contained student responses. Enjoying and expecting to learn in school was one of the prevailing themes throughout the course of all interviews. Lack of learning was also a prevalent theme reported by students. Included in the context of why he thought he did well in special education classes and agreed that being in self-contained classes had helped him to graduate, Zack responded:

I think being in self-contained or ESE is like cheating, because it is easier than regular class. I've had regular classes and there's more work; and still I have a hard time passing Math and Science because they are boring and I fall sleep in most of them, I am really not learning sometimes.

When probed with the purpose of explaining what a boring class felt and looked like, Zack further elaborated after some thought: 
Classes are boring really 'cause' of two reasons, they are either so easy that you learned it back in elementary school, or so hard that it's way above your head so you're like screw ${ }^{11}$ this.

Corroborating Zack's observation, Lorenzo added when explaining what he liked about school the least:

I would have expected to learn more stuff, and for it to get harder by now, and it hasn't happened. The classes are easier; in Intensive Reading they really don't give a lot of work, it will be just one small thing and we spend the rest of the period having free-time on the Internet.

On this topic Magdalena explained, "ESE is helpful, but a lot of times it's not all learning; a lot of times we get free-time." Based on their answers, both students were asked to explain if "free-time" involved any activity related to the topic being discussed in class. Lorenzo remarked, "No, free-time is like your time to relax after doing the work" and Magdalena retorted, "If free-time was about doing something for the class it wouldn't be called free-time, it's like your time to do whatever." After being further probed on the topic of free-time, specifically on whether or not some students misbehaved during this time, Magdalena added:

For sure! If any problems happen in class, they happen during free-time; and you get pissed- off ${ }^{12}$ when you are working and other people are eating crap $^{13}$ around you.

Barbara provided yet greater details when asked why she did not do well in certain classes:

I don't feel I am learning. I personally feel I am too smart for those classes [ESE] because they are for slow learners. If you are like me somewhere in the middle

\footnotetext{
${ }^{11}$ Screw: Slang word sometimes used as a synonym for 'forget it.'

${ }^{12}$ Pissed-off: Slang phrase sometimes used to describe being angry and/or upset.

${ }^{13}$ Eating crap: Slang phrase sometimes used to describe messing around.
} 
you fall behind of the normal classes because they [ESE classes] are made for very slow learners.

Gregory also asserted that, "Sometimes the work is easier in self-contained, maybe too easy some days; but not all the time." Both participants were subsequently asked to explain what teachers could do to make the classes more challenging. Barbara responded, “Just teach us like we are normal, we may have some problems, but it's not like we're retarded.” Gregory took quite a while to answer, but finally replied, "I don't know exactly, but I do know that I pay attention when they teach me stuff that makes me think."

Inclusion student responses. The participants from inclusive settings voiced the same type of concerns reported by their counterparts from self-contained settings. Despite the fact the students interviewed as part of the inclusion sample were expectedly in inclusion classes at the time these interviews were conducted; some still referred back to their experiences in self-contained settings. As evidence of this phenomenon Joshua reported:

I like being in inclusion and it has helped me. When I was in self-contained, the part that I found weird is that I guess as more time went by they [the classes] got more easier. I didn't feel I was learning; but sometimes all the teachers got together and decided to give more work and you had a bunch of assignments due.

To clarify his answer, Joshua was asked to define if what he meant by learning consisted of understanding something new, or was based upon the idea of having more work; he responded, "Well, you kind of need both to learn, right?"

Tomas and Ernesto also made similar comparisons between both settings. Ernesto, however, was much more positive than Tomas about his experiences in selfcontained classes. He reported: 
When I was self-contained the classes that did not help me to graduate like with teaching me stuff, but it has helped me with my emotions; instead of going off and getting in trouble or arrested, I have learned to take breathers and to relax.

In response to a probe asking him to rate how important learning to deal with his emotions was in order to graduate, he replied, "I could not have done it without first learning to cope in my old self-contained classes, and that's the truth.” Tomas, on the other hand, explained:

When I had self-contained a long time ago, I did not learn as much 'cause' some of the students were not really interested. I think the teachers were not allowed to choose what books they wanted to read with the students 'cause' they had to teach some books for FCAT and nobody, not even the teachers liked them.

When asked how he knew his teachers were instructed to teach certain books and how he knew they didn't like the books, Tomas added:

Teachers sometimes talk crap about the principals and they don't think we are listening, but we are. They are not wrong though, some of the books the principal makes them teach us are the worst. You can also tell 'cause' they tell us to read them, but they don't really check if we are really reading and they don't really bring them up.

Monica also brought up the topic of the FCAT, but in a slightly different context.

When asked why she reported not doing as well in intensive classes ${ }^{14}$ she answered:

All I can say is that overall I really don't think I learned much with those [Intensive] classes. I took the FCAT three times and the intensive classes didn't help at all. I just concentrated more the last time around, but honestly I think it was just luck because I did the same strategy. I don't know I just passed it, maybe it was a miracle!

Monica was subsequently asked to explain why she felt she did not learn much in intensive classes, and she responded quite dramatically, "Those classes make you 'wanna' puke! Look, they give you FCAT stuff to practice in the computer, and you just

\footnotetext{
${ }^{14}$ Intensive Classes: In M-DCPS when students do not pass the FCAT, they are mandated to take to take an intensive class. This often results in the student having an extra hour of math or English and consequently losing an elective class.
} 
sit there like a moron, and once you finish it, that's supposed to mean you learned it; yeah right!" Lola was more general in her observations and responded the following when asked how she was able to overcome certain obstacles in order to graduate:

I just didn't get it sometimes, I didn't learn. In math when I was in ninth grade, I really didn't understand what they were teaching me, but somehow I passed. I think 'cause' I show respect and I do try.

\section{Meta-theme 6: "I Want to Become the Future of my Family"}

Self-contained student responses. The question the majority of the participants elaborated upon and personalized the most with minimal probing, related to what had been the most important influence in their decision to graduate. To this Zack responded, "I made it a point to get on that bus every morning to help my family when I get a career. That is what makes me get up and go." Likewise, Lorenzo and Gregory offered family was the catalyst in their decision to graduate. Lorenzo explained, "What helped me graduate are the dreams that I follow in the graphic designing of video games, so that I can help my family.” Gregory later added:

I graduated to help my mom, she was always telling me to study hard because if I study hard I can get good grades. She says to always try hard. My best friend and my sister have also helped me study.

On the same topic Ignacio, Magdalena, and Barbara described much more

personal motivations to graduate. Ignacio disclosed the following:

The fact is that I want to make something of myself since my family past is really bad and I made a promise to my great-grandmother that I would become the future of my family. Even if I was still in normal classes, I would have the same influence to do better. I want to change and have a better life and destroy everything from the past.

To further promote transparency; it must be noted that the researcher considered asking Ignacio to discuss what exactly had happened in his past. However, the researcher 
decided against it, due to the fact the participant's facial gestures and overall body language suggested he had become very sad when mentioning his family's past.

Consequently, the topic was immediately changed in order to protect his emotional wellbeing.

Magdalena's and Barbara's answers were also very personal and powerful. Magdalena acknowledged the fact that her family was important in her decision to graduate and explained, "I have a history with my dad that I really don't want to tell you, but my aunt, my uncle, my whole family actually; they give me support and love. I want to make them proud by graduating." On the same topic, Barbara revealed:

I haven't overcome my moods from being bipolar completely, but I have learned to deal with it. I can't stay crying all the time or do whatever I want because the only person that I am hurting is me. I want to make my family proud and graduate. I want to have a good future.

The researcher prompted Barbara to explain if the school or any teachers had helped her to deal with having bipolar disorder; and she responded, "My counselor is really good and she helps me out a lot, she picks me up when I'm having problems, she talks to me; that's the only person."

Inclusion student responses. The responses of the students in inclusive settings were very much in line with those of the students in self-contained classes, and just as revealing and touching. Epitomizing this notion, Tomas responded the following when asked what was most significant in his decision to graduate:

I graduated because of my mom, is more of the fact behind it then just the person. My mom lives in Cuba and she said to make something of myself so that we could be back together when the time was right. I am doing that, I want to become the future of my family. 
Analogous to Tomas' response, Lola simply stated, "I want to graduate next year and I'm doing really good so far. I want to make my family proud and have a good future. I won't mess- up for nobody!"

Monica and Ernesto's responses paralleled those of the other participants, except in that they concentrated more on the financial ramifications of graduating high school. Monica explained:

Well, the fact that I actually 'wanna' be something in the future and not struggle through life, and help my family is why I'm graduating soon. I know that now-adays you have to have a diploma, even from college, if you want to actually make money. High school is not enough to make decent money; you have to go to college. I want to graduate to go to college.

When probed with regards to how she had come across this valuable information, Monica answered:

I see what people that drop out go through. They get knocked-up ${ }^{15}$ and get food stamps, and are always moving 'cause' they can't afford their apartment. I don't want that for me.

Also mentioning the financial implications of graduation, Ernesto replied:

I want to make something of my future like my brother did, because I see that he is going to college that makes me want to graduate too. It makes me think about wanting a better future and going to college, and making my family proud, and having a nice car, and a nice house, and giving them money.

He added with a big smile, "They take care of me now; I take care of them later."

\section{Summary of Results for Research Question 3}

Within the context of answering the third research question which sought to include the perceptions of students with SLD or EBD in self-contained or inclusive settings with regards to support systems that promote graduation, this study found several

\footnotetext{
${ }^{15}$ Knocked-up: Slang term used to describe becoming pregnant out of wedlock.
} 
meta-themes. These overlapping themes (see Table 13) ranged from topics such as learning expectations, relevant content, quality of student- teacher interactions, and differences between self-contained and inclusive educational settings, to familial support.

In addressing the topic of learning expectations and relevant content all students educated in self-contained settings as well as those in inclusive settings expressed an interest in learning. The students in self-contained settings explained that they expected to learn something new every day, and that they were more likely to be successful, as well as enjoy classes, when the teacher was nice and did not mind explaining things more than one time. Similarly, the students in inclusive settings alluded to the idea that they enjoyed learning new things in school. In addition, they also expressed that how teachers explained the content, as well as their overall attitude, was essential to their success in the class.

The theme of student teacher interactions also elicited similar responses from the participants regardless of their educational setting (i.e., self-contained or inclusion). The students in self-contained settings expressed that they viewed the teacher as being mostly responsible for the ultimate success of the students. Based on their perceptions, the teacher was the one variable that determined their success in the class. Along this line, the students in self-contained settings also alluded to the idea that effective teachers are not judgmental and provide students with a myriad of learning tools. Supporting this notion, some of the participants from self-contained settings explained that they did not mind being in self-contained classes because the teacher was effective and taught them based on their preferred learning styles. 
All of the participants from inclusive settings mentioned that they greatly benefited from the co-teaching model which involves having two teachers (i.e., the general and the special education teacher) in the classroom. From their point of view, having two teachers helped them to understand the material better because they were provided with two different ways of conceptualizing a given topic.

When describing differences between self-contained and inclusive settings, most of the participants from self-contained settings agreed that teachers in special education classes provided them with learning strategies that significantly increased their learning outcomes. Some also expressed that they greatly benefited from being in a smaller class because they were able to obtain the extra help that they required. However, it is important to note that one of the participants suggested that special education classes were not as academically challenging as general education classes. It is also important to restate that when referring to self-contained classes the participants generally used derogatory vocabulary that indicated they did not feel these represented the norm.

All the participants regardless of educational setting generally referred to special education classes as being slower and special education students as being slow. During analysis of the naturalized versions of the student interviews, it became apparent to the researcher that the students were using the word slow with negative connotations because it was generally noted that the participants frowned, looked down, or averted the researcher's gaze when discussing the slower nature of self-contained settings. Corroborating this point, most of the participants from inclusive settings explained that self-contained classes generally functioned at a slower pace than inclusion classes and thus were not as interesting or challenging. To honor the perceptions of all the 
participants, it must be emphasized that some of the students from self-contained settings expressed that they benefited academically from moving at a slower pace. Yet, these participants also looked away and towards the floor when explaining this to the researcher.

The responses of the participants from inclusive settings echoed some of the same issues raised by the students in self-contained settings. From their perspectives inclusion classes were part of general education, but even better due to the co-teaching model. On this topic, it is important to note that some of the participants went out of their way to emphasize that they were now in general education because they were placed in inclusion classes.

Lack of learning also became a prevalent theme during the guided student interviews. Specifically, most of the participants from self-contained settings and inclusive settings generally agreed that the work load was significantly more lax in selfcontained classes than in inclusion classes. Accordingly, one of the participants equated being in self-contained classes with cheating because the related requirements were so little when compared to the demands placed on general education students.

Despite the fact the students interviewed as part of the inclusion sample were expectedly in inclusion classes at the time these interviews were conducted; some still referred back to their experiences in self-contained settings when addressing lack of learning. Specifically, the participants from inclusive settings explained that based on their expectations the subject matter was supposed to become increasingly difficult with time, but this never occurred in self-contained settings. In spite of these observations, one 
of the participants explained that within the context of his disability, the coping strategies learned in self-contained classes enabled him to be successful in inclusion classes.

The topic of familial support required minimal prompting from the researcher since all the participants seemed very passionate about this particular subject and generally disclosed very personal experiences. Across both educational settings (i.e., selfcontained and inclusion), the participants generally agreed that familial support was the driving force behind their decision to graduate. However, it is important to note that some of the participants from self-contained settings explained that they did not necessarily have support from their family, but decided to graduate in order to change the extenuating circumstances that they had generally experienced.

The participants from inclusive settings explained that their decision to graduate related to their desire to make a better future for them and for their family. One of the participants described that the fact his brother was attending college played an important role in his decision to graduate. Others focused more on the related post-school experiences, and discussed how life can be generally less stressful with the attainment of a college degree. As generally reported by the students from inclusive settings, the concept of extended family and being able to provide for their relatives was essential in their decision to graduate. 


\section{CHAPTER V}

\section{CONCLUSIONS}

The following section details the conclusions derived from the results of the quantitative and qualitative components of this study, as well as the overlapping themes that became apparent across both components. The process of arriving at these conclusions included conducting critical analyses of the results based on the existing literature and conducting a thematic analysis of the foci points associated with each component in order to identify overlapping themes. Specifically, the conclusions related to the quantitative component will be discussed and substantiated based on the literature cited throughout. Similarly, the results for the qualitative component will be analyzed following the student-generated, meta-themes previously outlined and discussed within the context of the related literature.

In order to outline and discuss overlapping themes between the quantitative and qualitative components, Ridenour and Newman's mixed methodology model was applied. Specifically, as proposed by Ridenour and Newman (2008), for the quantitative researcher the goal is hypothesis testing and for the qualitative researcher the goal is theory building. Accordingly, the theories tested by the quantitative component will be discussed and built upon by the related qualitative themes and critically analyzed based on the existing literature.

\section{Quantitative Component}

The quantitative component of this study aimed to identify the school-related variables that predict the graduation potential of students with SLD or EBD within the current educational climate which mandates inclusive practices. A critical analysis of the 
results yielded will be discussed throughout this section and substantiated based on the existing literature.

Dropout continues to affect students with disabilities at alarming rates (National Center for Statistics [NCES], 2007), and intensifies in EBD populations (Blackorby \& Wagner, 1996; \& Cobb et al., 2006). The results yielded by the quantitative component of this study not only support the latter statement, but also suggest that even within the current inclusive climate students with EBD are still not making adequate progress within the context of graduation potential.

Based on the sample investigated, the only significant predictor of graduation across both exceptionalities was a successful academic history or achieving passing grades, when statistically controlling all the other school-related variables. Since one of the main goals of this study was to investigate the effect of inclusive settings on graduation potential, it is important to clarify that it was not found to be significant when statistically controlling all the other school-related variables. However, it is also important to note that when testing for possible interactions among the specified variables students in inclusive settings were found to obtain better grades. Specifically, this study found the existence of a first order interaction between inclusive settings and obtaining passing grades. The latter as stated was the one significant predictor of increasing graduation potential.

Along this vein, the only other variable that came close to significance was the student's ethnicity. Based on the sample investigated, Black students with SLD or EBD were significantly more likely to graduate than Hispanic students under the same disability categories. This particular finding coincides with current national dropout 
trends that indicate Hispanics are the ethnic group at greatest risk for dropout (NCES, 2007). Within the context of school-related variables that increase dropout among Hispanic students Carpenter and Ramirez (2007) found that (a) being held back a grade, (b) having been suspended from school often, (c) spending little time engaged in homework assignments, and (d) not being enrolled in a dropout prevention program significantly increased the likelihood of dropping out. It is also important to note that having English as a second language did not significantly impact dropout. Accordingly, this same study found that Hispanic students born outside of the United States were less likely to dropout than those born here.

This study also sought to investigate the existence of first order interactions between the students' educational setting and their academic and behavioral success, as well as between the students' exceptionality and their academic and behavioral success. In addressing the first set of interactions, educational setting and academic and behavioral history, this study found that there is a significant interaction between educational setting and academic achievement. Specifically, students in inclusive settings were more likely to pass their classes or achieve academically than students in self-contained settings. As evidence, only $6 \%$ of the students in the sample educated in self-contained settings had a successful academic history. These findings support Rea et al.'s (2002) conclusions, which indicated that students with disabilities in inclusive settings performed better academically, as well as this study's contention that inclusion can be implemented as a potential dropout prevention variable for students with disabilities. Moreover, given previously stated findings which indicated that low academic achievement increases dropout (e.g., Bear et al., 2006; Blackorby \& Wagner, 1996; Dunn et al., 2004; Scanlon 
\& Mellard, 2002; Suh \& Suh, 2007), extensive consideration must be given to the idea that students in inclusion classes experience significantly better academic results than their self-contained counterparts.

In developing this conclusion extensive consideration was given to the idea that students in self-contained classes may be different than students in inclusion classes. As stated, students who require more extensive educational services are generally placed in self-contained settings. Based on the perspectives of some of the participants the fact that they were in inclusive settings prompted them to want to learn because they saw other students display this behavior. In addition, other participants expressed that the overall environment in inclusion classrooms was more conducive to learning because there were less behavioral problems. Consequently, from the lens of this study the effects of inclusive settings on the students' academic behaviors can potentially curtail existing differences among students in self-contained and inclusive settings. Having said this, the potential existence of psychological factors which may potentially differentiate the two groups (i.e., students in inclusive settings and students in self-contained settings) must also be considered. This suggests the potential need for another related study with longitudinal properties addressing the long-term academic and behavioral history of both groups.

In line with studies cited throughout (e.g. Bost, 2006; Cobb et al., 2006; Rea et al., 2002), which indicated that inclusive settings promoted pro-social behaviors, this study found that inclusive settings have a significant interaction with behavioral history, or a student's behavioral record. Specifically, educational setting plays a significant role in 
increasing or decreasing suspensions or related disciplinary actions regardless of exceptionality.

In analyzing the second set of interactions, exceptionality and academic and behavioral success, it was found that there is a first order interaction between exceptionality and academic success. Specifically, based on the sample-analyzed students with EBD were more likely to dropout than all other students. This reaffirms previously discussed findings by Blackorby and Wagner (1996) and Cobb et al. (2006), which concluded students with EBD are at the greatest risk for dropout among all other disability categories.

When looking at these findings in context, specifically when considering the previous interaction which indicated that students in inclusive settings experienced better academic outcomes, it can be implied that students with EBD are not being included as much as students with SLD. As evidence of this trend, Bost (2006) also found that students with EBD were the least included. Given the inherent behavioral problems generally associated with the EBD label and its detrimental effect on graduation potential (Blackorby \& Wagner, 1996; Cobb et al., 2006), it was surprising to find that based on the sample-analyzed students with SLD were more likely to be suspended from school than students with EBD. However in further scrutinizing this finding, it must be noted that when it comes to students with disabilities, school districts are required to determine whether or not the problem behavior is a manifestation of the student's disability (MDCPS, 2008b). If the latter is found to be the case, considerable restraint and caution is generally exercised when determining if suspension or possible expulsion applies. Consequently, given the myriad of potentially troublesome behavioral manifestations 
associated with the EBD label, these can perhaps curtail the type and magnitude of consequences imparted. Moreover, inclusive settings seldom follow the structured behavioral programs oftentimes implemented in self-contained settings, which as stated were most effective in reducing dropout associated with anti-social and/or aggressive behaviors (Cobb et al., 2006).

In considering the educational ramifications of the findings of this study, which among others included that when statistically controlling all other school-related variables being able to achieve passing grades was the only significant predictor of graduation potential, significant measures must be taken when addressing the academic needs of students with disabilities. To achieve this, general education teachers in inclusive settings must become familiar with accommodations ${ }^{16}$ and adaptations ${ }^{17}$ and must also be given adequate support from administrators and special education experts (Hehir, 2005). It is also recommended that pre-service teachers spend more time at actual school settings (Fisher \& Frey, 2003) in order to learn within the context of the demands of daily practice. This can be achieved by becoming more involved in service learning where lessons can become hands- on experiences.

Findings of this study also suggest that students with EBD were more likely to drop-out than all other students. Consequently, the way in which this population is being educated within the context of current inclusive mandates and related practices must be urgently addressed. Results of this study yielded that students with SLD or EBD did receive better academic grades in inclusive settings. Based on this, it is suggested that

\footnotetext{
${ }^{16}$ Accommodations: Supports and services given to students with disabilities without changing the actual curriculum or related expectations.

${ }^{17}$ Adaptations: Changes made to the curriculum expectations to meet the needs of students with disabilities.
} 
students with EBD be exposed to inclusive settings more frequently or for longer periods of time. Having said this, significant attention must be given to the fact that it was also found that students with SLD were suspended more often than students with EBD, perhaps due to the lack of structured behavioral programs in inclusive settings. Accordingly, it is suggested that a structured behavioral program including a generalization phase be followed in inclusive settings, with the support of the special education teacher (Cobb et al., 2006). Dropout trends have been moderately reduced in general education since the early 1990s (NCES, 2007); it is both a moral and a professional obligation to ensure that the same occurs in special education.

\section{Qualitative Conclusions}

Student voice represents a raw, powerful, and un-politicized description of the truth. As documented by Mitra (2006) and Fielding (2001), students can become relevant agents of change since they are typically less inhibited than adults when assessing educational practices, in particular if these deal with taboo topics. Giving students the opportunity to evaluate their education has been found to empower them as individuals while in turn assisting their schools in creating more realistic goals and related practices (Mitra, 2006; Zeldin, Camino \& Mook, 2005). With this in mind, the same student generated meta-themes were followed in the process of generating conclusions. These were subsequently discussed and substantiated based on the existing literature.

\section{"I Actually Want to Learn...I Really Do"}

Regardless of disability label or educational setting, students expect to go home having learned something new. If students become engaged in learning, and thus become part of the school's general culture, they are less likely to drop out (Bost, 2006). 
Supporting this notion, this study found a significant interaction between inclusive settings and obtaining passing grades. The interview data corroborated this finding in that most of the participants, regardless of educational setting, indicated that they learned best in inclusive settings. The question then becomes: How can the educational milieu best meet the expectations of students with SLD or EBD regarding learning, and thus increase their graduation potential?

In conceptualizing a possible answer to the question, many aspects of educating students with disabilities come into play, some of which include: the placement process and related provisions, curriculum planning, and behavioral interventions. However, while these are certainly important tenets of everyday practice, it would prove difficult to provide a viable answer to the question of meeting the learning expectations of students with SLD or EBD just based on these procedures (Hehir, 2005). Rather, the answer to this question must be based on the realization, in both conscience and practice, that the disability must never become the place from which expectations are created. All vested stake holders in the education of students with disabilities must consider the individual student in his/her totality, prior to developing interventions that highlight the disability. On this topic, "knowing" each student as an individual in his/her totality means being aware of, and taking into consideration, his or her aspirations, capabilities, interests, dislikes, as well as areas that require growth. Unfortunately, the latter is often the single catalyst for the current instructional trends impacting students with disabilities (Hehir, 2005). Exemplifying this notion, districts base their action plans and schools develop 
their School Improvement Plans ${ }^{18}$ (SIP) based on their respective problem areas. Consequently, since students with disabilities often do not meet Adequate Yearly Progress ${ }^{19}$ (AYP) (Hardman \& Dawson, 2008), they are often perceived as representing the problem areas, and thus, the targeted population when it comes to remediation programs. Hence it can be argued, that the educational programs for students with disabilities are based on deficits and thus highlight the disability.

As explained by the participants, learning includes, "going home having learned something new, being creative, and being challenged." Where are the novelties, creative processes, or challenges; in being reminded on a daily basis of what was not learned or mastered? Moreover, daily reminders of these short-comings are often prolonged since students who do not make AYP, most of whom are students with disabilities (Frattura \& Capper, 2006), are generally mandated to take intensive courses addressing the topics they failed to master. The trouble is that in the process of "teaching intensively" isolated topics, learning often goes out the window. As evidence, students with disabilities chronically continue to not meet AYP, drop out at higher rates than their non-disabled counterparts, and thus have limited employability skills (Frattura \& Capper, 2006).

\section{"The Teacher Makes it or Breaks it"}

Regardless of educational placement (i.e., self-contained or inclusion), all participants reported the importance of experiencing positive interactions with teachers. Some of the students interviewed even went as far as disclosing that teachers were the

\footnotetext{
${ }^{18}$ School Improvement Plan (SIP): Comprehensive document that shows the yearly plan of action of a school.

${ }^{19}$ Adequate Yearly Progress (AYP). Outlines what all students, regardless of disability, must achieve at grade level in Reading and Math.
} 
reason why they liked or disliked school. While this notion may seem exaggerated to some, and may also be perceived as shifting personal responsibility from the student to the teacher, student-teacher interactions are a crucial part of being successful in school. As explained, through the years research in the area of school attrition has shown that when students experience poor relationships with teachers they are decidedly more likely to drop out (Bear et al. 2006; Bearden et al., 1989; Bost, 2006; Gallagher, 2002; Lee \& Burkman, 2003). Given the less than fulfilling experiences most students with SLD or EBD have had in school, where they must first fail consistently in order to be recommended for special education services (Hehir, 2005; Donovan \& Cross, 2002), student-teacher interaction becomes even more intricate. On this topic, effective communication, support, and engagement have been found to positively impact the academic and social outcomes of students with disabilities (Murray \& Greenberg, 2006).

Based on the responses of the participants in this study, positive interactions with teachers involve: "not judging students, being willing to explain things over, helping students learn and be successful, and just plain being nice." Their perceptions echo recent research. Walker-Dalhouse and Risko (2008) as well as Regan (2009) found that successful student-teacher interactions involve not having preconceived notions of students, facilitating instruction in a concise manner that provides room for review or repetition, establishing connections that transcend a specific topic and can be generalized to other similar situations, and caring for, as well as challenging the students. Showing the stark opposite to what the participants in this study claimed fostered positive studentteacher interactions, Baloglu (2009) found that responding to students in a hostile manner, not explaining well due to rapid speech, and negatively singling-out students, 
were among the most problematic teacher behaviors. Given that the nature of these negative behaviors directly impact instruction and can also affect learning outcomes, and the findings of this study which indicated obtaining passing grades was a significant predictor of graduation potential; serious consideration must be given to the quality of student-teacher interactions.

While teacher behavior has been considerably addressed in the literature (Bracey, 2009), it is often done with an emphasis on the type of teacher behavior that results in greater student achievement on high-stakes tests. Epitomizing this notion is the popular misconception that good teachers generate good student test scores, and bad ones can be identified by the converse (Bracey, 2009; Hanushek, 2002). The same trend is generally observed with regards to district administrators' perceptions of what qualifies as a good teacher. As evidence, generally school districts offer schools that perform well on highstakes tests financial compensation for their teachers. Although teachers deserve compensation for a job well-done, good teaching cannot be solely measured based on test scores. This type of narrow scope on what good teaching constitutes fails to reflect what students perceive a good teacher should encompass. Yet more pressing, it also runs the danger of creating an environment where teachers will be less willing to teach students who do not do well on high-stakes tests since that is the most prevalent measure of their teaching ability. Measuring good teaching goes far beyond promoting high test scores, it must also include addressing the power and significance of fostering positive studentteacher interactions, as well as recognizing its impact on student achievement, social development, and ultimately graduation potential (Bost, 2006; Pianta \& Hamre, 2009). 
On this topic, federal mandates regarding high-stakes tests have inherently forced school administrators to place most of their efforts on raising test scores (Gentilucci \& Muto, 2007). Consequently, compared to the magnitude of the administrative push towards demanding that teachers produce increasingly high test scores, not as much emphasis is generally placed on establishing school climates where positive interactions with students are valued and promoted. Given the overwhelming amount of evidence that supports the idea that positive student-teacher interactions are crucial in increasing the graduation potential of all students, some of the related trends are alarming. For example, Pianta and Allen (2008) found that positive student-teacher interactions were observed only $1 \%$ of the time throughout an entire school day. According to Bracey (2009), this $1 \%$ can be potentially lower in schools where remedial classes offer a scripted curriculum, since most scripted programs require utmost faithfulness to reading the instructions verbatim. On this topic, it is pertinent to restate that students with SLD or EBD generally do not do well on high-stakes tests, and consequently, often do not make AYP. This typically results in them being placed in remedial or intensive classes (Hardman \& Dawson, 2008) where scripted curricula are generally found. The participants enrolled in intensive courses, which often implement scripted curricula, explained that they did not learn from these and consequently became bored.

\section{"Is Kind of Like a Normal Class...but with Shortcuts"}

Most of the participants in this study had been receiving special education services since elementary school, which potentially makes them experienced sources of information on the nature of the methodology implemented in special education classes. Positively, regardless of disability label or educational setting, most of the participants 
felt that special education classes had provided them with learning tools and strategies that proved very helpful in promoting their success in school. On the other hand, these same students use words such as 'normal' and 'regular' to describe general education, given the negative connotations and stigma these terms can place on special education classes. Along this vein, it was also troublesome to hear students in inclusion classes insist that these were not special education classes, but rather "regular," perhaps indicating a possible institutional hierarchy exists between self-contained, inclusion, and general education classes. While inclusion classes are legally and theoretically considered general education classes, generally MDCPS places students with disabilities in inclusion classes with two teachers, one of them being the special education teacher. After these students demonstrate academic aptitude in inclusion classes, they are then mainstreamed into general education classes with one teacher. Based on the participants' responses, they are very aware of these practices and understand the hierarchy established by the system.

The participants characterized the teaching pedagogy in special education as: "giving them shortcuts that helped them learn better." "showing them special ways of doing things," and "giving them more attention." These comments suggest several important implications. First and foremost, the participants' comments indicate that their special education teachers are successfully differentiating instruction, targeting various learning modalities and individualizing the curriculum; which are all considered important tenets of quality instruction regardless of disability status (Frattura \& Capper, 2006). Moreover, the comments made by the participants can also imply that special educators understand the learning needs and challenges of students with SLD or EBD. 
However, it must be noted that these positive assessments of the methodology implemented by special education teachers, contradict findings that indicate accommodations and individualized instruction decrease in the secondary grades, particularly in high school (Bulgren, Deshler, \& Lenz, 2007). Notably, most of the participants used vocabulary with negative connotations when referring to special education classes. Even the students that expressed that they benefited from the generally slower pace of self-contained settings exhibited non-verbal cues that indicated they were somehow ashamed. Specifically, in the naturalized version of the interviews it was noted that during this discussion the participants averted their gaze and/or looked down when communicating that they performed better at a slower pace. This is perhaps not surprising due to generally held beliefs about what a disability constitutes. As explained by Nocella (2009), the term disability often evokes thoughts of something being "broken, not working properly, something wrong."

The educational system must view the term disability through a more inclusive lens, one where disability relates uniqueness not inferiority. Given that all the participants described general education as "normal," it is understandable that the students in inclusion classes emphasized that they where no longer in self-contained or "special" classes. To them, it was as if being in self-contained represented the bottom of a perceived hierarchy where regular or general education is on top and everything else falls out of the normal scope. This can be potentially troublesome within the context of increasing graduation potential since it can create feelings of alienation, which is a major cause of dropping out of school (Bost, 2006; Brown, Higgins, Pierce, Hong \& Thomas, 2003). 


\section{"There are Normal and Slow Classes"}

All of the participants agreed that special education classes were helpful;

however, according to comments such as, "ESE classes did help me a lot...they are just slower...," and "The normal classes have more interested kids, I can get into them," it seems that they do not believe special education classes are as academically challenging as general education classes. Moreover, even when some of the students expressed they actually performed better at the "slower" pace of self-contained classes, they still used words such as normal and slow to contrast both settings. Interestingly, this perception was also evident when the participants described the social setting in the classroom. For example, two of the participants expressed that being around general education students made them "try to compete with them and take school seriously" and also emphasized that "there were less problem behaviors in inclusion classes." On this topic, it is important to emphasize that these comments are in line with findings reported by Rea et al. (2002), which were previously noted as providing some of the framework for this study, and indicated that inclusion classes motivated the students to perform better both academically and behaviorally. However, it is also pertinent to restate that while this study found that the instructional setting, in this case inclusion, did have a significant interaction with academic behavior (i.e., obtaining passing grades), it also found that students in inclusive settings were more likely to be suspended from school than those in self-contained settings.

As previously noted, Hehir (2005) pointed towards ableism, or the practice of watering down both expectations and academics for students with disabilities, as the catalyst for making educational decisions that 'maximize' the disability. While it is 
understood that the goal of special education is to individualize instruction to best meet the learning needs of students with disabilities, this must not consist of lowering academic expectations and related practices. Given that students with SLD or EBD do not perform as well as their non-disabled peers on high-stakes tests, often do not meet AYP, and graduate at significantly lower rates (Bost 2006; Dunn et al, 2005), it is urgent to reassess the nature and effectiveness of the content taught in special education classes to these student populations. The fact this study found students in inclusive settings, regardless of disability label, were more likely to obtain passing grades and thus graduate further supports this notion. A clinical model where the disability is at the core of any academic or behavioral intervention designed to meet the educational needs of students with SLD or EBD has generally dominated special education curricula (Biklen, 1992; Hehir, 2005). Given the documented lower than average graduation rates and consequently poor post-school outcomes of students with SLD or EBD, the effectiveness of said model becomes questionable.

As argued earlier, the vocabulary used by the participants to describe special education classes and disability categories indicates a potential misunderstanding of what a disability constitutes, and more importantly, their comments also suggest a generally negative perspective on what it means to be a student in special education. The latter became quite obvious when a participant with an EBD label commented that: "EBD kids are not normal... and I am not the only one that thinks that...you need a lot of patience to be their teacher." Accordingly, a concerted school-wide effort to increase student selfadvocacy and disability awareness must be in place. 


\section{"I Don't Feel I am Learning"}

Despite the motivation to learn reported by the participants, and their generally positive opinions of the pedagogy implemented by special education teachers, nearly all the students interviewed also reported that they were not learning as much as expected. However, it must be noted that most of the participants' concerns with regards to a lack of learning targeted the self-contained settings, not inclusion classes. As evidence, most of the students receiving instruction in inclusive settings referred back to their experiences in self-contained classes when dealing with the issue of unchallenging or watered-down curricula. In this study, students in inclusive settings obtained better grades than those in self-contained settings. This potentially highlights the importance of revising the clinical model discussed earlier which generally dominates the special education paradigm, along with the importance of integrating students with disabilities into the general culture of the school.

Along this vein, the previously made argument regarding ableism resonated when one of the participants stated: "ESE classes are like cheating because they are so much easier than regular classes...they don't give as much work." The same observations were made with regards to intensive classes: “...in intensive reading they really don't give a lot of work...." In taking a closer look at this issue, it seems that there is an institutionalized tendency to have lower expectations of students in classes that are inherently remediation oriented (i.e., special education or intensive courses). Yet, research indicates that with regards to students with disabilities, low academic achievement does not typically indicate low academic aptitude (Bear et al., 2006), as evidence this study found that 
students with SLD or EBD in inclusion classes, following the general education curriculum, were more likely to obtain passing grades than those in self-contained settings.

The discrepancy between what students with SLD or EBD believe they can achieve with regards to learning, and how the educational milieu generally views their potential must be effectively addressed. On this issue, given that educational policy is a crucial catalyst in improving daily practices (Hehir, 2005), policy must also be addressed when discussing generally held beliefs regarding the potential of students with disabilities, and how these impact related institutional practices. Despite the fact the educational system has mandates in place that claim not to "leave any child behind," as evidenced by their dropout rates, many students with SLD or EBD are indeed being left behind. This is partly because the same expectations and requirements placed on their general education peers are not placed on them. While much of the effort behind educational policy designed to increase learning gains and graduation rates among students with disabilities focuses on the notion of teachers being highly qualified, it fails to address the institutional expectations and practices regarding the potential of students with disabilities.

Along this vein, school districts place great emphasis on increasing the number of students with disabilities in general education classes, but generally offer very little guidance or assistance in ensuring that these students are provided with equitable expectations, receive the appropriate accommodations or adaptations, and thus become truly integrated in the general school culture (Bulgren et al., 2007) Both of which (i.e., high expectations and becoming part of the school culture) have been documented to 
increase graduation potential (Bost, 2006). Furthermore, while it is commonly applied knowledge that IDEA provides the framework for educating students in the least restrictive environment (LRE) to the greatest extent possible, in comparison little is known or consequently applied regarding its supervision components, specifically Section 612 [11]. As explained by Hehir (2005), this is where IDEA's supervision clauses come into play and make it possible to ensure that students with disabilities are not only receiving access but also quality education. In order to accomplish the latter, as also recommended by Hehir (2005), civil rights enforcement at the state level is necessary since it provides the framework for topics such as disability awareness and related expectations to be discussed at the local level. Unfortunately, most states are not avid followers of IDEA's supervision component (Hehir, 2005; National Council on Disability, 2001). Consequently, it is not surprising that while students with SLD or EBD are being included, based on their dropout rates they are arguably not being provided with the same expectations and thus equal opportunities as their non-disabled peers. Specifically, as implied by IDEA 2004, Section 612 [11], if students with SLD or EBD report that they are not learning as much as expected in self-contained settings, systemic monitoring by the state and subsequent revisions to the overall purpose of the more restrictive special education settings must be conducted. In addition, a closer look at the epistemology of special education must be considered being that it generally looks for practical answers and seldom addresses the theoretical implications. The latter can potentially provide useful insights and thus facilitate understanding which potentially leads to better informed, comprehensive solutions. 


\section{"I Want to Become the Future of My Family"}

All of the participants reported that the concept of family, regardless of socioeconomic status or parental education, was the most important influence in their decision to graduate. However, this contradicts earlier findings (Farmer \& Payne, 1992; Gruskin et al., 1987; Orr, 1987; Payne, 1989; Reyes, 1989; Roderick, 1993; Tindall, 1988; Valdivieso, 1986; Vallerand et al., 1997; Wehelage, 1989) that indicate parental education and socioeconomic standing are the most serious culprits behind school attrition regardless of disability status. Furthermore, the findings of this study also challenge Bordieu's (1977) classically held beliefs that the family's socioeconomic status generally dictates future outcomes. Arguably, Bordieu's perspective was based on Eurocentered views on what family constitutes. As evidenced by the participants' explanations on what motivated them to graduate, such as “...I want to make something out of myself since I made a promise to my great-grandmother that I would become the future of my family," perhaps to minority students family has a much broader scope. It includes aunties and abuelas ${ }^{20}$ along with the stories and knowledge communicated throughout the family's history.

As discussed earlier in the Conceptual Framework section (see Figure 2), Yosso's (2002) theory regarding cultural capital seemed to best fit the motivational constructs that helped the participants graduate. Their aspirational capital or ability to maintain dreams and aspirations despite potentially difficult situations was epitomized by the following comment: "I graduated because of my mom, is more of the fact behind it then just the

\footnotetext{
${ }^{20}$ Abuelas: Grandmother in Spanish. Students of Hispanic origin often use the Spanish word for grandmother when referring to them.
} 
person. My mom lives in Cuba and she said to make something of myself so that we could be back together when the time was right. I am doing that, I want to become the future of my family.”

In seeking to increase the graduation rates of students with disabilities a more culturally responsive and holistic approach must be implemented. Specifically, in finding solutions the educational system must also focus on the cultural wealth of these students. After all, their beliefs and aspirations carried them through school, regardless of the odds that according to the prevalent research were stacked against them. Teaching and learning do not occur in a vacuum, hence they do not begin or end in school or in the classroom; they are carried by each learner along with everything else that is of value to them within the context of their cultural capital. Once the current educational system gives credence to the idea that the dropout phenomenon among students with SLD or EBD is not a symptom of the disability, but rather a by-product of generally one-dimensional educational constructs, these student populations will generally excel and graduate (Hehir. 2005).

\section{Thematic Analyses of Quantitative and Qualitative Components}

The previously introduced mixed-methodology model will be followed in analyzing the main themes yielded by the quantitative and qualitative components. As proposed by Ridenour and Newman (2008) and stated earlier, for the quantitative researcher the goal is hypothesis testing and for the qualitative researcher the goal is theory building. Accordingly, the hypotheses tested by the quantitative component will be discussed and built upon by the related qualitative themes. 
Table 21 contains the quantitative results and related qualitative findings that will be discussed throughout. Specifically, each of the four sets of quantitative results and qualitative themes illustrated will be analyzed within the context of current inclusive practices and substantiated by the existing literature. As shown in Table 21, the numbered items indicate the quantitative results and the lettered items encompass the related qualitative themes. The latter were derived from the student generated meta-themes and thus constitute the foci points addressed by the participants in this study as impacting their graduation potential.

As illustrated in Table 21, in response to the first set of results and related themes, the quantitative component of this study found that academic history or achieving passing grades was the only significant predictor of graduation in SLD and EBD populations when statistically controlling all the other specified variables. This finding was further substantiated in the qualitative themes, where the participants regardless of disability label, generally agreed that they wanted to succeed academically and also reported that they expected to learn something new in school each day. Moreover, the participants also agreed that when teachers gave them the appropriate tools or "shortcuts," they were successful. Having said this, some of the participants also expressed that they were not learning as much as expected. According to this study and others before (e.g., Bear et al., 2006; Bost, 2006; Dunn et al., 2004; Scanlon \& Mellard, 2002; Suh \& Suh, 2007) academic achievement is paramount in promoting graduation potential. Consequently, the educational system must ensure that all students regardless of disability receive a quality education. The latter includes access to relevant and challenging curricula, 
combined with the necessary accommodations or adaptations that the participants referred to as "shortcuts", and reported as being very beneficial to their learning.

Table 21

Quantitative Results and Related Qualitative Themes

Results and Themes

1. Academic History is the only significant predictor of graduation potential

(a) Regardless of disability label students want to learn

(b) Students report feeling like they're not learning

(c) Students report greatly benefiting from learning shortcuts

2. Students with EBD are more likely to dropout than all other students

(a) Students report that personality clashes with the teachers affect their learning

(b) Students report hating some classes due to poor social interactions with the teacher

(c) Students report benefiting from having a teacher or counselor that they can trust

3. Students in inclusion classes have better academic histories than those in self-contained settings

(a) Students in self-contained classes report not feeling academically challenged

(b) Students report benefiting from having two teachers

(c) Students report the learning environment is more conducive to learning in inclusion classes

4. Students with SLD get suspended more often than students with EBD

(a) Students report the behavioral strategies taught helped them to 'cope' with frustrating situations

(b) Students report the behavioral strategies taught helped them to 'cope' with emotional issues

(c) Students report they fail some classes because teachers sometimes don't want to help and are not fair

"Ableism" or the practice of creating expectations based primarily on the disability (Hehir, 2005) has an adverse effect on the learning potential of students with 
disabilities. As evidence, the participants reported being keenly aware of the differences in work load and related difficulty level between general education and special education classes and generally used derogatory terms when referring to special education classes. Given these less than ideal institutionalized practices, it is not surprising that students with disability labels generally and consistently underperform their non-disabled peers within the context of graduation potential.

With regards to the second set of results and related themes, this study also found that students with EBD were more likely to drop out than all other students. In analyzing this issue from the lens of current inclusive practices it is important to restate that students with EBD are both, the least included (Bost, 2006) and the least successful when included (NLTS-2, 2008). Furthermore as represented in the qualitative themes, students with EBD generally exhibit disability related behavioral challenges that must be taken into account since these can hinder the type of relationships they develop with their teachers. Supporting this notion, all participants stated that experiencing positive interactions with teachers was essential to their academic success.

Accordingly, while this study proposes that inclusion can be a used as a dropout prevention tool for students with SLD or EBD; it also strongly suggests that the necessary behavioral interventions and counseling services must be in place. As evidence, some participants with the EBD label agreed that speaking to a counselor on a weekly basis was very helpful. The inclusion of students with disabilities must be a well-thought out process, specifically given the reported lack of success experienced by students with EBD in inclusive settings. 
The third set of results and related themes addressed this study's finding that the only significant predictor of graduation when statistically controlling all the other schoolrelated variables (including educational setting) was a successful academic history. However, it must be emphasized that this study also found a first order interaction between educational setting and academic history.

Specifically, based on the sample analyzed students in inclusion classes were more likely to obtain passing grades and thus were more likely to graduate than those in self-contained classes. To further build upon this theory grounded on the qualitative themes, it must be noted that most of the participants from self-contained settings indicated that they did not feel challenged by the curriculum. In contrast, the participants from inclusive settings reported that inclusion classes had better learning environments as well as the advantage of having two teachers. The latter is particularly important since all participants stated that having two teachers in the classroom generally facilitated their understanding of the subject. It can be argued that if the students can master the academic objective, they will generally achieve better grades, which as emphasized throughout was found to be a significant predictor of graduation potential. Furthermore, it can also be argued that classroom environments that are conducive to learning can facilitate obtaining better grades (Rea et al., 2002). It is also important to note that in the qualitative findings most participants reported that inclusion classrooms had better learning environments. One of the participants from inclusive settings alluded to the fact that being in a class where students seemed invested in their learning, helped him become invested as well. This further supports Rea et al.'s (2002) finding that students in inclusion classes experienced better academic and social outcomes. However, with 
regards to the latter, this study did not find a significant interaction between educational setting and behavioral history or promoting pro-social behaviors within the context of increasing graduation potential.

The fourth set of results and related themes revealed one of the most surprising findings of this study due to the often problematic behavioral ramifications associated with the EBD label. Specifically, based on the sample analyzed students with SLD were suspended more often than students with EBD. However, this can be due to a lack of structured behavioral components in inclusive settings. The fact students with SLD are placed in inclusive settings at significantly higher rates than students with EBD (Bost, 2006; NLTS-2, 2008) can also compound the issue since arguably they may not be provided with the structured behavioral programs often found in self-contained settings. Yet, when analyzing this study's findings which yielded that students in inclusive settings were more likely to obtain passing grades, which in turn significantly increases their graduation potential, the chance of being suspended from school more often can constitute a justifiable risk, especially when considering behavioral infractions can be curtailed given that the appropriate interventions are in place. As such, extensive thought must be given to the idea that the present educational constructs impacting students with disabilities are designed in such a manner that the choice of weighting academic success against the possibility of suspension from school becomes a consideration.

Based on the qualitative findings some of the participants with EBD stated that the behavioral strategies learned from the generally structured behavioral features of most self-contained settings, helped them to cope with frustrating situations and emotional issues. One of the participants explained that his success in inclusion classes was made 
possible by having been taught effective coping strategies when he was in self-contained classes. Moreover, based on the previously discussed importance of experiencing positive interactions with teachers, and the fact that some participants reported not doing well academically in classes where teachers were not helpful or fair, being able to cope with potentially stressful situations can be an important skill to have within the context of increasing graduation potential.

The quantitative results and related qualitative themes discussed indicate that within the context of graduation potential students with SLD or EBD must achieve academically and can benefit from being in effective inclusive settings. Specifically, in order to experience academic success students with SLD or EBD should be placed in inclusive settings that provide relevant and challenging curricula, the necessary accommodations or adaptations to excel academically, high expectations, as well as any required structured behavioral interventions.

\section{Limitations}

The following section will encompass potential limitations affecting both the quantitative and qualitative components of this study. In the quantitative sample the related limitations were arrived at by analyzing the accuracy of the data obtained, as well as the generalization potential of the findings (Ridenour \& Newman, 2008). In the qualitative sample, limitations were considered based on the idea of being able to portray a typical representative sample of students with SLD or EBD, exploring potential researcher bias (Bogdan \& Biklen, 2007), in addition to assessing whether or not full disclosure on behalf of the participants was obtained (Ruben \& Ruben, 2005) . 


\section{Limitations of Quantitative Component}

The quantitative strand of this study was found to include several limitations. As discussed earlier, school districts have significant freedom in selecting which type of statistical procedure they implement to quantify the number of students that drop out. Like most other districts in the nation, M-DCPS uses the event cohort method which is the least accurate of all and tends to provide lower dropout figures (Kemp, 2006). Consequently, the data analyzed potentially underestimated the number of students with SLD or EBD that dropped-out. In addition, generally students with disabilities placed in inclusive settings have demonstrated success with the curriculum in self-contained settings (Bost, 2006) and consequently may be more likely to be academically successful. Meaning, the fact that most students in this sample are in inclusion classes may potentially underrate dropout trends in special education. Another potential limitation relates to the fact that there were no White students in the sample which can potentially limit the generalization of this study's results to students from primarily Black or Hispanic school districts. The fact that longitudinal data regarding the psychological, academic, and behavioral history of the sample were not investigated was considered another potential limitation of this study. Specifically, lack of longitudinal information can potentially underscore significant existing differences between the students who made-up the educational settings investigated (i.e., inclusion and self-contained).

\section{Limitations of Qualitative Component}

The qualitative strand of this study also posed several potential limitations. Given that the qualitative participants were part of the quantitative sample, the stated lack of longitudinal data regarding the psychological, academic, and behavioral history of the 
sample investigated was also considered a potential limitation in the qualitative component of this study. Not being able to obtain full disclosure on behalf of the participants was considered another potential limitation. Specifically, the participating students were asked some questions (see Appendix) that essentially required them to evaluate their schools, and the interviews took place within the school setting, which could have potentially made some of the students not as willing to discuss problematic institutional practices. The fact that some students asked not to be directly quoted was also a potential limitation. However, it is important to note that their perceptions corroborated those of the participants that were quoted and were considered when developing the student generated meta-themes.

Additionally, potential bias on the part of the researcher was also deemed a potentially limiting factor, due to the idea of being too close to the topic being investigated. It must be noted that the researcher is a veteran teacher with experience in teaching both self-contained and inclusion classes, and inherently had some strong personal opinions with regards to the topics being discussed. In an effort to limit researcher bias, all student answers were transcribed, member checking was conducted, and all student answers were subsequently reported without any edits. In the end however, the researcher's experiences became useful when it came to probing or expanding on some of the student responses, and being able to recognize some terminology used by the students which was endemic to M-DCPS.

\section{Implications for Future Research}

To continue investigating the impact of inclusive settings on students with disabilities, it is recommended that a study with longitudinal properties be conducted. 
Specifically, the long-term psychological, academic, and behavioral histories of the sample would be taken into account when measuring the overall impact of inclusive settings. It is important to note that NTLS (2001) conducted a similar study but not within the context of the current educational climate where most students with high incidence disabilities are included for most of the school day.

To further explore how the general culture of the school affects dropout trends, and given the fact the sample selected in this study was from schools graded ' $\mathrm{C}$ ' or lower, a similar study can be conducted in 'A' and 'B' schools. Specifically, the significance of the school's grade as it relates to dropout trends in special education can be investigated. Students with SLD or EBD from 'A' and 'B' schools can also be interviewed along with students from schools with grades of ' $\mathrm{C}$ ' or lower on the topic of dropout, in order to show potential differences in perspectives.

It is also suggested that to obtain a better picture of the dropout phenomenon students with SLD or EBD who have dropped-out be interviewed along with students under the same disability categories who have graduated. Due to the importance the participants in this study placed on student-teacher interactions, it is also recommended that general and special education teachers be interviewed regarding student-teacher relationships within the context of promoting graduation. To depict potential differences in perspectives, the student and teacher interviews can be combined with actual classroom observations. Moreover, classroom observations of students similar to those in this sample may provide corroborative insight into the typical school day for students with SLD or EBD in each of the settings. 
Based on the idea all students in the qualitative sample reported that experiencing positive student-teacher interactions impacted their academic outcomes in the class, it would be beneficial to further investigate how well prepared to teach students with SLD or EBD teachers feel. Subsequently, the teachers' perceptions can be further analyzed within the context of their overall passing rates when it comes to students with disabilities. Specifically, it would be beneficial to determine if teacher perceptions on their ability to teach students with SLD or EBD significantly impact the passing rates of students with these disability labels.

In order to expand upon the participant's perceptions that the concept of family was important in their decision to graduate, a similar study can be conducted where family members of both graduating and non-graduating students with SLD or EBD are interviewed to show potential differences. Similarly, based on the participants' idea that extended family can also be a means of inspiration and support for students with disabilities, various types of families (i.e., extended families, single parent families, and intact families) can be interviewed. Moreover, these variables can be tested for significance within the context of promoting graduation.

\section{Research Contributions}

The following section will specify the contributions this study made to the literature. To highlight any potentially seminal information yielded in this study, the research contributions will be organized based on whether or not these corroborated with the research pool on: (a) dropout, (b) inclusive practices, (c) educational placement of students with disabilities, and (d) students with SLD or EBD. 
Study Results Previously Corroborated by the Literature:

- Academic history (i.e., obtaining passing or failing grades) significantly predicts the graduation potential of students with SLD or EBD

- There is a significant first order interaction between inclusive settings and academic history or obtaining passing grades

- Students with EBD are more likely to drop out than all other students

- Hispanic students are more likely to drop out than Black students

- Regardless of educational setting, students with SLD or EBD report that experiencing positive student-teacher interactions is essential to their success

- Generally students with SLD or EBD report that the learning environment in inclusion classes positively affects their disposition towards learning

Study Results Not Previously Corroborated by the Literature:

- Inclusive settings can be potentially utilized as dropout prevention tools in special education

- Behavioral history (i.e. number of suspensions) is not a significant predictor of graduation among students with SLD or EBD.

- Performance in high stakes exams is not a significant predictor of graduation among students with SLD or EBD.

- Students with SLD are more likely to be suspended than students with EBD 
- From the participants' perspectives, familial capital ${ }^{21}$ and resistance capital ${ }^{22}$ play an important role in promoting the graduation potential of students with SLD or EBD

- Generally students with SLD or EBD report that they are not challenged academically in self-contained classes

\section{Summary}

Based on the findings of this study and others before (e.g., Bear et al., 2006; Bost, 2006; Dunn et al., 2004; Scanlon \& Mellard, 2002; Suh \& Suh, 2007), promoting the graduation potential of students with disabilities must include facilitating their academic success. As also established in this study and corroborated by the literature (e.g., Bear et al., 2006; Bost, 2006; Dunn et al., 2004; Hehir, 2005; Scanlon \& Mellard, 2002; Rea et al., 2002; Suh \& Suh, 2007), inclusive settings have been found to have a significant interaction with academic success.

The participants in this study reported that along with inclusive settings, several tenets must also be in place in order to promote academic success and thus increase graduation potential. These included: (a) facilitating relevant and challenging curricula, (b) providing the necessary accommodations or adaptations to excel academically, (c) communicating high expectations, (d) establishing positive and equitable student- teacher interactions and (e) providing structured behavioral interventions for the students that require them. In order to facilitate the stated tenets within the context of daily practice, this study suggested a comprehensive or holistic approach where the student is viewed in

\footnotetext{
${ }^{21}$ Familial capital: Term coined by Yosso (2002) explaining the importance of extended family

${ }^{22}$ Resistance capital: Term coined by Yosso (2002) explaining persevering in order to succeed in spite of potentially extenuating circumstances
} 
his/her totality rather than from the point of reference of the disability (Hehir, 2005).

Students with disabilities are at greater risk of dropout than their general education peers (e.g., Bost, 2006; Croninger \& Lee, 2001; Dunn et al., 2004; Kaplan et al., 1997; Kemp, 2006; Scanlon \& Mellard, 2002; Sinclair, 1994; Smith, 1986; Wagner, 1991), which in turn can indicate that having a disability status creates a specific set of circumstances that can potentially make it more difficult to graduate. On the latter Hehir (2005) suggested that oftentimes this perceived set of circumstances that can make schooling more difficult for students with disabilities, have more to do with society's views on disability than the actual impact of the disability on learning potential. In response to this contention, and the participants' marked use of derogatory words when referring to special education classes, this study recommended establishing and disseminating new perspectives on disability. Changing cultural perceptions on what a disability constitutes can begin at the university. Specifically, this study contended that disability studies should be reframed to emphasize the social ramifications of having a disability within the context of society's cultural and political framework (Linton, 1998; Nocella, 2009).

Given this study's findings and those of others before (e.g., Bear et al., 2006; Bost, 2006; Dunn et al., 2004; Scanlon \& Mellard, 2002; Suh \& Suh, 2007), which indicate students with SLD or EBD must be successful academically in order to graduate, the educational system must make a concerted effort to ensure that this occurs. As generally supported by the literature (e.g., Bear et al., 2006; Bost, 2006; Dunn et al., 2004; Hehir, 2005; Rea et al., 2002; Scanlon \& Mellard, 2002; Suh \& Suh, 2007), students with SLD or EBD in inclusive settings obtain better grades and thus are more 
likely to experience academic success, which in turn increases their graduation potential. Yet, as shown in this study students with EBD are more likely to drop out than all other students and are both the least included (Bost, 2006) and the least successful when included (NLTS-2, 2008). Consequently, significant consideration must be given to their current rate of inclusion, and the behavioral interventions that must be in place to facilitate their success in inclusive settings. The educational system has a legal obligation to ensure that students with disabilities receive an appropriate education which arguably also includes facilitating their graduation potential (Hehir, 2005; National Council on Disability, 2001). More importantly, increasing students' graduation potential can have an impact on their post school experiences and therefore on their quality of life (Christle et al., 2007; Dunn et al. 2004; Murray \& Naranjo, 2008; U.S. Bureau of Census, 2004).

Several potential limitations were found in this study. In the quantitative sample, the setting where the study took place (M-DCPS) employs the event cohort method, which is the least accurate of all methods used to calculate dropout trends and tends to provide lower dropout figures (Kemp, 2006). In addition, the fact that most students in this sample were in inclusion classes may potentially underrate dropout trends in special education since generally students with disabilities placed in inclusive settings may be more likely to be academically successful than those in self-contained settings (Bost, 2006). Lack of longitudinal information can also potentially underscore significant existing differences between the students who made-up the educational settings investigated (i.e., inclusion and self-contained). Another potential limitation consisted of the fact there were no White students in the sample, which can potentially limit the generalization of this study's results. In the qualitative sample not being able to obtain 
full disclosure on behalf of the participants was considered another potential limitation. Additionally, potential bias on the part of the researcher was also deemed a potentially limiting factor due to the idea of being too close to the topic being investigated.

In considering potential implications for future research, conducting a similar study in schools graded 'A' or 'B' was suggested in order to investigate the significance of the school's grade on promoting graduation potential. Similarly, students with SLD or EBD from 'A' and 'B' schools can be interviewed along with students from schools with grades of ' $\mathrm{C}$ ' or lower on the topic of dropout, in order to show potential differences in perspectives.

To obtain a better picture of the dropout phenomenon students with SLD or EBD who have dropped out can be interviewed along with students under the same disability categories who have graduated. General and special education teachers can also be interviewed regarding student-teacher relationships within the context of promoting graduation. Moreover, classroom observations of students similar to those in this sample may provide corroborative insight into the typical school day for students with SLD or EBD in each respective educational setting.

A similar study can be conducted where family members of both graduating and non-graduating students with SLD or EBD are interviewed to depict potential differences. Similarly, various types of families (i.e., extended families, single parent families, and intact families) can be interviewed to show potentially different perspectives. The effect of the various types of families on graduation potential can also be investigated. 


\section{REFERENCES}

Bakken, T., \& Kortering, L. (1999). The constitutional and statutory obligations of schools toward special education school dropouts. Remedial and Special Education, 20, 360-366.

Baloglu, N. (2009). Negative behavior of teachers with regard to high school students in classroom settings. Instructional Psychology, 36(1), 69-77.

Bartnick, W., \& Parkway, F. (1991). A comparative analysis of the "holding power" of general and exceptional education programs. Remedial and Special Education, 12, $17-22$.

Barton, P. E. (2005). One-third of a nation: Rising dropout rates and declining opportunities. (Policy Information Report). Princeton, NJ: Educational Testing Service.

Bear, G., Kortering, L., \& Braziel P. (2006). School completers and non-completers with learning disabilities: Similarities in academic achievement and perceptions of self and teachers. Remedial and Special Education, 27(5), 293-300.

Bearden, L. J., Spencer, W. A., \& Moracco, J. C. (1989). A study of high-school dropouts. School Counselor, 37, 113-120.

Biklen, D. (1992). Schooling without labels: Parents, educators, and inclusive education. Philadelphia, PA: Temple University Press.

Blackorby, J., \& Wagner, M. (1996). Longitudinal post-school outcomes for youth with disabilities: Findings from the National Longitudinal Study. Exceptional Children, 62, 399-413.

Bogdan, R., \& Biklen, S. (2007). Qualitative research for education: An introduction to theories and methods (5th ed.). Boston, MA: Pearson Education, Inc.

Bordieu, P. (1977). Outline of a theory of practice. Cambridge University Press, Cambridge: United Kingdom.

Bost, L. W. (2006, July). Effective interventions in dropout prevention for students with disabilities: Putting the evidence into practice. Paper presented at the Critical Issues in Urban Education Harvard Summer Institute, Boston, MA.

Bost, L. W., \& Riccomini, P. J. (2006). Effective instruction. Remedial and Special Education, 27(5), 301-311. 
Bracey, G. W. (2009). Identify and observe effective teacher behaviors. Phi Delta Kappan, 10(Je), 772-773.

Brown, M. R., Higgins, K., Pierce, T., Hong, E. \& Thoma, C. (2003). Secondary students' perceptions of school life with regard to alienation: The effects of disability, gender, and race. Learning Disability Quarterly, 26(4), 227-238.

Bulgren, J., Deshler, D. D., \& Lenz, B. K. (2007). Engaging adolescents with LD in higher order thinking about history concepts using integrated content enhancement routines. Journal of Learning Disabilities, 40(2), 121-133.

Carpenter, D. M., Ramirez, A. (2007). More than one gap: Dropout rate gaps between and among Black, Hispanic, and White students. Journal of Advanced Academics, 19(1), 32-64.

Christle, C. A., Jolivette, K., \& Nelson, M. (2007). School characteristics related to highschool drop-out rates. Remedial and Special Education, 28(6), 325-339.

Cobb, B., Sample, P. L., Alwell, M., \& Johns, N. R. (2006). Coginitive-behavioral interventions, dropout, and youth with disabilities. Remedial and Special Education, 27(5), 259-275.

Coleman et al. (1966). Equality of educational opportunity. Washington, DC: U.S. Government Printing Office.

Council of Great City Schools. (1994). National urban education goals, 1992-1993: Indicators report. Washington, DC: Author.

Croninger, R. G, \& Lee, V. E. (2001). Social capital and dropping out of high school: Benefits to at-risk students of teachers' support and guidance. Teachers College Record, 103, 548-581.

Donovan S., \& Cross, C. (2002). Minority students in special and gifted education. Washington, DC: National Academy Press.

Dowdy J. K., \& J. T. Wynne. (2005). Racism, research, and educational reform: Voices from the city. New York, NY: Peter Lang Publishing Inc.

Dunn, C., Chambers, D., \& Rabren, K. (2004). Variables affecting students decisions to drop out of school. Remedial and Special Education, 25(5), 314-323.

Farmer, J. A., \& Payne, Y. (1992). Dropping out: Issues and answers. Springfield, IL: C.C. Thomas. 
Fielding, M. (2001). Students as radical agents of change. Journal of Educational Change, 2(2), 123-141.

Fisher, D., \& Frey, N. (2003). Inclusive urban schools. Baltimore: MD: Paul H. Brookes Publishing Co.

Fisher, M., \& Meyer, L. H. (2002). Development and social competence after two years for students enrolled in inclusive and self-contained educational programs. Research and Practice for Persons with Severe Disabilities, 27(3), 165-174.

Frattura, E., \& Capper, C. A. (2006). Segregated programs versus integrated comprehensive service delivery for all learners. Remedial Special Education, 27 (6), 355-364.

French. D. C., \& Conrad, J. (2001). School dropout as predicted by peer rejection and antisocial behaviour. Journal of Research on Adolescence, 11, 225-244.

Gallagher, C. J. (2002). Stories from the strays: What dropouts can teach us about school. American Secondary Education, 30, 36-59.

Gentilucci, J. L., \& Muto, C. C. (2007). Principals' influence on academic achievement: The student perspective. National Association of Secondary Schools Principals, 91(3), 219-236.

Grayson, T. E. (1998). Dropout prevention and special services. In F. R. Rusch \& J. G. Chadsey (Eds.), Beyond high school: Transition from school to work (pp. 77-98). Belmont, CA: Wadsworth.

Greenspan, S. (2006). Functional concepts in mental retardation: Finding the natural essence of an artificial category. Exceptionality, 14(4), 205-224.

Gruskin, S. J., Campbell, M. A., \& Paulu, N. (1987). Dealing with dropouts: The urban superintendents' call to action. Washington, DC: U.S. Department of Education, Office of Educational Research and Improvement.

Guba, E. G., \& Lincoln, Y. S. (1981). Effective evaluation: Improving the usefulness of evaluation results through responsive and naturalistic approaches. San Francisco, CA: Jossey-Bass.

Guest, G., Bunce, A., \& Johnson, L. (2006). How many interviews are enough? Field Methods, 18(1), 59-82.

Hanushek, E. A. (2002). The long run importance of school quality. Cambridge, MA: National Bureau of Economic Research. Retrieved from www.nber.org/papers/w9071 
Hardman, M. L., \& Dawson, S. (2008). The impact of federal public policy on curriculum and instruction for students with disabilities in the general classroom. Preventing School Failure, 52(2), 5-11.

Harry, B., \& Klinger, J. (2006). Why are so many minority students in special education? Understanding race and disability in schools. New York, NY: Teachers College Press.

Harry, B., Klinger, J., \& Cramer, E. (2007). Case studies of minority student placement in special education. New York, NY: Teachers College Press.

Hart, J. E. (2003). African American learners and the 6-hour emotional disturbance: Investigating the roles of context, perception, and worldview, in the overrepresentation phenomenon (Unpublished doctoral dissertation). University of Miami, Fl.

Hehir, T. (2005). New Directions in special education: Eliminating ableism in policy and practice. Cambridge, MA: Harvard Education Press.

Huefner, D. S. (2000). The risks and opportunities of the IEP requirements under IDEA '97. Journal of Special Education, 33(4), 195-204.

Jencks et al. (1972). Inequality: A reassessment of the effect of family and schooling in America. New York, NY: Basic Books.

Johnson, J. L. (1997). Commuter college students: What factors determine who will persist and who will drop out? College Student Journal, 31(September), 323-332.

Kaplan, D. S., Peck, B. M., \& Kaplan, H. B. (1997). Decomposing the academic failuredropout relationship: A longitudinal analysis. Journal of Educational Research, 90, 331-343.

Kemp, S. E. (2006). Dropout policies and trends for students with and without disabilities. Adolescence, 41(162), 235-250.

Kortering, L., Haring, N., \& Klockars, A. (1992). The identification of high-school dropouts identified as learning disabled: Evaluating the utility of a discriminant analysis function. Exceptional Children 58, 422-436.

Kortering, L. J., \& Braziel, P. M. (1999). School dropout from the perspective of former students: Implications for secondary school programs. Remedial and Special Education, 20, 78-83. 
Lee, V. E., \& Burkman, D. T. (2003). Dropping out of high school: The role of school organization and structure. American Educational Research Journal, 40(2), 353393.

Lee-Tarver, A. (2006). Are individualized education plans a good thing? A survey of teachers' perceptions of the utility of IEPs in regular education settings. Journal of Instructional Psychology, 33(4), 263-272.

Lehr, C., Hansen, A., Sinclair, M., \& Christenson, S. (2003). Moving beyond dropout prevention towards school completion: An integrative review of data-based interventions. School Psychology Review, 32, 342-364.

Linton, S. (1998). Claiming disability. Knowledge and identity. New York, NY: New York University Press.

McDonnell, J., Polychronis, S., Riesenland, T., Jameson, M., Johnson, J. W., \& Kercher, K. (2007). Comparison of one-to-one embedded instruction in general education classes with small group instruction in special education classes. Education and Training in Developmental Disabilities, 41(2), 125-138.

Menard, S. (1995). Applied logistic regression analysis. Thousand Oaks, CA: Sage Publications. Series: Quantitative Applications in Social Sciences, No. 106.

Meyers, L. S., Gamst, G, \& Guarino, A. J. (2005). Applied Multivariate Research: Design and Interpretation (2nd ed.). Thousand Oaks: CA: Sage Publications Inc.

Miami-Dade County Public Schools. (2008a). Demographics report. Retrieved from http://dadeschools.net

Miami-Dade County Public Schools. (2008b). Mobility index, dropout, graduate, and suspension data report. Retrieved from http://dadeschools.net

Mitani, H. (2007). States differ in standard diploma requirements. Retrieved from http://www.edweek.org/rc/articles/2007/06/23/sow0623.h26.html

Mitra, D. L. (2006). Student voice or empowerment? Examining the role of school-based youth-adult partnerships as an avenue toward focusing on social justice. International Electronic Journal for Leadership in Learning, 10 (22).

Morrow, G. (1986). Standardizing practice in the analysis of school dropouts. Teachers College Record, 87, 342-355.

Murray, C., \& Greenberg, M. T. (2006). Examining the importance of social relationships and social contexts in the lives of children with high-incidence disabilities. The Journal of Special Education, 39(4), 220-233. 
Murray, C. \& Naranjo, J. (2008). Poor, black, learning disabled, and graduating: An investigation of factors and process associated with school completion among high-risk urban youth. Remedial and Special Education, 29(3), 145-160.

Nagelkerke, N. J. D. (1991). A note on the general definition of the coefficient of determination. Biometrika, 78(3), 691-692.

National Center for Statistics. (2007). Statistical analysis report: Dropout rates in the United States: 2005. Washington, DC: U.S. Department of Education, Office of Educational Research and Improvement.

National Council on Disability. (2001). Back to school on civil rights. Washington, DC: Independence.

National Longitudinal Transition Study 2 (NTLS 2). (2001). A summary of findings. Retrieved from http://www.sri.com/policy/cehs/nlts/nltssum.html

Newman, I., \& Benz, C. R. (1998). Qualitative-quantitative research: Exploring the interactive continuum. Carbondale, IL: University Press.

Nocella, A. J. (2009). Disabling Dis-ability: Re-building inclusive into social justice. Theory in Action, 2(1), 140-158.

Nygreen, K. (2006). Reproducing or challenging power in the questions we ask and the methods we use: A framework for activist research in urban education. The Urban Review, 38(1), 1-26.

Oliver, D. G., Serovich, J. M., \& Mason, T. L. (2005). Constraints and opportunities with interview transcription: Towards reflection in qualitative research. Retrieved from http://www.pubmedcentral.nih.gov/articlerender.fcgi?artid=1400594

Orfield, G., Losen, D., Wald, J., \& Swanson, C. (2004). Losing our future: How minority youth are being left behind by the graduation crisis. Cambridge, MA: The Civil Rights Project at Harvard University.

Orr, M.T. (1987). Keeping students in school: A guide to effective dropout prevention programs and services. San Fransisco, CA: Jossey-Bass.

Osgood, R. L. (2005). The history of inclusion in the United States. Washington, DC: Gallaudet University Press.

Payne, C. (1989). Urban teachers and dropout-prone students: The uneasy partners. In L. Weis, E. Farrar, \& H. G. Petrie (Eds.), Dropouts from school: Issues, 
dilemmas, and solutions (pp. 113-128). New York, NY: State University of New York Press.

Pianta, R. C., \& Allen, J. P. (2008). Building capacity for positive youth development in secondary school classrooms: Changing teachers interactions with students. In M. Shinn \& H. Yoshikawa, H. (Eds), Toward positive youth development: transforming schools and community programs. New York, NY: Oxford Press.

Pianta, R. C., \& Hamre, B. K. (2009). Measurement and improvement of teacher child interactions:Implications for policy and accountability frameworks of standardized observation. New York, NY: Routledge.

Press, S. J., \& Wilson, S. (1978). Choosing between logistic regression and discriminant analysis. Journal of the American Statistical Association, 73, 699-705.

Rea, P. J., McLaughlin, V., \& Walther-Thomas, C. (2002). Outcomes for students with learning disabilities in inclusive and pullout programs. Council for Exceptional Children, 68(2), 203-222.

Regan, K. S. (2009). Improving the way we think about students with emotional and/or behavioral disorders. Teaching Exceptional Children, 41(5), 60-65.

Reiff, H. B., Ginsberg, R., \& Gerber, P. J. (1995). New perspectives on teaching from successful adults with learning disabilities. Remedial and Special Education, 16, 29-37.

Reis, S. M., Neu, T. W., \& McGuire, J. M. (1997). Case studies of high-ability students with learning disabilities who have achieved. Exceptional Children, 63, 463-479.

Repetto, J. B., Pankaskie, S. A., De Palma-Hankins, A., Schwartz, S. E., \& Perry, L. (1997). Promising practices in dropout prevention and transition for students with mild disabilities. The Journal of At-Risk Issues, 4(1), 19-29.

Reyes, P. (1989). Factors that affect the commitment of children at risk to stay in school. In J. M. Lakebrink (Ed.), Children at risk (pp. 18-31). Springfield, IL: Thomas.

Rice, J. C. (1994). Logistic regression: An introduction. In B. Thompson, (Ed.), Advances in social science methodology, (pp. 191-245). Greenwich, CT: JAI Press. Popular Introduction.

Riccomini, P. J., Zhang, D., \& Katsiyannis, A. (2005). Promising school-based interventions for reducing aggressive behavior and student dropout. The Journal of At-Risk Issues, 11(2), 11-16. 
Ridenour, C. S., \& Newman, I. (2008). Mixed methods research: exploring the interactive continuum. Southern Illinois, Carbondale: University Press.

Roderick, M. (1993). The path to dropping out: Evidence for intervention. Westport, CT: Auburn House.

Rubin, H. J., \& Rubin, I.S. (2005). Qualitative interviewing: The art of hearing data (2nd ed.). Thousand Oaks, CA: Sage Publications Inc.,.

Rumberger, R. W. (1997). High school dropouts: A review of issues and evidence. Review of Educational Research, 57, 101-121.

Rumberger, R. W., \& Thomas, S. L. (2000). The distribution of dropout and turnover rates among urban and suburban high schools. Sociology of Education, 73(1), 3967.

Scanlon, D., \& Mellard, D. F. (2002). Academic and participation profiles of school-age dropouts with and without disabilities. Council for Exceptional Children, 68(2), 239-258.

Siegel, L. S., (1999). Issues in the definition and diagnosis of learning disabilities: A perspective on Guckenberg v. Boston University. Journal of Learning Disabilities, 32(4), 304-319.

Sinclair, M. F. (1994). Are we pushing students in special education to drop out of school? Minneapolis, MN: University of Minnesota Center on Residential Services and Community Living College of Education.

Smith, J. O. (1986). Voices of exiles: The public schools from the dropouts' perspective (Unpublished master's thesis). Mansfield University, Mansfield, PA.

Solorzano, D. G., \& Yosso, T. J. (2001). From racial stereotyping and deficit discourse toward a critical race theory in teacher education. Multicultural Education, 9(1), 28.

Sugai, G., \& Horner, R.H. (1999). Discipline and behavioral support: Preferred processes and practices. Effective School Practices, 17, 10-22.

Suh, S. \& Suh, J. (2007). Risk factors and levels of risk for high school dropouts. Professional School Counseling, 10(3), 297-306.

Tashakkori, A., \& Creswell, J.W. (2007). Editorial: Exploring the nature of research questions in mixed methods research. Journal of Mixed Methods Research, (1), 37. 
Teddlie, C., \& Tashakkori, A. (2006). A general typology of research designs featuring mixed methods. Research in Schools, 13(1), 12-28.

Tindall, L. W. (1988). Retaining at-risk students: The role of career and vocational education. Columbus, $\mathrm{OH}$ : Center on Education and Training for Employment. (ERIC Document Reproduction Service No. ED303683)

U.S. Bureau of the Census. (1994). Educational attainment in the United States. Washington, DC: Author.

U.S. Department of Education. (2002a). Executive summary. Washington, DC: Author

U.S. Department of Education.(2002b). Twenty-third annual report to Congress on the implementation of Public Law 101-476: The Individuals with Disabilities Education Act. Washington, DC: Author.

Valdivieso, R. (1986). Must they want another generation of Hispanic and secondary school reform? New York, NY: Clearing House on Reform Evaluation.

Vallerand, R. J., Fortier, M. S., \& Guay, F. (1997). Self-determination and persistence in a real-life setting: Toward a motivational model of high school dropout. Journal of Personality and Social Psychology, 72, 1161-1176.

Wagner, M. (1991). Dropouts with disabilities: What do we know? What can we do? A report from the National Longitudinal Transition Study of Special Education Students. Menlo Park, CA: SRI International.

Walker- Dallhouse, D., \& Risko, V. J. (2008). Learning from literacy successes in highachieving urban schools. The Reading Teacher, 61(5), 422-424.

Walther-Thomas, C., Korinek, L., McLaughlin, V., \& Williams, B. (2000). Collaboration for inclusive education. Boston, MA: Allyn \& Bacon.

Watnick, B., \& Sacks, A. (2006). A snapshot of teacher perceptions on full inclusion in an international urban community: Miami-Dade County, Florida. The Journal of the International Association of Special Education, 7(1), 67-74.

Wehlage, G. G. (1989). Dropping out: Can school be expected to prevent it? In L. Weis, E. Farrar, \& H. G. Petrie (Eds.), Dropouts from school: Issues, dilemmas, and solutions (pp. 1-19). New York, NY: State University of New York Press.

Wolman, C., Bruininks, R., \& Thurlow, M. L. (1989). Dropouts and dropout programs: Implications for special education. Remedial and Special Education, 10(5), 6-20.

Yosso, T. J. (2002). Toward a critical race curriculum. Equity and Excellence in 
Education, 35(2), 93-107.

Zeldin, S., Camino, L., \& Mook, C. (2005). The adoption of innovation in youth organizations: creating the conditions for youth-adult partnerships. Journal of Community Psychology, 33(1), 121-135. 


\section{APPENDIX}

\section{Strand 2 Interview Questions}

1. What do you like about school the most?

2. What do you dislike about school the most?

3. If you were principal for an entire school year what changes would you make?

4. How long have you been in special education?

5. Do you feel being in special education and having a disability label has helped you to graduate?

6. Are you in self-contained or inclusion classes?

7. Do you feel being in self-contained or inclusion class has helped you graduate?

8. (If the previous response was a yes) How exactly has this setting helped you? (If the previous response was a no) How exactly has this setting hindered you?

9. What has been the most important influence in your decision to graduate?

10. Would you mind discussing your grades with me?

11. (If the previous answer was yes) What classes do you pass most of the time?

Please explain why?

12. What classes do you have difficulty passing? Why?

13. Would you mind discussing your behavioral history with me?

14. (If previous answer was yes) Why do you sometimes get into trouble in school?

15. How has the FCAT affected you?

16. What has been the most difficult hurdle to overcome in your path towards graduation?

17. How were you able to overcome this hurdle? 
18. Is there anything that I did not ask that you think is important to discuss regarding this topic? 
VITA

\section{LIANA GONZALEZ}

May 14, 1973

1997

$1997-2000$

2000

2001- 2007

2005-Present

2006-2007
Born, Habana, Cuba

B.A., Special Education

Florida International University

Miami, Florida

Special Education Teacher

Robert Renick Educational Center

Miami, Florida

Rookie Teacher of the Year Nominee

Miami, Dade County Public Schools

Miami, Florida

Science Department Chairperson

Robert Renick Educational Center

Miami, Florida

M.S., Science Education

Florida State University

Gainesville, Florida

Teacher on Special Assignment

Ruth Owens Kruse Educational Center

Miami, Florida

Project QUEST Summer Seminar Coordinator Florida International University

Miami, Florida

Teacher of the Year Nominee

Ruth Owens Kruse Educational Center

Miami, Florida

CEC, Chapter 121, Inclusion Teacher of the Year Award

Miami Dade County Public Schools

Miami, Florida 
2008-Present

2008-Present
Adjunct Instructor

Florida International University

Miami, Florida

Special Education Teacher

West Miami Middle School

Miami, Florida

\section{PUBLICATIONS AND PRESENTATIONS}

Gonzalez, L. (2007). Activating the Desire to Learn. Academic Leadership the Online Journal, 5 (2). http://www.academicleadership.org/

Nevin, A., Gonzalez, L. et. al. (2006). Reviews of Single Subject Research Designs: Applications to Special Education and School Psychology. Miami, FL: Florida International University. (ERIC Documentation Reproduction Service No.ED491545)

Nevin, A., Gonzalez, L. et. al. (2005). What Do Experts Say About Urban Special Education Issues. Miami, FL: Florida International University. (ERIC Documentation Reproduction Service No.ED491410)

Gonzalez, L. (April, 2009). Project QUEST: Summer Seminar. Paper presented at the Council for Exceptional Children National Conference, Seattle Washington

Gonzalez, L., Shealey, M., and Frankson, D. (April, 2008). Urban Education Research: A Paradigm Shift. Paper presented at Florida International University's Annual College of Education Research Conference, Miami, Florida.

Gonzalez, L. (October, 2008). Project QUEST: Merging the Gap Between Theory and Practice. Paper presented at the Teacher Education Division of the Council for Exceptional Children, Dallas, Texas.

Gonzalez, L. (April, 2007). Urban Inclusion Models. Paper presented at the Council for Exceptional Children Conference, Ft. Lauderdale, Florida.

Gonzalez, L. (April, 2007). Visual Organizers and Academic Adaptations: Inspiration Software. Paper presented at the Council for Exceptional Children Conference, Ft. Lauderdale, Florida. 